Portland State University

PDXScholar

\title{
An Investigation of Urban Mobile Source Aerosol Using Optical Properties Measured by CRDT/N: Diesel Particulate Matter and the Impact of Biodiesel
}

Monica Elizabeth Wright

Portland State University

Follow this and additional works at: https://pdxscholar.library.pdx.edu/open_access_etds

Part of the Environmental Chemistry Commons, Environmental Monitoring Commons, and the Oil, Gas, and Energy Commons Let us know how access to this document benefits you.

\section{Recommended Citation}

Wright, Monica Elizabeth, "An Investigation of Urban Mobile Source Aerosol Using Optical Properties Measured by CRDT/N: Diesel Particulate Matter and the Impact of Biodiesel" (2012). Dissertations and Theses. Paper 673.

https://doi.org/10.15760/etd. 673

This Dissertation is brought to you for free and open access. It has been accepted for inclusion in Dissertations and Theses by an authorized administrator of PDXScholar. Please contact us if we can make this document more accessible: pdxscholar@pdx.edu. 
An Investigation of Urban Mobile Source Aerosol Using Optical Properties Measured by

CRDT/N: Diesel Particulate Matter and the Impact of Biodiesel

by

Monica E. Wright

A dissertation submitted in partial fulfillment of the requirements for the degree of

Doctor of Philosophy

in

Environmental Sciences and Resources: Chemistry

Dissertation Committee:

Dean B. Atkinson, Chair

Linda George

James Pankow

Andrew Rice

Carl Wamser

Portland State University

2012 


\begin{abstract}
Mobile source emissions are a major contributor to global and local air pollution. Governments and regulatory agencies have been increasing the stringency of regulations in the transportation sector for the last ten years to help curb transportation sector air pollution. The need for regulations has been emphasized by scientific research on the impacts from ambient pollution, especially research on the effect of particulate matter on human health. The particulate emissions from diesel vehicles, diesel particulate matter (DPM) is considered a known or probable carcinogen in various countries and increased exposure to DPM is linked to increased cardiovascular health problems in humans. The toxicity of vehicle emissions and diesel particulate emissions in particular, in conjunction with an increased awareness of potential petroleum fuel shortages, international conflict over petroleum fuel sources and climate change science; have all contributed to the increase of biodiesel use as an additive to or replacement for petroleum fuel. The goal of this research is to develop a method to investigate how the increased use of biodiesel could impact urban air quality. To determine if biodiesel use contributes to a health or climate benefit, both the size range and general composition were investigated using a comprehensive comparison of the particulate component of the emissions in real time. The emissions from various biodiesel and diesel mixtures from a common diesel passenger vehicle were measured with a cavity ring-down transmissometer (CRDT) coupled with a condensation particle counter, a SMPS, a nephelometer, $\mathrm{NO}_{\mathrm{x}}, \mathrm{CO}, \mathrm{CO}_{2}$, and $\mathrm{O}_{3}$ measurements. From this data, key emission factors for several biodiesel and diesel fuel mixtures were developed. This approach reduces sampling artifacts and allows
\end{abstract}


for the determination of optical properties, particle number concentration, and size distributions, along with several important gas phase species' concentrations.

Findings indicate that for this particular testing set-up biodiesel additions to diesel fuel do not necessarily have an air quality benefit for particulate emissions. The often cited linear decrease in particulate emissions with increasing biodiesel content was not observed. Mixtures with half diesel and half biodiesel tended to have the highest particulate emissions in all size ranges. Mixtures with more than 50\% biodiesel had slightly lower calculated mass for light absorbing carbon, but this reduction in mass is most likely a result of a shift in the size of the emission particles to a smaller size range, not a reduction in the total number of particles. Evaluation of the extensive optical properties indicates that a biodiesel addition to diesel fuel has an impact on emission particle extinction in both visible and near-IR wavelengths. The B99 mixture had the smallest emission factor for extinction at $532 \mathrm{~nm}$ and at $1064 \mathrm{~nm}$. For the extinction at $532 \mathrm{~nm}$, the trend was not linear and the emission factor peaked at the B50 mixture. Results from intensive properties indicate that emissions from B5 and B25 mixtures have Ångström exponents close to 1, typical for black carbon emissions. The mixtures with a larger fraction of biodiesel have Ångström exponent values closer to 2, indicating more absorbing organic matter and/or smaller particle size in the emissions. 


\section{Dedication}

For my family, your love and support made this dissertation possible. 


\section{Acknowledgements}

Mom and Dad, thank you for encouraging me to follow my own path. Rick, Brendan, Kevin and Austin thank all of you for the moral support and comic relief. I appreciate all of you for the countless ways you contributed to the completion of this dissertation. I will be forever thankful that I grew up in such a supportive and fun family.

I am grateful for the support and donations of fuel, time and space for this research from Star Oilco, Sequential Biofuels, Air Sciences Inc. and Portland Adventist Academy.

I would like to express my appreciation and gratitude to my advisor, Dr. Dean Atkinson. His consistent and patient support and encouragement were instrumental in the completion of this dissertation. Dr. Atkinson is a talented researcher and gifted teacher and I feel very fortunate that I had the chance to work with him.

I would also like to thank my committee members, Drs. Linda George, James Pankow, Andrew Rice and Carl Wamser for their constructive feedback, guidance, and research design suggestions. Additionally, Drs. Elita Pastra-Landis, Jimmy Radney, Hossein Bazargan, and Jeremy Parra, as well as Jacob Reams, Adeniyi Adenuga, Matt Mavko, and Chris Parker all made contributions to my research and overall intellectual growth.

And finally, thank you to my husband, Arick (Kit) Rouhe. Thank you for doing more than your share, for the cups of coffee late at night and early in the morning, for the inspiration, encouragement and love. 


\section{Table of Contents}

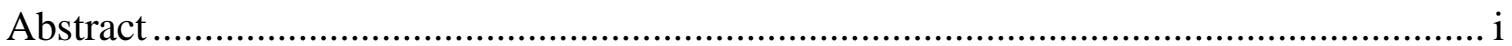

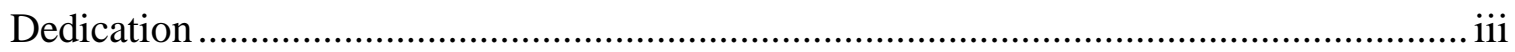

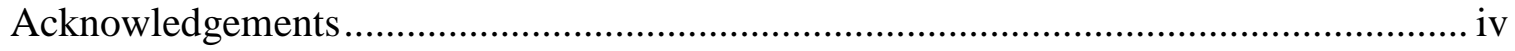

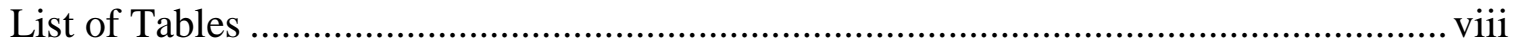

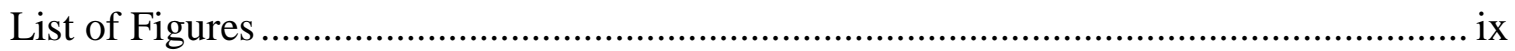

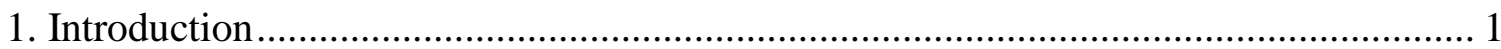

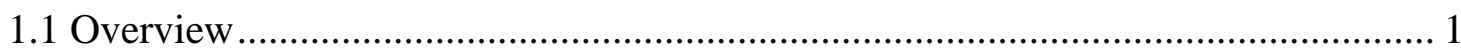

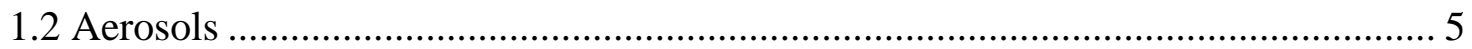

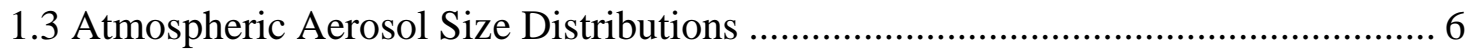

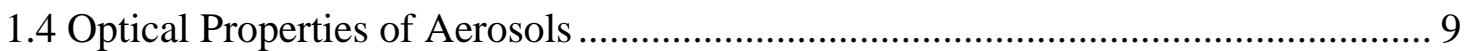

1.5 Aerosol Measurement Techniques.................................................................... 12

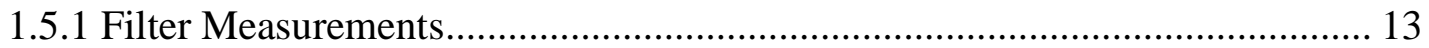

1.5.2 Particle Sizing and Counting Instruments.............................................. 15

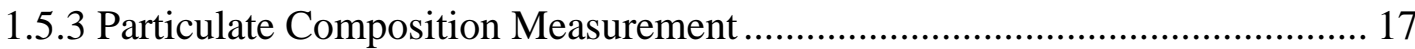

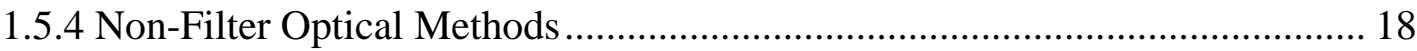

1.5.6 Cavity Ring-Down Measurement of Aerosol Extinction Coefficient............. 21

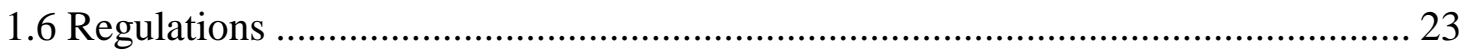

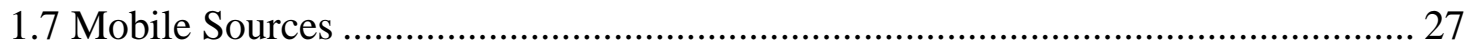

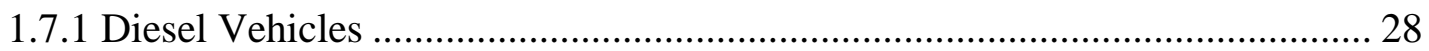


1.7.2 Diesel and Biodiesel

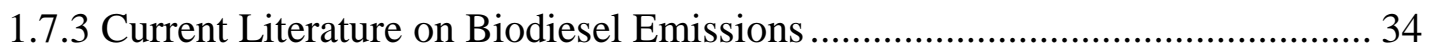

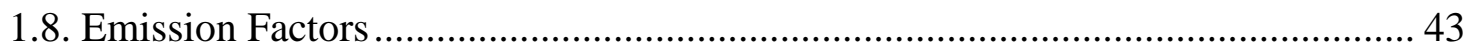

2. Measurement of Diesel and Biodiesel Emissions ................................................. 46

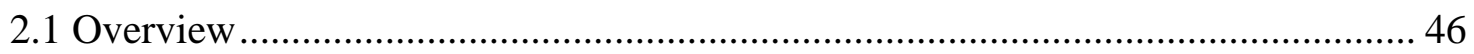

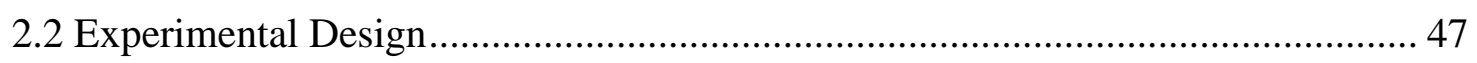

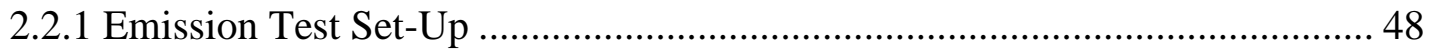

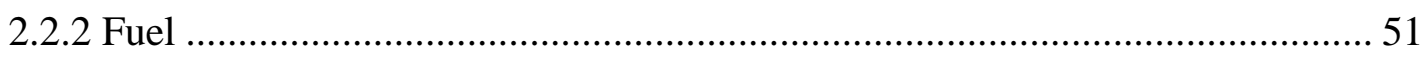

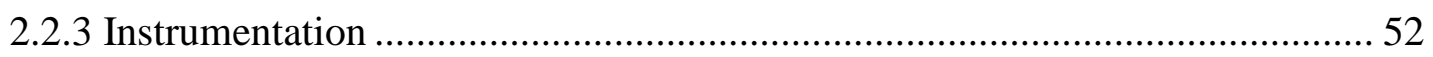

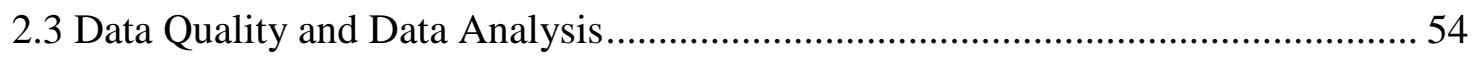

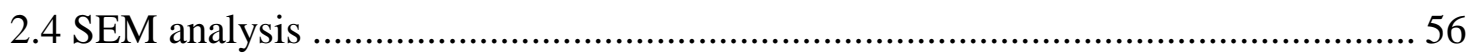

2.5 Development of Emission Factors ............................................................. 57

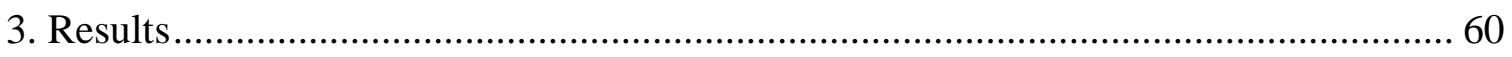

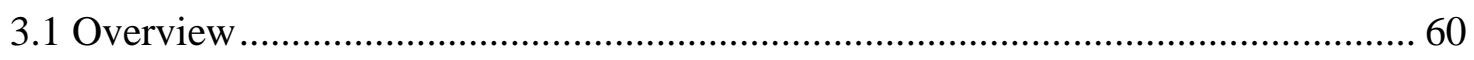

3.2 Particle Number and Size and Extensive Optical Property Emission Factors....... 70

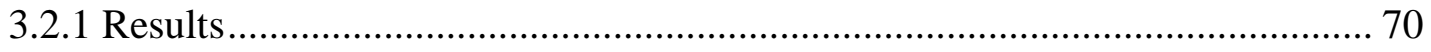

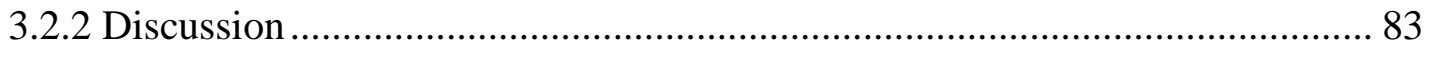

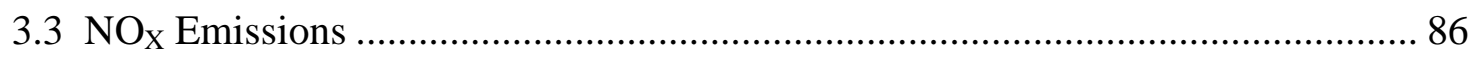

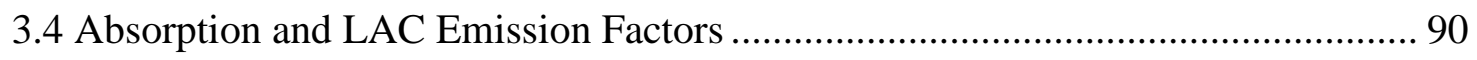




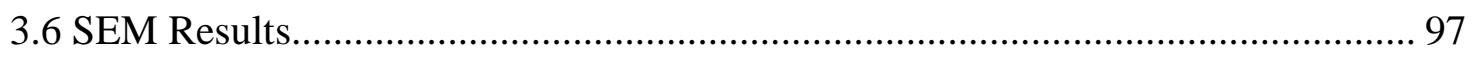

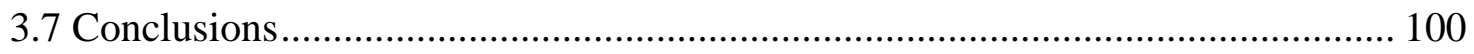

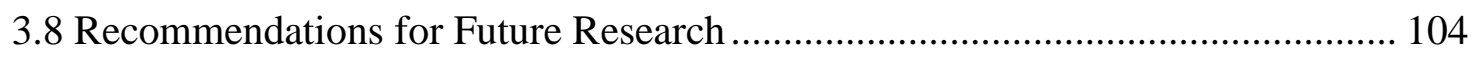

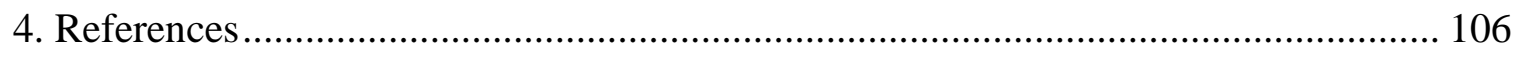

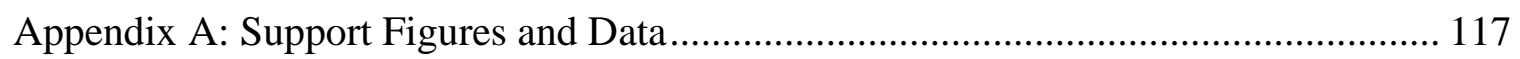

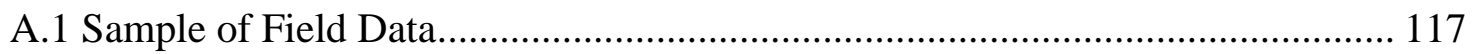

A.2 Correlation Plots for Emission Factor Determination....................................... 118

Appendix B: CRDT/N Validation Studies.................................................................. 137

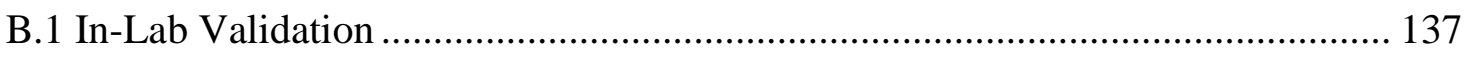

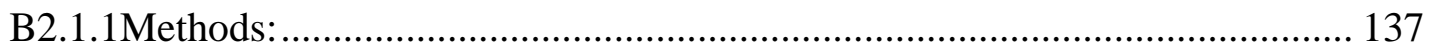

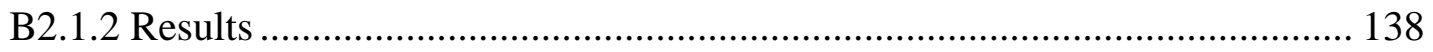

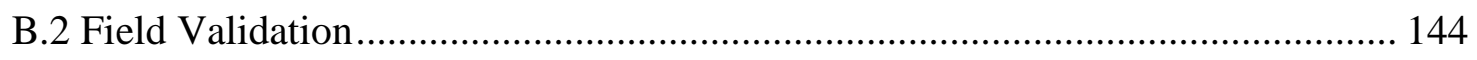

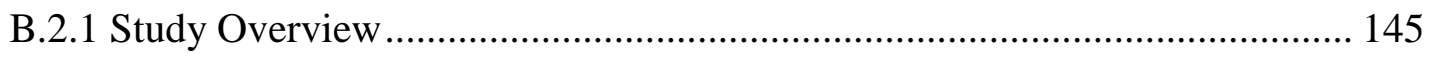

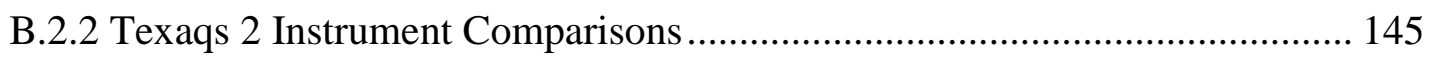




\section{List of Tables}

Table 1: National Ambient Air Quality Standards for selected pollutants.

Table 2: Reported emission change coefficient (a) values from the 2001 US EPA

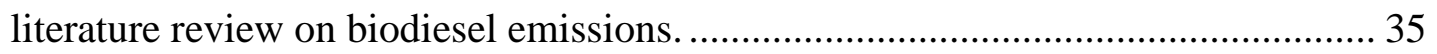

Table 3: Comparison between PM emissions for diesel and gasoline vehicles................ 38

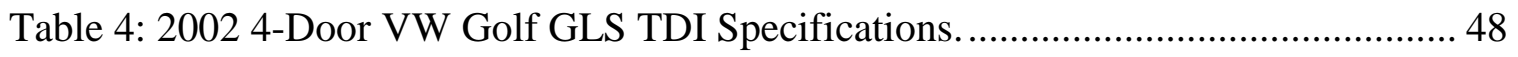

Table 5: EPA Quality Assurance Standards for Ambient Air Monitoring ...................... 49

Table 6: Chemical and Physical Properties of SeQuential Biodiesel. ........................... 51

Table 7: Fuel Mixtures used for Diesel and Biodiesel emissions testing. ...................... 52

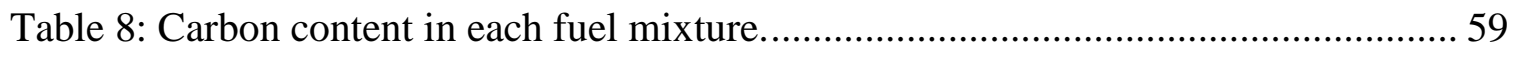

Table 9: Summary of the emission factors obtained from this work............................ 67

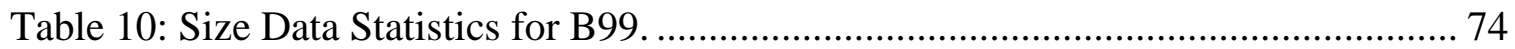

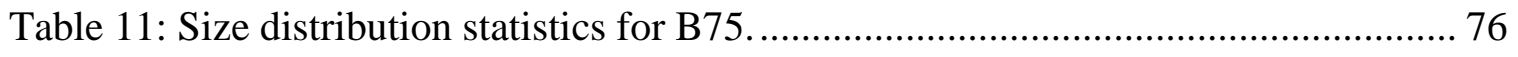

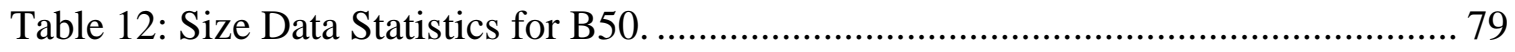

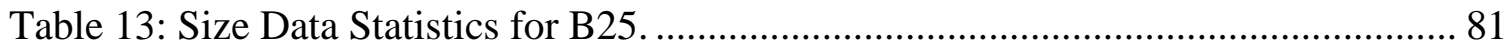

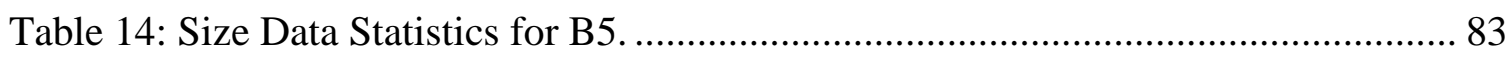

Table 15: Calculated Absorption and LAC emission factors. ..................................... 91

Table 16: Calculated Ångström Exponent and Single Scattering Albedo........................ 94 


\section{List of Figures}

Figure 1: Atmospheric lifecycle of aerosols from formation to deposition........................ 6

Figure 2: Volume and Number Size Distributions for Typical Ambient Aerosol............... 8

Figure 3: Conceptual diagram of a cavity ring-down experiment.................................. 22

Figure 4: Relative Pollutant Concentration vs. Distance from freeway. ........................... 26

Figure 5: A skeletal diagram of the transesterification reaction used in the production of biodiesel.

Figure 6: Summary of recent emission studies from biodiesel fueled vehicles and comparison to the 2001 US EPA emission trend....................................................... 37

Figure 7: Emission testing/sampling protocol. …………………………………...... 50

Figure 8: Correlation plot between Extinction $532 \mathrm{~nm}$ and $\mathrm{CO}_{2}$ for all $\mathrm{B} 5$ plumes......... 61

Figure 9: Correlation plot between Scattering $530 \mathrm{~nm}$ and $\mathrm{CO}_{2}$ for all $\mathrm{B} 5$ plumes......... 62

Figure 10: Correlation plot between Extinction $1064 \mathrm{~nm}$ and $\mathrm{CO}_{2}$ for all $\mathrm{B} 5$ plumes..... 63

Figure 11: Correlation plot between Particle Count and $\mathrm{CO}_{2}$ for all $\mathrm{B} 5$ plumes............. 64

Figure 12: Correlation plot between $\mathrm{NO} \mu \mathrm{gm}^{-3}$ and $\mathrm{CO}_{2}$ for all B5 plumes. ................... 65

Figure 13: Correlation plot between $\mathrm{NO}_{2} \mu \mathrm{gm}^{-3}$ and $\mathrm{CO}_{2}$ for all $\mathrm{B} 5$ plumes ................... 66

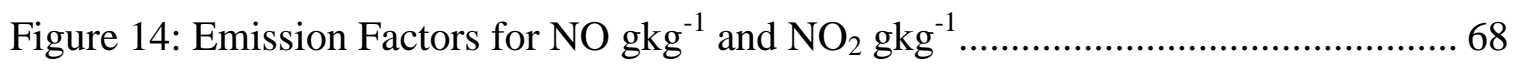

Figure 15: Emission Factors for Extinction $1064 \mathrm{~nm}$ and Extinction $532 \mathrm{~nm}\left(\mathrm{~m}^{2} \mathrm{~kg}^{-1}\right) \ldots 68$

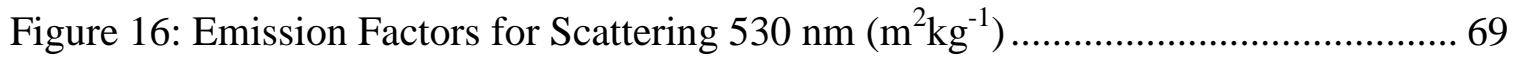

Figure 17: Emission factors for Particle Count $\left(\# * 10^{14} \mathrm{~kg}^{-1}\right)$....................................... 69

Figure 18: Number and Volume distributions for B99............................................... 73

Figure 19: Number and Volume Distribution for B75 Plume. ........................................ 75

Figure 20: Number and Volume Distribution for B50................................................ 78

Figure 21: Number and Volume Distribution for B25................................................. 80

Figure 22: Number and Volume Distribution for B5.................................................. 82

Figure 23: Comparison of percent change in $\mathrm{NO}_{\mathrm{X}}$ emissions with biodiesel use from this

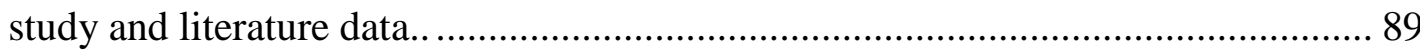

Figure 24: Angstrom Exponent vs. Single Scattering Albedo........................................... 96

Figure 25: B5 and B50 emission particles as imaged with an SEM................................ 98

Figure 26: B25, B75 and B99 emission particles as imaged with an SEM..................99 


\section{Introduction}

\subsection{Overview}

Aerosols have both natural and anthropogenic sources. ${ }^{1-13}$ Internal combustion engines are considered one of the major anthropogenic global sources of atmospheric aerosol or particulate matter (PM). Even though the magnitude and direction of the PM contribution to radiative forcing is considered to be the most uncertain portion of the current climate models. ${ }^{14}$, there is general acceptance that PM contributes to climate change, causes visibility reduction, and can adversely affect human health. ${ }^{15-17}$

Government agencies have been increasing the mandatory controls on combustion engines to reduce this potential environmental and public health impact. ${ }^{18,19,20}$ Many of the new regulations have directly targeted the emissions of diesel vehicles. This is because diesel vehicles emit about 50 percent more of the absorbing materials (as diesel particulate matter, DPM) than gasoline vehicles. This increase in absorbing aerosol is thought to result in increased localized heating and a reduction in the amount of sunlight that reaches the Earth's surface. Additionally, DPM has been shown to induce systemic inflammation in animals by imparting oxidative stress in susceptible cells which can contribute to cardiopulmonary diseases and cause asthma symptoms. ${ }^{1774,77,79}$ To improve understanding of how combustion aerosol impacts climate, and to address regulatory needs, additional research on vehicle particle emissions is warranted. 
Even with increased controls the use and popularity of diesel vehicles is on the rise. Diesel engines are known to outlast gasoline vehicles and typically can travel more miles on a gallon of fuel. In response to increased controls and lowered emission limits for vehicles, the investigation and use of alternative fuels and additives for diesel vehicles has increased. One of the most popular diesel alternatives, biodiesel, is thought to help reduce $\mathrm{PM}$ and some gaseous emissions. ${ }^{21} \mathrm{~A}$ general trend of higher $\mathrm{NO}_{\mathrm{X}}$ and lower $\mathrm{PM}$ mass concentration in emissions from diesel engines fueled with increasing biodiesel ratio in mixtures is presented in the literature, ${ }^{90}$ but there are results that contradict these findings. ${ }^{30-49}$ The differences between studies often depended on the sampling method and instrumentation used, as well as the engine condition and type and the biofuel source. A majority of these studies investigated heavy-duty engines using filter-based measurement techniques to determine total aerosol mass.

In order to compare emissions from different fuels, experiments should be designed to capture real-world variations in engine performance. Additionally, the instrumentation used must be capable of measuring the key properties of the pollutants. Many gaseous emissions can be completely characterized by their concentrations. Particulate matter, on the other hand, should be described by a set of physical and chemical parameters. For example, black or light absorbing carbon (BC or LAC), is typically associated with warming and global dimming. Organic carbon (OC) and sulfate, aerosols that scatter light, are associated with global radiative cooling. ${ }^{26-29}$ Thus the chemical composition of 
the particles is linked to their radiative effects. Along with composition, particle size also plays a role in determining how a given particle can affect climate and health. Since the diameter range for ambient aerosols spans over four orders of magnitude (nanometers to micrometers), mass concentration and number concentration distributions can peak in different size ranges. In order to assess particulate emission impacts on climate and health, the composition, number and volume size distributions should be determined for a comprehensive characterization. ${ }^{10,23-25}$

With an increase in diesel engine use and regulations that encourage or require alternative fuel sources in many areas, the effect of the changing emissions on an urban area must be understood. A change in the size, number, or composition of PM in the emissions from diesel vehicles may impact air quality on both a local and regional scale. ${ }^{12,50-53}$ Changes in the emissions from biodiesel use should be incorporated into a regulatory air quality model to confirm that the local and regional impact is the desired outcome.

To determine the biodiesel impact on PM emissions, a new approach to emission testing was utilized to investigate how biodiesel fuel mixture use in on-road passenger diesel vehicles would affect PM emissions. This approach to sampling vehicle emissions allows for a comprehensive comparison of the particulate component of the emissions in real time. A cavity ring-down transmissometer (CRDT) coupled with a condensation particle counter, a scanning mobility particle sizer (SMPS), a nephelometer, $\mathrm{NO}_{\mathrm{x}}, \mathrm{CO}, \mathrm{CO}_{2}$, and 
$\mathrm{O}_{3}$ measurements provide data needed to determine emission factors for all fuel mixtures tested. This approach reduces sampling artifacts and allows for the determination of optical properties, particle number concentration, and size distributions, along with several important gas phase species' concentrations. Results can be extrapolated to predict the regional or global scale changes that any change in emissions would cause.

All fuel samples for emission testing were mixed from commercially available stock diesel (B5) and biodiesel (B99) donated by Star Oilco and SeQuential Biofuels. Using stock fuel sources during emission testing removes uncertainties caused by using different fuel brands or fuel processing methods or improperly labeled station fuel. Emissions were sampled using one vehicle under simulated real-world conditions. Every fuel mixture was subjected to a minimum of 18 trials, resulting in at least 3.5 hours of emission data from each mixture investigated. This allows for an understanding of the mean vehicle performance for each fuel mixture. Emitted particles were also collected on filters and analyzed for a qualitative determination of particle morphology (shape and size) using scanning electron microscope (SEM) analysis. Filter samples were also collected for use in associated quantitative lab studies investigating the oxidative properties of biodiesel PM emissions.

Results indicate that there is a difference in emissions depending on fuel type. SEM analysis shows that for mixtures with high biodiesel content, particles tend to be smaller 
and more fractal-like. Half and half mixtures of biodiesel and petroleum diesel have the greatest particle number concentration, largest LAC emission factors and the highest $\mathrm{NO}_{\mathrm{X}}$ emissions, indicating that the relationship between biodiesel and diesel emissions is complex and should not be described by the near linear relationship currently found in literature.

\subsection{Aerosols}

Atmospheric aerosols are defined as solid or liquid particles suspended in air. Since the sources of aerosols can be either biogenic or anthropogenic, their composition and size vary. Despite the many natural processes that produce aerosols, human activities are responsible for generating much of the aerosol load in today's atmosphere ${ }^{56}$. Biomass and fossil fuel burning, agriculture activities, and industrial pollution all produce primary aerosol particles, those that are directly injected into the atmosphere ${ }^{10,57}$. Precursor gases from these sources can also condense and form secondary aerosols ${ }^{6,14,25,58}$. The size and composition of the aerosol and the meteorological conditions govern the atmospheric

lifetime and the deposition pathways. ${ }^{11,54,57,59}$ Figure 1 outlines atmospheric aerosol lifecycle from origin to deposition. 


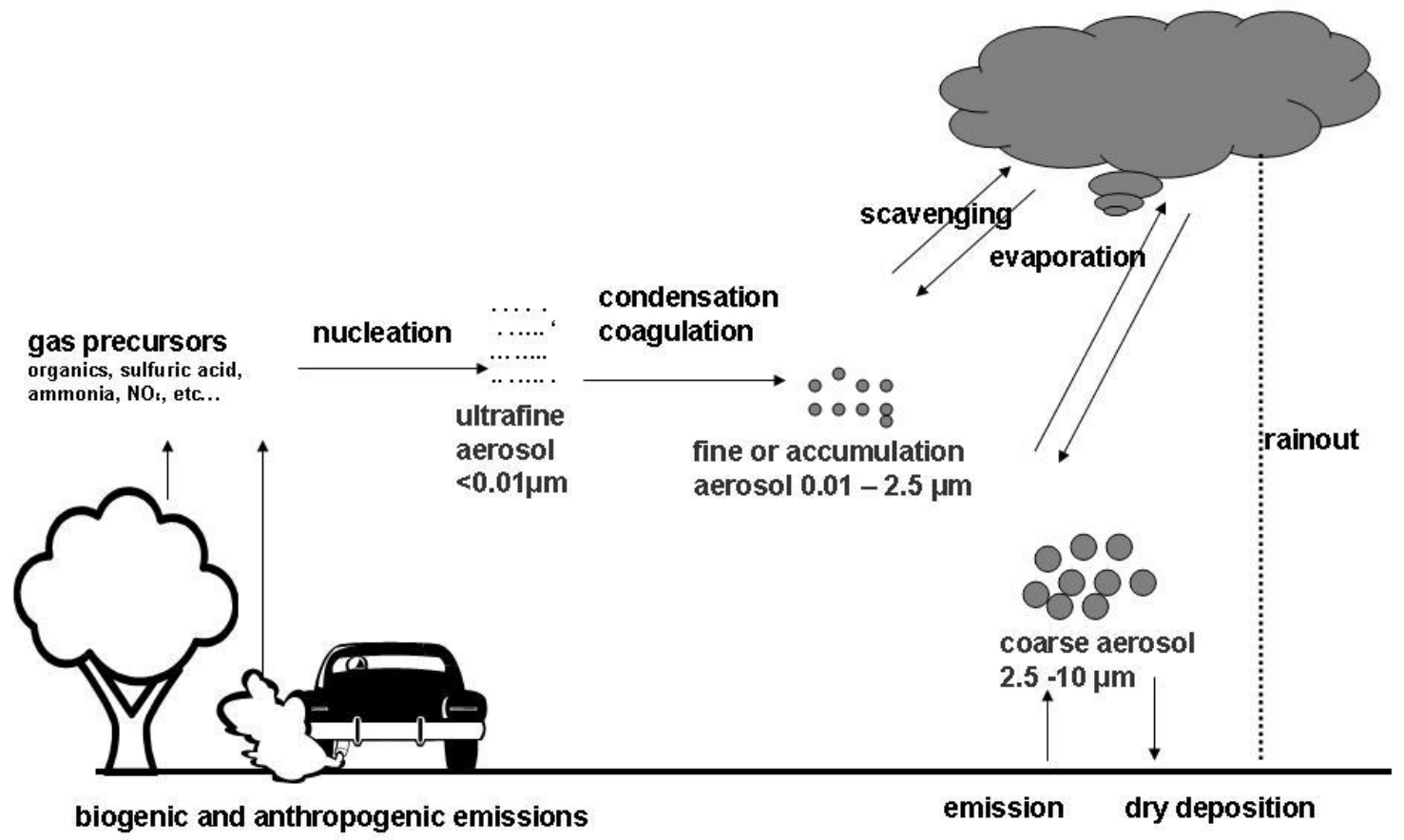

Figure 1: Atmospheric lifecycle of aerosols from formation to deposition. Coarse aerosols are typically found in the region of the source, while secondary and ultra fine aerosol are transported by winds, sometimes up to $5000 \mathrm{Km}$ from the source. Modified figure based on Lapuerta, et al. ${ }^{147}$

\subsection{Atmospheric Aerosol Size Distributions}

The size of a particle is typically expressed in terms of the diameter of a volumeequivalent sphere. There are several typical size ranges for atmospheric aerosol. Regulatory definitions group all particles with a diameter under $2.5 \mu \mathrm{m}$ into the fine particle category and all particles between 2.5 and $10 \mu \mathrm{m}$ into the coarse category. The fine category is often sub-divided into three additional modes, the Aitken, the nucleation 
and the accumulation modes. Nucleation mode particles are the smallest particles with diameters under $0.01 \mu \mathrm{m}$. They are created by gas molecules condensing in the atmosphere to form secondary particles. ${ }^{25}$ Accumulation mode particles are generally formed by coagulation of smaller particles and condensation of gas onto existing particles.

Volume and number size distributions of atmospheric aerosols are shown in Figure 2. To obtain the number size distribution, the number concentration for a given size range has been divided by the log of the corresponding size range and is plotted versus particle size on a logarithmic scale. For surface or volume distributions, all particles are treated as spheres to reduce complexity. The diameter of a particle can then be squared and multiplied by pi to obtain the surface area of a particle. Multiplying the surface area function by the number distribution gives the aerosol surface area distribution. The volume distribution is calculated by multiplying the surface area distribution function by the diameter divided by six. 


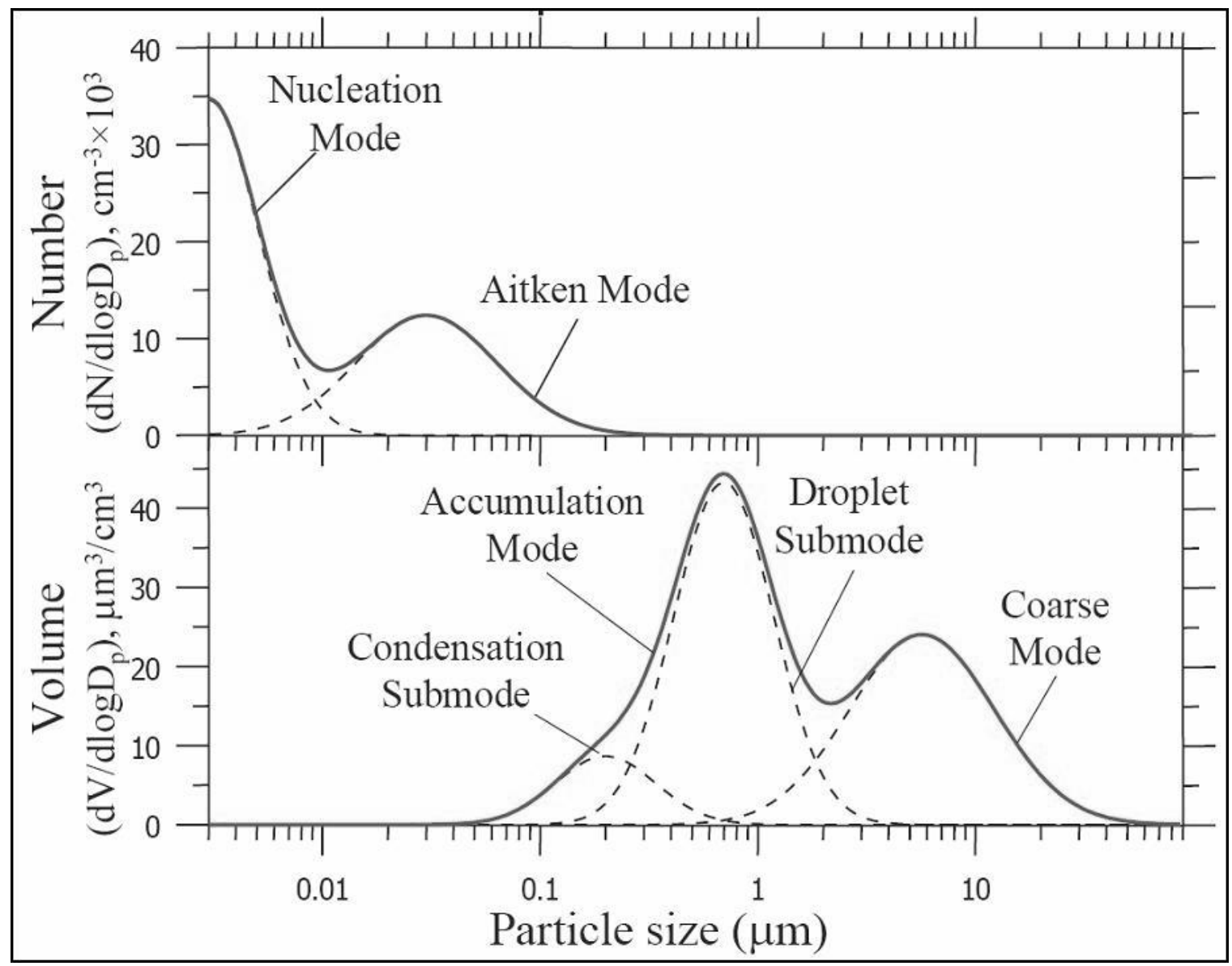

Figure 2: Volume and Number Size Distributions for Typical Ambient Aerosol.

The Number concentration (particles per $\mathrm{cm}^{3}$ of air) in the size range logDp to $\log \mathrm{D} p+\mathrm{d} \log \mathrm{Dp}$ is the area under the curve (the integral of the distribution function). Similarly, the volume distribution is the volume of particles per $\mathrm{cm}^{3}$ of air having diameters in the range $\log \mathrm{Dp}$ to $\log \mathrm{Dp}+\mathrm{d} \log \mathrm{Dp}$. 


\subsection{Optical Properties of Aerosols}

The sum of the scattering and absorption of electromagnetic radiation is called extinction. The extinction of light passing through an aerosol is determined by the chemical make-up and the size, structure and shape of the matter and the wavelength of the radiation. The extinction of visible light can result in altered appearance of distant objects. This reduction in visual range can be determined from the extinction coefficient, $b_{\text {ext }}$. The extinction coefficient is defined by the Beer-Lambert law as shown in Equation 1. This equation represents the decrease in intensity as light moves through the atmosphere, where $\mathrm{I}$ and $\mathrm{I}_{0}$ are the intensities after and before the light travels a distance $\mathrm{d}$ through a scattering and absorbing medium. The units for extinction are inverse distance, indicating that as extinction increases, visibility degrades.

$$
I=I_{0} \exp \left(-b_{\text {ext }} d\right)
$$

The scattering of light by particles is conceptually divided into two regimes, Rayleigh and Mie (although Mie theory includes the Rayleigh regime as a special case). Rayleigh scattering is observed when the particles are much smaller than the wavelength of the light. This type of scattering is most common in gases, but can occur for particles that are smaller than ten percent of the incident wavelength as well. The probability of Rayleigh scattering per incident photon is dependent on the size of the particle and the wavelength of light (proportional to $\lambda^{-4}$ ) but is independent of scattering direction. Thus Rayleigh scattering is relatively isotropic, grows with particle size and is most efficient at smaller 
wavelengths, with blue light $(\lambda \sim 450 \mathrm{~nm}) 4.4$ times more efficiently scattered than red light $(\lambda \sim 650 \mathrm{~nm})$. Rayleigh scattering by gasses $\left(b_{\mathrm{Rg}}\right)$ is one component of extinction as shown in Equation 2.

$$
b_{\text {ext }}=b_{\text {Rg }}+b_{\text {ag }}+b_{\text {scat }}+b_{\text {ap }}
$$

The sum of Rayleigh scattering, absorption by gases $\left(b_{\mathrm{ag}}\right)$, and scattering and absorption by particles ( $b_{\text {scat }}$ and $b_{a p}$ ) results in the extinction coefficient. When the aerosol particle diameters are closer to the wavelength of light (expressed as the size parameter $\mathrm{X}=$ dp/lambda $\rightarrow 1$ ) Mie scattering dominates. For these larger aerosol particles, scattering in the direction of the incident radiation (forward scattering) is favored. The scattering cross section, also defined via the Beer-Lambert law on a per particle basis, may be slightly larger or smaller than the geometric cross section (the physical size) of the particle but still grows with particle size. Mie scattering is not as strongly wavelength dependent as Rayleigh, and physically manifests as a bright white ring around the sun, or the whitish color of clouds or smog. The scattering cross-section, $\sigma_{\text {scat }}$, can be calculated using Mie theory; the solutions to Maxwell's equations that describe the scattering of electromagnetic radiation by spherical particles. Mie theory is typically used to predict the scattering efficiency parameter, $Q_{s}$, which is the scattering cross-section divided by the geometric cross-section, $\mathrm{A}_{\mathrm{s}}$, for particles with specified size and refractive index. The scattering coefficient for a sample containing many scattering particles is calculated by 
multiplying the scattering cross-section(s) by the volume density, summed over all particle sizes.

In the ambient atmosphere, absorption usually comprises a small fraction of the total extinction by the aerosol. Even though the absorption by aerosols is small relative to extinction, absorption can have a large effect on regional and global climate. Light absorption by aerosols heats the local atmosphere because absorbed energy is reradiated as long wave radiation or non-radiatively coupled to the air that the particles are suspended in. Interactions with gases or aerosols that are able to absorb the long wave radiation will result in a warming of the atmosphere that can result in additional long wave radiation reaching the surface ${ }^{54}$.

The aerosol extinction, scattering and absorption coefficients are extensive properties because they depend on the particle concentration. These measurements can be used to determine the single scattering albedo $\omega_{0}$ which is an expression of the probability that a photon encountering the aerosol will be scattered vs. absorbed. The intensive property $\omega_{0}$ is described in Equation 3.

$$
\omega_{0}=b_{\mathrm{sp}} /\left(\mathbf{b}_{\mathrm{sp}}+\mathbf{b}_{\mathrm{ap}}\right)
$$


which is unitless and independent of aerosol concentration. The Ångström exponent $\AA$ is another intensive aerosol optical property that is a measure of the wavelength dependence of the extinction (or scattering or absorption) coefficient. Since the Ångström exponent for scattering (and usually extinction) is inversely related to particle size, it can provide information on the size and possibly composition of atmospheric particles. One commonly used expression is shown in Equation 4.

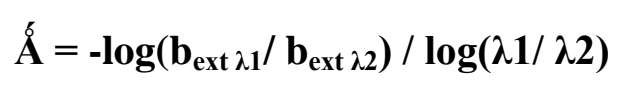

Ångström exponents for extinction give an indication of the dominant size of aerosol measured: for example when the exponent calculated for aerosol extinction measured at wavelengths $532 \mathrm{~nm}$ and $1640 \mathrm{~nm}$ is greater than 2, particles smaller than $100 \mathrm{~nm}$ are probably dominating the extinction, while an $\AA$ smaller than 1 implies that extinction is dominated by particles larger than 500nm. When evaluated together, the extensive and intensive aerosol optical properties can be used to provide a robust characterization of ambient aerosol that can be used to determine the probable human health and climate impact of the aerosol.

\subsection{Aerosol Measurement Techniques}

Current particulate air quality regulations and diesel PM regulations from the US

Environmental Protection Agency (EPA) and in the EU are based on the mass ( $\mu \mathrm{g})$ of 
particles in a given volume of air $\left(\mathrm{m}^{3}\right)$ and measurements are typically made with a gravimetric or other filter method. An important limitation to the particle mass standard is that ambient aerosol mass concentrations, especially in urban areas, are heavily biased towards larger particles as seen in Figure 2. Mass concentration is largest in the accumulation mode (with diameters between 0.1 and $2.5 \mu \mathrm{m}$ ) and number concentration is largest in the UFP mode (with diameters under $0.1 \mu \mathrm{m}$.) ${ }^{112}$ Since smaller particles have a better correlation with negative health effects than larger particles, knowledge of particle number concentrations might be a more effective regulatory standard than particle mass. ${ }^{69,72,73,75,80,87,113}$

\subsubsection{Filter Measurements}

The most common aerosol measurement techniques for regulatory purposes are filterbased mass measurements: the collection of ambient particles onto a pre-massed filter followed by a mass determination at controlled temperature and relative humidity. Aerosol is pulled through the filter using a calibrated constant flow pump. For accurate mass measurements, long sampling times are required, often 8-24 hours. The collection apparatus may have a single size cut impactor, to prevent unwanted large particles from obscuring the measurements and to define the PM 2.5 particle size distinction; or multiple impactors and filter stages in a cascade setup for measurement of mass size distributions. The micro-orifice uniform deposit impactor (MOUDI) is a popular method for cascade measurements. Filter-based mass measurements are time consuming and labor intensive 
because the filters must be manually massed pre- and post-sampling and real-time emissions cannot be measured. There are also concerns that the particles could lose or adsorb volatile components (causing either positive or negative biases) during their sampling and storage on the filter.

The tapered element oscillating microbalance (TEOM) is a measurement technique that can be used to measure real-time particle mass concentrations. The TEOM draws the aerosol through a filter at a constant flow rate. The filter is attached to a tapered oscillating glass rod which allows for the measurement of the accumulation of mass on the filter. ${ }^{109}$ To eliminate the influence of water vapor, the inlet of the TEOM is maintained at $50{ }^{\circ} \mathrm{C}$. This may cause the evaporation of volatile or semi-volatile compounds, producing a negative bias in the measurement of organic aerosols.

The aethalometer and the particle/soot absorption photometer (PSAP) are filter based optical measurements that provide aerosol absorption coefficient data. In the aethalometer instrument, a filter is illuminated by a light source. When the filter contains light-absorbing particles the transmitted light decreases. The time derivative of the signal of the photosensor is proportional to the absorption coefficient of the aerosol passing through the filter at a given time ${ }^{115}$. The PSAP works in a similar manner. ${ }^{116,117}$ These techniques have large uncertainties if mass is derived, due to the time variations in the conversion parameter, the mass absorption coefficient (MAC) ${ }^{101}$ The influence of 
scattering particles co-collected with the absorbing aerosol on the absorption measured is variable and incompletely characterized, despite years of study. ${ }^{97}$

Previous studies have been completed on gasoline, diesel, and biodiesel particulate emissions with impactor and filter techniques. ${ }^{42,47,48,113,114}$ Analysis of the particles collected on filters can be useful for determining metals, organic species, and total and speciated mass; however real time information on rapid changes in optical properties or particle number concentration have not been measured with these techniques. As noted above, all filter measurements can be affected by a variety of artifacts including adsorption of vapor onto the filter, volatilization of semi-volatile compounds from filtered particles, and an array of chemical reactions between filtered particles, the gas, and filter substrate ${ }^{121-123}$ Another drawback for filter measurements is that they are all time and labor intensive. For this study filter samples were collected for SEM analysis and laboratory studies investigating the oxidative properties of the emissions.

\subsubsection{Particle Sizing and Counting Instruments}

a. Condensation Particle Counters: This instrument works by drawing an aerosol sample continuously through a chamber containing vaporized alcohol or water. The aerosol sample and alcohol vapor mix and then pass into a condenser which causes the alcohol vapor to condense on the particles. Particles grow and then are counted by an optical detector. ${ }^{124}$ Particle counters do not provide size information, and are commonly used in 
conjunction with other aerosol measurements. A CPC was used to provide time-resolved number concentrations in this investigation.

\section{b. Scanning Electrical Mobility Spectrometers: Size distribution measurements of} aerosols can be made using commercially available instruments, including scanning electrical mobility spectrometers (SEMS). ${ }^{125}$ Two common instruments for this type of measurement are the electrical low pressure impactor (ELPI) and the scanning mobility particle sizer (SMPS). The differences between the two methods are the selection method for particle size and the particle detection. The ELPI separates particles using low pressure inertial impaction and detects the previously charged particles using sensitive electrometers. The SMPS creates a situation where charged particles with a selected electrical mobility can pass through a differential mobility analyzer ${ }^{120}$ (DMA) and a condensation particle counter (CPC) is used to measure the concentration of the sizeclassified particles. ${ }^{119-121}$ Despite these differences, these methods generally agree on the number concentrations and size distributions in emission studies when a uniform particle density was assumed. These instruments are simple to operate and have moderate time resolution (between 30 and 90 seconds per scan) ${ }^{118}$.

The major problems associated with these instruments are that they are expensive and often improperly characterize non-spherical particles, like diesel PM which are in the 
form of fractal aggregates, ${ }^{128}$ The assumption of uniform particle density can also result in large uncertainties in mass measurement. ${ }^{129.130}$

An SMPS will be used for both in-lab validation studies that are conducted on particles with known diameters or composition or both and as a complement to the DPM studies. Size distribution measurement or control facilitated instrument validation allowing comparisons between CRDT measurements and Mie theory. For the DPM studies the SMPS was used to determine size distributions of the ambient aerosol and the exhaust emissions for each fuel type measured.

\subsubsection{Particulate Composition Measurement}

Detailed information on the individual particle types emitted by diesel engines can be gathered using single particle mass spectrometry techniques or aerosol mass spectrometry (AMS). AMS is a technique that allows for the on-line characterization of aerosol particles. ${ }^{131}$ The AMS focuses aerosol particles in select size ranges onto a hot surface $\left(\sim 600^{\circ} \mathrm{C}\right)$ using an aerodynamic lens assembly and a beam chopper. The non-refractory particle components are flash-evaporated on the hot surface and the resulting gas-phase compounds are ionized by an electron ionizer and filtered by mass to charge ratio via a quadrupole mass analyzer. ${ }^{132}$ The chopper makes it possible to collect mass spectra as a function of particle flight time, and thus aerodynamic diameter. Some instruments are capable of providing time averages of mass concentrations of the non-refractory aerosol 
components as well as species-resolved size distributions. AMS measurements benefit from a complementary aerosol measurement for refractory particles like BC aerosol, dust and sea salt (depending on the flash surface temperature).

Since the AMS does not measure BC, the species of interest in this study, it is not an ideal technique for diesel emission studies. However measurements from an Aerodyne QAMS, operated as described by Ziemba, et al. ${ }^{133}$ have been previously compared with CRDT responses to the same ambient aerosol and are described in Wright et al. ${ }^{152}$ Even though the Q-AMS is insensitive to refractory components, the mass concentrations for several of the aerosol components measured agree with values calculated from CRDT measurements. When these compounds dominate the ambient aerosol mass concentration, comparisons were possible.

\subsubsection{Non-Filter Optical Methods}

Filter measurements, particle size instruments and the AMS all have limitations, artifacts and speed constraints. None of these methods alone provides a comprehensive measurement of DPM. Measurements of aerosol optical properties can provide information on the ambient aerosol size distribution and on aerosol scattering and absorption. Optical properties of aerosols have most often been determined by measuring $b_{\text {scat }}$ with a nephelometer and $b_{a b s}$ using a filter based technique like the previously described aethalometer or particle/soot absorption photometer (PSAP). To avoid filter 
artifacts, it is desirable to make optical property measurements of the aerosol while it is suspended. Two methods exist to sample the aerosol in this way, CRDT and photoacoustic spectroscopy (PAS).

a. Photoacoustic Aerosol Spectroscopy (PAS): The PAS method measures the acoustic signal (sound) from an absorbing aerosol sample that is excited by a power modulated laser beam inside a resonant acoustic cavity. The aerosol absorbs the laser and heats up, then releases the heat to the surrounding gas. The modulated heating causes a pressure wave that is detected as sound by sensitive microphones. The amplitude of the sound is proportional to the quantity of light absorbed. The acoustic signal is also influenced by relaxation processes in the particles; so the precision and sensitivity depend on maintaining a specific laser modulation frequency and the method generally requires calibration. Due to the expense of the instrument and the need for calibration, PAS was not used in the experiments described here. Instead, the absorption coefficient was measured via the CRDT/N difference method described below.

\section{b. Cavity Ring-Down (CRD) Spectroscopy: Cavity Ring-Down spectroscopy measures} aerosol $b_{\text {ext }}$ directly. Using a cavity ring-down transmissometer/nephelometer (CRDT/N) combination, the $b_{\text {ext }}$ is measured at $532( \pm 0.1) \mathrm{nm}$, the $b_{\text {scat }}$ is measured at $530( \pm 10) \mathrm{nm}$, and $b_{a b s}$ is obtained by difference. The single scattering albedo $\omega_{0}$, can be calculated by taking the ratio $b_{\text {scat }} / b_{\text {ext }}$. The CRDT/N used in these studies also measures particle 
extinction at $1064 \mathrm{~nm}$. With $b_{\text {ext }}$ at two wavelengths $(532 \mathrm{~nm}$ and $1064 \mathrm{~nm}$ ) the Ångström exponent can be calculated and used to estimate the average size of the aerosol. ${ }^{134}$

c. Measurement of Aerosol Scattering Coefficient: Scattering coefficients $b_{\text {scat }}$ can be measured with a nephelometer. In this method, aerosol flows through a chamber between a light source and a light detector that is not in the direct path of the source beam. The light that is deflected to the detector by the particles is a function of the bulk scattering from the particles. The scattering coefficient measurement by the nephelometer depends strongly on the angular range into which the scattered light is collected and in general it also varies with the refractive index of the particulate material. ${ }^{51} 10,135$ Typically the maximum scattering for particles occurs when the particle diameter is comparable in size to the wavelength of the radiation. When particles that have the same mass but are three times larger or smaller than the wavelength of light are measured in a nephelometer, the light-scattering is an order of magnitude less. One problem with the measurement of the scattering coefficient in this way is that larger particles have an increasing tendency to scatter light preferentially in the forward direction, along the initial beam direction. This light is not detected unless the detector is very near the original beam direction, which is not true in most nephelometer designs. The resulting low measurement bias for larger particles is referred to as the "truncation angle" problem. 
Despite the truncation angle problems, light scattering measurements can be used to estimate particle mass concentration when the appropriate mass scattering coefficient is known for the measured aerosol. Additionally nephelometers can be equipped with sizeselective inlets so only particles in the size range of interest are measured. For this experiment the scattering coefficient at $530 \mathrm{~nm}$ for the DPM was measured using a Radiance Research nephelometer (Radiance Research Co., M903-530, Seattle, WA.) The low bias has not been well-quantified for the Radiance Research nephelometer but it is known to be larger than the bias of the more commonly used TSI model 3563 Integrating Nephelometer. For the DPM studies, the particles of interest were small enough that correction for the truncation bias was not necessary.

\subsubsection{Cavity Ring-Down Measurement of Aerosol Extinction Coefficient}

The cavity-ring down technique has previously been described in detail. ${ }^{136-140}$ The use of a custom-built CRDT instrument for atmospheric aerosol measurement is discussed by Smith and Atkinson, 2001, so only a brief description of the CRDT will be given here. The CRD technique uses two highly reflective mirrors (>99\%) to create an optical cavity in which light can be trapped. The light is usually delivered to the cavity from a pulsed laser. Light leakage through one of the mirrors, sometimes aided by resonance effects, is used to determine the decay rate, as seen in the conceptual diagram of the CRDT given in Figure 3 . 


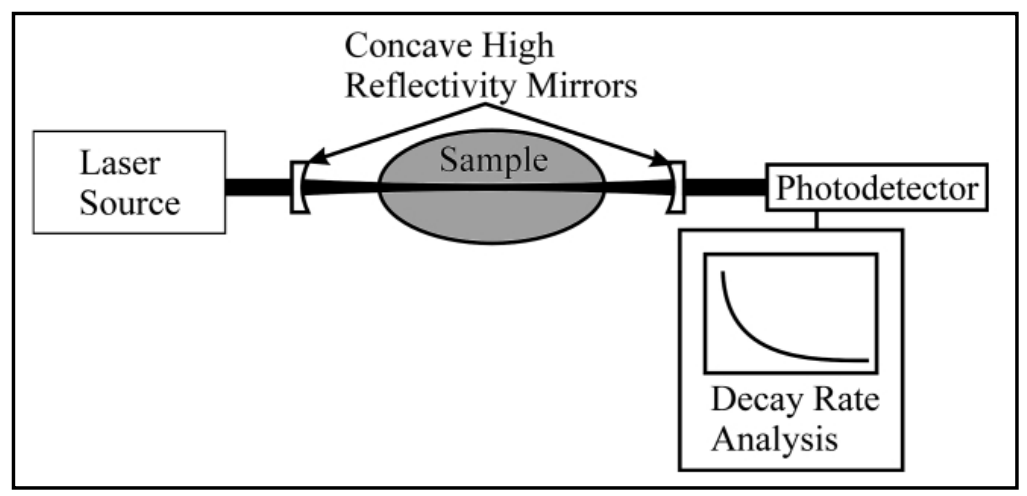

Figure 3: Conceptual diagram of a cavity ring-down experiment. ${ }^{138}$

The cavity loss is determined by measuring the decay rate of the trapped light as it leaks from the cavity. The light intensity decays exponentially in time because of constant small losses through the mirrors and in the cavity. The light intensity that is transmitted to a detector outside of the cavity can be described by Equation 5 .

$$
\mathbf{I}=\mathbf{I}_{\mathbf{0}} \mathbf{e}^{-\beta \mathbf{t}}
$$

where $\mathrm{I}$ and $\mathrm{I}_{0}$ are the intensity at time $\mathrm{t}$ and at the beginning of the decay, respectively, and $\beta$ is the exponential decay constant with inverse time (i.e., $\left.\mathrm{s}^{-1}\right)$ units.

Particle scattering and absorption reduces the time that light is in the cavity (increases $\beta$ ). To extract the extinction due to particles, the decay rate of light as it passes through a sample is compared to the decay rate through filtered air. The difference is the fractional losses that are due only to the particles and can be related to the extinction coefficient by changing from time to distance units. Equation 6 shows how this is calculated. 


$$
b_{\text {ext }}=\left[\left(\boldsymbol{\beta}_{\text {aerosol }}-\boldsymbol{\beta}_{\text {clean }}\right) /\left(\mathbf{c} \times\left(\mathbf{L}_{\text {aerosol }} / \mathbf{L}_{\text {cavity }}\right)\right)\right] \times 10^{6}
$$

Where $\beta_{\text {aerosol }}$ and $\beta_{\text {clean }}$ are the decay constants for the ambient and filtered samples and $\mathrm{c}$ is the speed of light (the conversion from time to distance for light). The length factor $\mathrm{L}_{\text {aerosol }} / \mathrm{L}_{\text {cavity }}$ is usually needed because the aerosol is not allowed to come into contact with the mirrors to avoid reflectivity degradation, so the distance that the beam travels in the cavity is greater than the length that it travels through the aerosol. For slightly absorbing aerosols the difference between the extinction coefficient and the scattering coefficient is small, so it is important that both parameters be measured with a high degree of accuracy.

Bulk light scattering, absorption, and extinction coefficient measurements can be used to estimate particle mass concentration. The relationship between light extinction and particle mass is empirical and extinction methods are most appropriate for real world and in-lab measurements when the size-distribution and refractive index of the aerosol does not change during the sampling time.

\subsection{Regulations}

Since ambient aerosols are linked to human health effects, the National Ambient Air Quality Standards (NAAQS) include PM in the primary standards, the Clean Air Act regulations intended to protect public health. The current standard for $\mathrm{PM}_{2.5}$ states that the 
24-hour concentrations averaged over 3 years must not exceed $35 \mu \mathrm{g} / \mathrm{m}^{3}$ and the annual mean averaged over 3 years must not exceed $15 \mu \mathrm{g} / \mathrm{m}^{3}$ for community-oriented monitors. Several of the current NAAQS standards are given in Table 1.

Table 1: National Ambient Air Quality Standards for selected pollutants.

\begin{tabular}{l|l|l}
\hline \hline Pollutant & Level & Averaging Time \\
\hline \multirow{2}{*}{ Carbon Monoxide } & $9 \mathrm{ppm}\left(10 \mathrm{mg} / \mathrm{m}^{3}\right)$ & 8-hour \\
\cline { 2 - 3 } & $35 \mathrm{ppm}\left(40 \mathrm{mg} / \mathrm{m}^{3}\right)$ & 1-hour \\
\hline \multirow{2}{*}{ Nitrogen Dioxide } & $\begin{array}{l}0.053 \mathrm{ppm}\left(100 \mu \mathrm{g} / \mathrm{m}^{3}\right) \\
0.1 \mathrm{ppm}\left(188 \mu \mathrm{g} / \mathrm{m}^{3}\right)\end{array}$ & $\begin{array}{l}\text { Annual (Arithmetic Mean) } \\
\text { 1-hour }\end{array}$ \\
\hline $\begin{array}{l}\text { Particulate Matter } \\
\left(\mathrm{PM}_{10}\right)\end{array}$ & $150 \mu \mathrm{g} / \mathrm{m}^{3}$ & 24-hour \\
\hline $\begin{array}{l}\text { Particulate Matter } \\
\left(\mathrm{PM}_{2.5}\right)\end{array}$ & $15.0 \mu \mathrm{g} / \mathrm{m}^{3}$ & Annual (Arithmetic Mean) \\
\cline { 2 - 3 } & $35 \mu \mathrm{g} / \mathrm{m}^{3}$ & 24-hour \\
\hline Ozone & $0.075 \mathrm{ppm}(2008 \mathrm{std})$ & 8-hour \\
\cline { 2 - 3 } & $0.08 \mathrm{ppm}(1997 \mathrm{std})$ & 8-hour \\
\cline { 2 - 3 } & $0.12 \mathrm{ppm}$ & $\begin{array}{l}\text { 1-hour (Applies only in limited } \\
\text { areas) }\end{array}$ \\
\hline \hline
\end{tabular}

$\mathrm{PM}$ is regulated by mass concentration which is measured at outdoor monitoring sites that are a proxy for population exposure. Several US EPA sponsored studies have found that when data are analyzed over time, personal exposure and outdoor ambient measurements are correlated to various degrees. ${ }^{76}$ The difference between individual exposure and measured ambient levels or 'exposure error' is linked to spatio-temporal variability, variations in personal habits both between individuals and seasons, and the effect of gaseous co-pollutants on mortality or sickness. ${ }^{77}$ Despite the significant and 
varying levels of 'exposure error', especially for $\mathrm{PM}_{2.5}$ ambient $\mathrm{PM}$ concentrations are used as predictors of personal exposure. ${ }^{68,78}$

When particle number concentration is considered instead of particle mass, the nucleation size range contains the majority of ambient particles, while particle surface area distributions maximize in the accumulation mode.$^{74}$ Because the EPA regulations and monitoring methods primarily focus on mass concentrations, the daily averages tend to show little variation between urban centers and rural upwind locations. ${ }^{79}$ However when other measurement techniques are used, such as those that focus on light absorbing carbon (LAC) content or particle number, the spatial distribution changes dramatically as the distance from a source increases. ${ }^{79,92}$ Results from Zhu, 2002 summarized in Figure 3 show that particle number, carbon monoxide and LAC concentrations have similar trends while fine PM mass measurements are less affected by highways. ${ }^{77}$ 


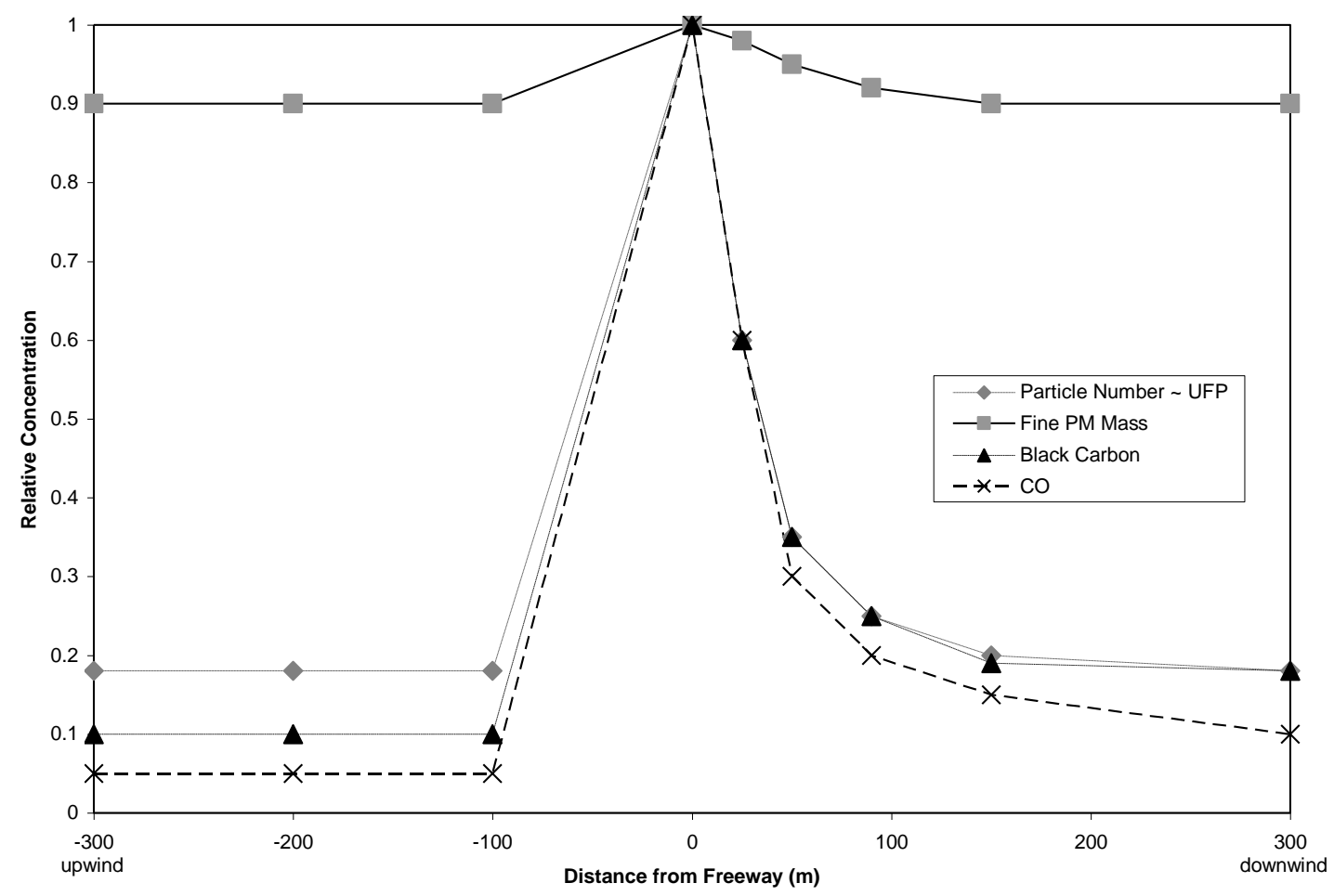

Figure 4: Relative Pollutant Concentration vs. Distance from freeway. The particle number and gas pollutants have a greater dependence on distance from the freeway. The mass concentration only has a slight peak near the freeway. ${ }^{77}$

In order to respond to emerging research that highlights the negative effects of mobile emissions, policy makers have proposed and implemented more stringent emission control rules and regulations for on-road vehicles, especially diesel vehicles. ${ }^{18-20,104-107}$ For example, the US EPA 2007 emissions standard reduces the diesel PM mass emission from heavy-duty engines tenfold from the old $0.1 \mathrm{~g} \mathrm{bhp}^{-1} \mathrm{~h}^{-1} \mathrm{PM}$ limit to $0.01 \mathrm{~g} \mathrm{bhp}^{-1} \mathrm{~h}^{-1}$. Stricter NAAQS have also been adopted to help control vehicle pollution, including the addition of short term $\mathrm{SO}_{2}$ and $\mathrm{NO}_{2}$ standards. 


\subsection{Mobile Sources}

Currently the transportation sector is one of the largest contributors to air pollution and in urban areas vehicle emissions are estimated to account for two-thirds of the total anthropogenic emissions. ${ }^{7}$ In the U.S. only about $5 \%$ of on-road vehicles are dieselfueled but they account for between 10 and $40 \%$ of ambient pollutants including $\mathrm{NO}_{\mathrm{x}}$, $\mathrm{CO}$ and PM. More than 20 percent of fine and ultrafine PM originates from mobile sources and this number is thought to be higher in urban areas or near major highways. ${ }^{77,93,94}$

Mobile sources consist of on-road gasoline (light duty vehicles and trucks), on-road diesel (mostly heavy-duty diesel with a growing number of light duty diesel passenger cars) as well as non-road gasoline (lawn/garden, recreational marine) and non-road diesel (construction and farm equipment, trains, boats) vehicles. Mobile sources are also responsible for a major portion of anthropogenic $\mathrm{BC}$ emissions with diesel vehicles emitting about 50 percent more black carbon than gasoline engines. ${ }^{95}$ Additionally, diesel vehicles are the main source of ultrafine emission particles near roadways since diesel engines produce the highest number concentrations of particles, particularly in traffic areas where driving cycles are disrupted by vehicles that are starting, stopping or idling. $^{78,79}$ 


\subsubsection{Diesel Vehicles}

The diesel engine combustion cycle has three main steps: air is compressed to a high pressure and temperature in the cylinder; fuel is atomized and sprayed into the compressed air where it vaporizes and mixes with the air, undergoing a series of chemical reactions that lead to ignition; once the fuel ignites, the pressure rises rapidly and the rate of mixing between the injected fuel and compressed air in the chamber controls the rate of further combustion. As the piston moves to release the high pressure, the expansion cools the in-cylinder mixture and reaction rates slow. This can result in chemical products that are out of thermodynamic equilibrium with the reagents. The timing of the

combustion process can thus have an impact on the emissions. ${ }^{90,91}$

Extensive work has been done to maximize the efficiency of diesel engines, and to improve diesel fuel, including designing additives that improve performance. ${ }^{80} \mathrm{In}$ principle, when a hydrocarbon fuel burns, the oxygen in the air combines with the hydrogen to form water and with the carbon to form carbon dioxide. A balanced chemical equation for the complete combustion of the 'average' diesel hydrocarbon is given in Reaction 1.

$4 \mathrm{C}_{12} \mathrm{H}_{23}(\mathrm{l})+71 \mathrm{O}_{2}(\mathrm{~g})$--> $48 \mathrm{CO}_{2}(\mathrm{~g})+46 \mathrm{H}_{2} \mathrm{O}(\mathrm{g})$

(R1) 
No engine operates under perfect stoichiometric conditions, so the complete combustion of diesel fuel does not occur for every molecule in the fuel in a compression ignition engine. In an apparent reversal of the combustion process, fractal-like agglomerates of solid carbon nanoparticles are formed, especially when there is incomplete combustion caused by a low air to fuel ratio in engine 'hot spots'. ${ }^{97}$ These incomplete combustion products in diesel emissions are termed diesel exhaust particles or diesel particulate matter (DPM). The composition of DPM are normally aggregates of refractory carbonaceous cores coated with hundreds of adsorbed volatile/semi-volatile organic species. ${ }^{23}$ These aggregates have mobility diameters in the ultrafine range $(<0.15 \mu \mathrm{m})$, and may be classified as 'elemental' (EC) or 'black' carbon (BC), depending on whether the chemical or optical properties are measured. ${ }^{34,98-101}$

In order to reduce DPM and gaseous emission levels, several strategies have been proposed and implemented to help meet the new standards. Mandates on engine design and control technologies are being considered for both heavy-duty trucks and diesel passenger vehicles. ${ }^{100,101}$ Because diesel vehicles tend to have a long lifetime, aftermarket exhaust filters are also being encouraged by tax subsidies. Some of these emission-control devices (such as diesel particulate filters, DPF) have been demonstrated to be highly efficient in removing larger (>100 nm) DPM. ${ }^{39,102}$ 
Another approach to cleaning up diesel emissions is the treatment and processing of diesel fuel, which can eliminate compounds in the fuel (chiefly sulfur and aromatic hydrocarbons) that increase PM emissions. ${ }^{97}$ Lower sulfur fuels have been shown to have lowered emissions of PM mass and compounds that contribute to acid rain. In addition to processing, fuel additives may also help to reduce emissions. ${ }^{109}$ For example, organic nitrate additives may be able to increase a fuel's cetane number $(\mathrm{CN}$, a measure of the ignition delay of a fuel). A higher $\mathrm{CN}$ has been linked to a shorter delay between fuel

injection and ignition. ${ }^{97,109}$ This decreased delay may result in higher combustion efficiency and lower $\mathrm{NO}_{\mathrm{x}}$ and $\mathrm{PM}$ emissions.

\subsubsection{Diesel and Biodiesel}

Diesel and biodiesel are general terms that refer to different classes of fuel. Diesel fuel encompasses a family of hydrocarbon fuels that are used to power compression injection or diesel engines. Petroleum diesel is typically obtained from crude oil that has undergone fractional distillation, which separates crude oil by hydrocarbon chain length using boiling point. The resulting diesel fuel is not a single compound, but rather a mixture of hydrocarbons that can range between $\mathrm{C}_{10} \mathrm{H}_{20}$ and $\mathrm{C}_{15} \mathrm{H}_{28}$. Diesel fuel available from a service station typically has undergone several purification filter steps after fractional distillation and the resulting fuel is a proprietary mixture of hydrocarbons and other additives like antioxidants intended to enhance storage capabilities and fuel performance. 
Biodiesel is an oxygenated fuel made from vegetable oils or animal fats by conversion of triglyceride fats to esters via a transesterification reaction. Methanol is typically the alcohol used, but other alcohols could be substituted. When methanol is used, the products of the reaction are three methyl esters and glycerol. A skeletal diagram of the reaction is given in Figure 5, where $\mathrm{R}$ is a carbon chain, typically a 6 to 10 carbon alkane. The catalyst is usually a strong base $(\mathrm{NaOH}$ or $\mathrm{KOH})$ when biodiesel is produced in industrial settings. ${ }^{111}$

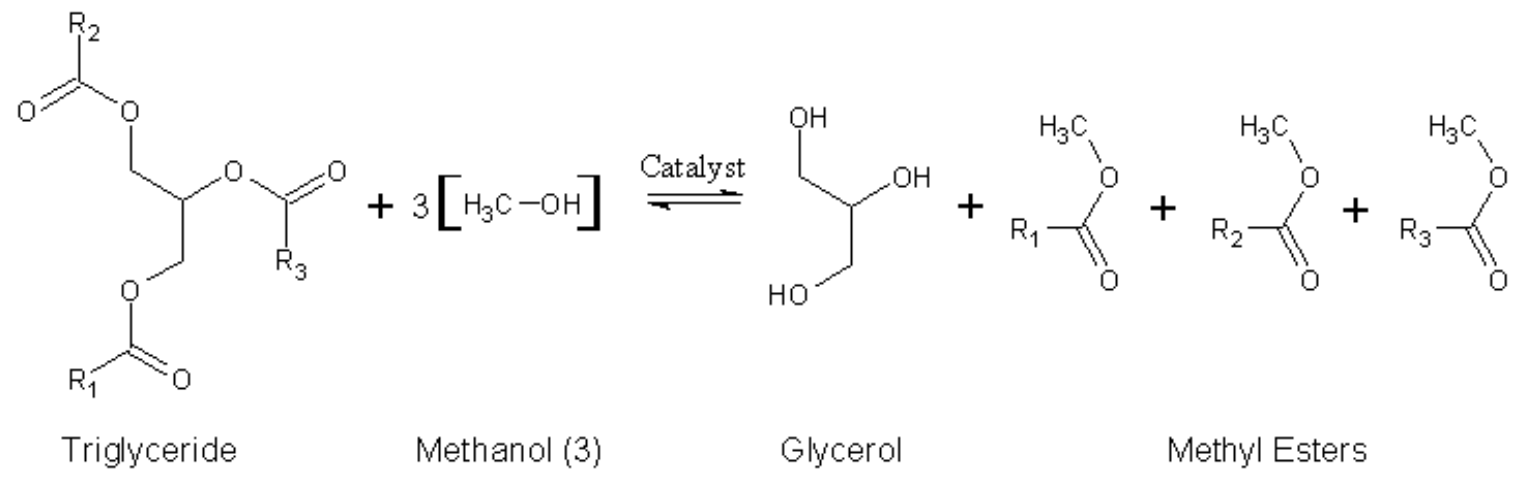

Figure 5: A skeletal diagram of the transesterification reaction used in the production of biodiesel.

Biodiesel is the first renewable diesel fuel alternative that is a commercially accepted part of the energy infrastructure in the United States and many countries in Europe and Asia. ${ }^{21,96}$ In the US, a 300\% increase in domestic biodiesel production from 2004 to 2005 was recorded. ${ }^{104}$ Since biodiesel can form blends with petroleum-derived diesel in any ratio, and for blends up to 20 percent biodiesel (B20) no change in the storage or 
dispensing hardware that handles petroleum diesel fuel are required, it has been a popular choice as an additive. ${ }^{96}$ Biodiesel proponents also promote it as a promising alternative to fossil fuels. ${ }^{21,96}$ Pure biodiesel (B100) only requires minor changes in some materials used for seals and transport hoses where it can act as an oxidant to rubber compounds. ${ }^{81}$

The main difference between diesel and biodiesel is the chemical "backbone" of the fuel: a long chain hydrocarbon for petroleum diesel vs. methyl esters for biodiesel. The hydrocarbon chains ( $\mathrm{R}$ groups in Figure 5) attached to the ester vary in length and saturation depending on the triglyceride used in the initial reaction.

The difference in the chemical properties of diesel and biodiesel affect the way these fuels work in a CI engine, which relies on compression of ambient air in the combustion cylinder to raise the pressure and air temperature so that when fuel is injected, the resulting air-fuel mixture will auto-ignite. The timing of fuel injection in pump-linenozzle (PLN) injection systems, the most common system in vehicular diesel engines, is related to fuel pressure. Once fuel is injected, the length of time between injection and auto-ignition depends on how easily an injected fuel oxidizes, the temperature of the air, the size of injected fuel droplets, and the extent of air-fuel mixing. The efficiency of continued combustion once auto-ignition has commenced is related to the rate and extent that the injected fuel mixes with the hot compressed air in the cylinder. 
Biodiesel is significantly more viscous than diesel and has a higher bulk modulus. This means that without engine adjustment or modification, biodiesel meets the pressure requirements sooner and is injected earlier in a PLN system. An earlier injection means that combustion begins earlier, causing the burning mixture to have a longer residence time in the combustion chamber. Additionally, biodiesel does not spray as evenly as petroleum diesel due to the higher viscosity, so more fuel rich pockets are expected with biodiesel. Biodiesel is oxygenated, which can reduce the length of time the burning fuel is in the combustion chamber before combustion. The cumulative effect of all of these differences on emissions can be difficult to predict because each phase can be associated with an increase or decrease of emissions depending on vehicle settings, maintenance, specific fuel structure, and engine design.

Biodiesel may be less polluting than petroleum diesel because it contains very little sulfur and virtually no aromatics, and the increased oxygen content is thought to create an environment where the fuel can burn more completely in an engine. A more complete burn should result in a smaller amount of carbon monoxide, soot, and unburned hydrocarbons being emitted. ${ }^{96}$ However current scientific research reports have many conflicting findings regarding the decreases, if any, that mixtures of diesel and biodiesel, or pure biodiesel have on vehicle emissions. ${ }^{30-49}$ 


\subsubsection{Current Literature on Biodiesel Emissions}

Determining the emissions properties from biodiesel-fueled vehicles can help to determine if it is a viable option for reducing airborne pollution. Many of the studies reported in the scientific and transportation literature focus on regulated pollutants $\left(\mathrm{NO}_{\mathrm{X}}\right.$, $\mathrm{PM}, \mathrm{CO}$ and $\mathrm{HC}$ ) and compare emissions between diesel and biodiesel by reducing results to a percent change between the different fuels. One of the most cited literature reviews, completed in 2001 by the US EPA, used the results of 39 different studies on biodiesel emissions to present correlations between the percent biodiesel used in fuel and the change in emissions of $\mathrm{NO}_{\mathrm{X}}, \mathrm{PM}, \mathrm{HC}$ and $\mathrm{CO} .{ }^{102}$ In this review the authors attempted to account for such factors as test cycle, base fuel properties, biodiesel source effects, and engine technology. Over 40 other studies were excluded because their experimental design did not meet the specific criteria used. The general trend observed for each of the criteria pollutants was reported in the form given in Equation 7.

$\%$ change in emissions $=\{\exp [\mathrm{a} \times($ vol\% biodiesel $)]-1\} \times 100 \%$

which resulted in nearly linear fits for all pollutants. The value of a for each pollutant was determined by the least squares method (Table 2). The plots showed significant scatter which was used to determine the goodness of fit. The scatter was especially pronounced for B20 and B100, but for the middle mixtures from B30 to B80 there were substantially fewer data points. Only $18 \%$ of the data analyzed came from fuel mixtures in this range. 
In contrast, $35 \%$ of the data were from B20 fuel, 33\% were from B100 and the remaining $14 \%$ of the mixtures tested were below B20. Based on the amount of scatter present for B20 and B100, additional measurements from the middle mixtures are needed to evaluate the dependence more completely.

Table 2: Reported emission change coefficient (a) values from the 2001 US EPA literature review on biodiesel emissions. Positive values predict an increase of emissions with biodiesel content.

\begin{tabular}{ll}
\hline \hline Pollutant & Coefficient a \\
\hline \hline $\mathrm{NO}_{\mathrm{x}}$ & 0.0009794 \\
$\mathrm{PM}$ & -0.006384 \\
$\mathrm{HC}$ & -0.011195 \\
$\mathrm{CO}$ & -0.006561 \\
$\mathrm{CO}_{2}$ & 0.0000177 \\
\hline \hline
\end{tabular}

This review included both heavy duty and light duty vehicles, but states that the amount of data available on light-duty vehicles was insufficient to group all engine types together. The authors caution that these relationships between emissions and biodiesel content should only be used for heavy-duty vehicles unless strong evidence for their universality is obtained. Despite this caution, the reductions in PM presented in the EPA study are cited by cities and states as evidence for promoting the use of passenger diesel vehicles fueled with biodiesel. For example, the city of Portland, OR passed a law in 2006 that all stations that sell diesel fuel must offer only B5 biodiesel or above, and that B50 or B99 be used in city owned vehicles, including light-duty cars and trucks. West Virginia, Montana, and Missouri are among the states that offer incentives for buying 
biodiesel. While the reasons given vary, reductions in emissions are always mentioned as one of the benefits of increasing biodiesel use.

A survey of the more recent literature yields a number of studies that investigated particulate matter emissions from diesel vehicles fueled with biodiesel and biodiesel mixes. Results from a number of these studies are summarized in Figure 6. When the percent change in emissions was given, the value reported was used for comparison. If only emission factors or concentrations were reported, the percent change in emissions was calculated using Equation 8.

$$
\% \text { change }=\left[\text { Emissions }_{\text {biodiesel }}-\text { Emissions }_{\text {diesel }}\right] / \text { Emissions }_{\text {diesel }} * 100
$$

The general trend reported in the 2001 EPA literature review is present when all emission tests are presented together, but when data are separated by type of reference fuel (ultra low sulfur diesel ULSD or low sulfur diesel LSD) two distinct trends emerge. Several of the studies did not specify the sulfur content in the reference fuel so they were not included. The data shown in Figure 6 includes both heavy-duty and light-duty vehicles. Once again, a determination of a trend of light-duty vehicles is difficult because there were only four studies that present data for that vehicle class. 


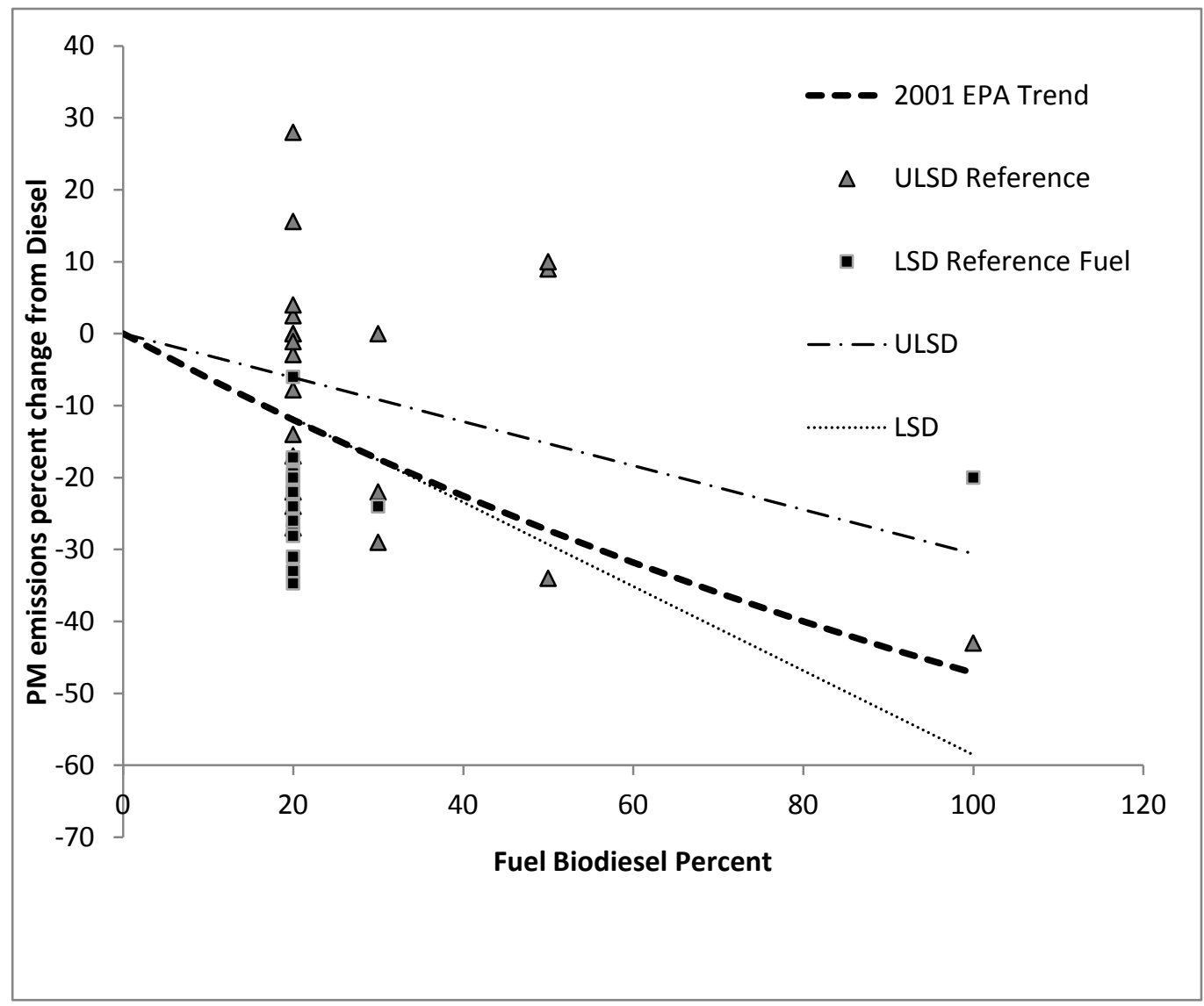

Figure 6: Summary of recent emission studies from biodiesel fueled vehicles and comparison to the 2001 US EPA emission trend. The current data agrees with the EPA trend, but also indicates that the type of reference fuel has an impact on the amount of change observed.

The knowledge gap for light-duty vehicles is significant when determining the impact of biodiesel on emissions because the use of diesel passenger vehicles is increasing in the US. Historically, the cost of diesel fuel kept diesel passenger cars to only a small share of the market, but higher gasoline prices and better fuel efficiency in diesel vehicles may cause this trend to shift. The choice of a diesel vehicle over a gasoline vehicle may have a 
significant impact on air quality even if biodiesel or mixtures are used, because diesel vehicles have higher NOx and PM emissions than gasoline vehicles. Even after the heavy-duty vehicle benefits described for biodiesel are applied, the total PM emissions from a diesel vehicle would be higher than for a gasoline vehicle. Table 3 shows emissions of criteria pollutants from a diesel vehicle and a gasoline vehicle from two studies done by Cadle et al. ${ }^{85}$ The change in emissions with the use of pure biodiesel and B20 were calculated based on the trends reported in the EPA literature review for comparison.

Table 3: Comparison between PM emissions for diesel and gasoline vehicles. The biodiesel benefit was calculated using the 2001 EPA trend.

\begin{tabular}{lllll}
\hline \hline Season & $\begin{array}{l}\text { Gasoline PM } \\
\text { Emissions } \\
(\mathrm{g} / \mathrm{mi})\end{array}$ & $\begin{array}{l}\text { Diesel PM } \\
\text { Emissions } \\
(\mathrm{g} / \mathrm{mi})\end{array}$ & $\begin{array}{l}\text { B20 Calculated PM } \\
\text { Emissions } \\
(\mathrm{g} / \mathrm{mi})\end{array}$ & $\begin{array}{l}\text { B100 Calculated PM } \\
\text { Emissions } \\
(\mathrm{g} / \mathrm{mi})\end{array}$ \\
\hline Summer & 0.00282 & 0.811 & 0.714 & 0.428 \\
Winter & 0.00351 & 0.460 & 0.405 & 0.243 \\
\hline \hline
\end{tabular}

Several hypotheses have been presented in the literature to explain the reduction of PM with increased biodiesel content in fuel, but a consensus has not been reached. Fuel rich areas are thought to lead to incomplete combustion products including soot, so the increased oxygen (and decreased carbon) content of biodiesel blends may reduce the amount of soot formed and improve the oxidation of soot that is formed. ${ }^{25}$ Others have credited the lower aromatic and sulfur (known particle precursors) content in biodiesel with reducing particulate emissions. ${ }^{47}$ Biodiesel also raises the cetane number of diesel 
fuel when added, which as noted earlier, can decrease soot formation and promote the oxidation of soot formed. ${ }^{93}$ The change in emissions observed between engine types and when using biodiesel are most likely due to a balance of competing factors and not one single difference, but additional research on light-duty vehicles would help to improve understanding of the biodiesel impact on PM emissions.

The lack of data for intermediate biodiesel mixtures (B30 to B80) should also be addressed when looking at light-duty vehicle performance, especially for passenger cars that are not part of a standard fleet fueling routine. If B100, B5 and B20 are all available at service stations, it would be difficult to ensure that consumers were always using a well studied blend. The National Renewable Energy Laboratories (NREL) published two reports on the quality of biodiesel sold at service stations. ${ }^{158}$ In 2004, before regulations on biodiesel labeling took effect, they found that $36 \%$ of fuel marked B20 was outside of the B18 to B22 range, falling into the less well studied mixture range. ${ }^{94}$

Kinast and Waynick found in different studies that 'splash' mixing of diesel and biodiesel often resulted in incorrect concentrations and an increase of harmful emissions. ${ }^{157,158}$ Waynick hypothesized that the increase in oxidation that occurred (during storage) when the fuels were splash mixed could increase the polymeric gums in the fuel. Other investigations found that fresh biodiesel has a high polarity, so the high molecular weight products of oxidation tend to stay in solution. ${ }^{161}$ As biodiesel is oxidized (during storage, 
before combustion) the polarity increases. When this aged biodiesel is mixed with very nonpolar diesel fuel, the high molecular weight products can precipitate out of solution. Frame, et al. found a tenfold increase in insoluble particles in biodiesel blends when compared to diesel fuel or B100. ${ }^{159}$ There are no controls on diesel pumps to prevent a consumer from intentionally or unintentionally making their own mixtures at a service station, so it is likely that diesel consumers can and will end up with middle-range mixtures. More detailed data on the emissions of these biodiesel mixtures will improve regulatory predictive models and help guide future regulations geared towards improving air quality.

Another gap in the current literature is the lack of data on aerosol composition. All of the studies included in both the EPA report and in Figure 6 report PM changes obtained from filter-based mass measurements. Aerosol products should also be described by the particle size distribution and chemical composition to determine the impact on the atmosphere and human health. The percent change in a mass measurement does not provide enough information to fully understand how biodiesel particles differ from diesel particles and what their impact will be once emitted into the atmosphere.

An increase in particle number below $50 \mathrm{~nm}$ has been reported when biodiesel was added to diesel fuel in DI engines, with higher biodiesel concentration leading to increases in ultrafine particle number. ${ }^{82,43,42,19}$ One study used both a scanning mobility particle sizer 
(SMPS) and an electrical low-pressure impactor (ELPI) and found that the increase in the number of particles under $40 \mathrm{~nm}$ with biodiesel content was observed by both instruments. ${ }^{50}$ Tsolakis compared emissions from biodiesel and ULSD fueled vehicles using an ELPI and found both a decrease in mean particle size and an increase in total particle number. ${ }^{20}$ The effect of the increased viscosity of biodiesel on the electronic control system that resulted in an increase in the injection pressure and an advance in the injection timing was hypothesized to cause the shift in size distribution. An advance in injection timing has been linked to a shift toward smaller particles which is sometimes associated with a reduction in total particle mass.

Turrio-Baldassarri, et al. used analytical electron microscopy to compare size distributions of diesel and biodiesel emissions and found that the abundance of B20 ultrafine fraction (particles with a diameter under $100 \mathrm{~nm}$ ) was slightly higher than that of diesel for all samples analyzed. ${ }^{45}$ Heikkil et al. found that the geometric mean diameter (GMD) of the soot particulate emissions for biodiesel was smaller than the GMD for diesel fueled vehicles, but the GMD and concentration of nonvolatile nucleation mode cores measured for biodiesel emissions were substantially greater than diesel fuel. ${ }^{163}$

Several other studies indicated that there was no significant difference between particle size distributions in biodiesel emissions when compared to diesel emissions. Bünger et al. measured B100 and diesel emissions with both an SMPS and a Berner low-pressure 
impactor (BLPI). ${ }^{164}$ Results from the SMPS did not show any significant difference between the particle size distributions. In contrast the BLPI measurements showed increased particle mass in the biodiesel emissions for all diameter ranges. Lapuerta et al. attributed these differences to the dilution ratios used because a low dilution ratio could result in a larger nucleation mode as hydrocarbons in the emissions condensed. ${ }^{147}$

If biodiesel does cause a larger number of ultrafine and fine particles, this may have negative implications on the ability of biodiesel to reduce the harmful effects of DPM. Smaller particles have a longer atmospheric lifetime, more surface area per mass for absorption of organic compounds, and a greater likelihood of being inhaled. If inhaled, smaller particles are known to travel deeper in the lungs and increase the inflammatory response which may lead to increased cancer and cardiovascular risk. Ultrafine particles are also known to cause problems with after treatment systems and to have a lower likelihood of being filtered. ${ }^{85,86}$

Considering the increase in the use of biodiesel fuel and the general belief that biodiesel is a lower emission alternative fuel, data collected under real-world conditions that addresses the shortcomings of existing literature is essential to understand the real impact of a wide-spread increase the use of biodiesel in modern passenger cars. A large change in the PM number and type in the emissions from diesel vehicles may impact air quality on both a local and regional scale. ${ }^{12,50-53}$ Several studies including Park, 2006 using the 
GEOS-Chem global chemical transport model (CTM) of coupled aerosol-oxidant chemistry found that including transportation pollution causes a several fold increase in PM when compared to background levels. ${ }^{49}$ Shine, 1999 showed that including more detailed emission data for soot and other anthropogenic pollution alters the global mean radiative forcing. ${ }^{12}$

This study focuses on determining LAC emission factors for light-duty diesel vehicles operating on a range of biodiesel fuel mixtures using a novel measurement approach. These emission factors can be used to evaluate the impact of biodiesel on local air quality and provide a better understanding of how well regulations may meet their intended goal of improving or protecting air quality.

\subsection{Emission Factors}

To determine the impact that on-road light duty diesel vehicles have on PM emissions in urban areas, and how regulations that change available fuel mixtures in a given area will affect the emissions from these vehicles, emission factors for the fuel mixtures need to be developed. ${ }^{10,11,54,55,140,141}$ Motor vehicle particulate emissions are primarily in the fine and ultrafine fraction and will contribute to the total ambient $\mathrm{PM}_{2.5}$ in a given location. Some vehicular direct and secondary emissions can also fall in the $\mathrm{PM}_{10}$ size fraction, also regulated in the United States by federal air quality standards ${ }^{55}$. Any major change in the PM number and type in the emissions from vehicles may impact air quality on both 
a local and regional scale: an effect that can be confirmed by model studies incorporating refined emission factors.

Until 2010, the MOBIL6 and PART5 emission models were the EPA preferred mobile source air quality models. These models deal with direct $\mathrm{PM}_{2.5}$ emissions and do not specifically incorporate black carbon, but rather represent it as elemental carbon. The emission inventories also do not incorporate secondary PM formed in the atmosphere via complex reactions between gas precursors. The ambient PM estimates are calculated using emission factors derived from dynamometers and on-road remote sensing of vehicle exhaust, both of which quantify tailpipe emissions for individual vehicles. Dynamometers can measure multiple duty cycles for individual cars, but do not represent real urban on-road conditions. ${ }^{65}$ The on-road sensing has the benefit of measuring vehicles during normal 'real-world' use in a short period of time. ${ }^{63}$

While on-road sensing gives an excellent representation of the vehicle fleet in a given area, it cannot easily differentiate between the types of fuel used in a given vehicle. The EPA has regulated on-road diesel PM for many years but the emission estimates have not been adjusted for regulations of ultra-low sulfur diesel or biodiesel additions. ${ }^{18,}{ }^{104}$ Since vehicle emissions are a significant portion of the anthropogenic contribution to ambient $\mathrm{PM}_{2.5}$ it is essential to understand which portions of the emissions come from different vehicles as well as from vehicles using various fuel types. ${ }^{12,57,62}$ 
This study examines the effect of changing from diesel to biodiesel fuel by determining emission factors which can be used for local, regional and global scale models to determine possible future impacts. 


\section{Measurement of Diesel and Biodiesel Emissions}

\subsection{Overview}

The increase in the use of biodiesel fuel and the popular notion that biodiesel is a lower emission fuel has spurred changes in types of diesel fuel available to consumers. In order to determine if these changes in fuel availability have the desired air quality impact, research addressing the knowledge gaps present in existing literature on biodiesel emissions is essential. Collecting data under 'real-world' conditions will assist in determining the impact of a widespread increase in the use of biodiesel in modern passenger cars.

The goal of this study was to develop light-duty diesel emission factors for several mixtures of biodiesel and petroleum diesel. To accomplish this goal, the optical properties of the emissions were measured using a CRDT/N coupled with gas phase measurements and an SMPS for size distribution measurement. The gas phase measurements $\left(\mathrm{CO}, \mathrm{CO}_{2}, \mathrm{O}_{3}, \mathrm{NO}\right.$, and $\left.\mathrm{NO}_{2}\right)$ were collected to allow a more complete understanding of the variations in emissions between the fuels and to calculate emission factors from the optical data, as described below. All emissions were sampled under realworld conditions and data were collected in near real-time. This novel approach to quantifying emissions addresses the shortcomings of the traditional filter methods for PM 
sampling, allowing for comparison of aerosol extensive and intensive optical properties, particle size distributions, and gas phase measurements in a real-world setting.

\subsection{Experimental Design}

Multiple validations of the CRDT/N were completed and published in peer reviewed journals. ${ }^{137,150}$ A summary of these papers is provided for reference in Appendix B. After validation was complete, the instrumental response to various emission testing scenarios was monitored to ensure a robust response to emissions from vehicles. Preliminary studies were completed on B5 and B33 at the test site. The results were used to refine the emission sampling procedure.

A range of mixtures including B20, B95 and B5 were sampled multiple times on multiple days. A two-way analysis of variance was completed to verify that the difference between the means of the mixtures due to the biodiesel content in the fuel was more significant than the test date. These data were also used to determine if any changes were needed on the sampling protocol. Once the sampling, testing, and data analysis procedures were established, emissions were sampled from the test vehicle running on five different mixtures; B5, B25, B50, B75 and B95. 


\subsubsection{Emission Test Set-Up}

To compare emission factors from diesel and biodiesel-fueled vehicles, a series of real time emission tests were performed. The test vehicle was a light weight diesel passenger car (4-door 2002 VW Golf GLS TDI). To represent reality, the vehicle did not undergo any maintenance other than what was normally recommended by the owner's manual. The fuel filter was changed once after the initial testing with B33. The manufacturer's quoted vehicle specifications are given in Table 4.

Table 4: 2002 4-Door VW Golf GLS TDI Specifications.

\begin{tabular}{l|l}
\hline \hline Model & Volkswagen Golf GLS TDI (4-door) \\
& $1896 \mathrm{cc}, 1.9 \mathrm{~L}$ in-line four-cylinder, direct inject turbo \\
& diesel, \\
Engine & 2 Valves/Cylinder \\
Power & $90 \mathrm{HP}$ \\
Transmission & Five-speed manual \\
Compression Ratio & $19.5: 1$ \\
Bore, Stroke & $79.5 \mathrm{~mm}, 95.5 \mathrm{~mm}$ \\
\hline \hline
\end{tabular}

A vacant garage and parking area located in Portland, OR was used as the testing site.

This garage has a flat surface area which is large enough for sampling of an idling vehicle or a vehicle moving in a constant radius. This test site was chosen because effects of road dust PM were minimized due to regular cleaning. There was also minimal interfering traffic. Figure 7 shows a sketch and photograph of the test site. Since fuel-based emission factors do not depend on fuel economy data and are less sensitive to load or driving conditions, sampling was completed while the vehicle was idling. 
For this study design ambient conditions, rather than engine dynamometer measurements, were required so EPA measurement procedures for ambient monitoring were consulted and used as a guide. ${ }^{102}$ The experiment was source oriented and the sampling point was adjacent to the source (a type F site). The experiment was operated on the micro-scale where the distance from the point source ranges between several meters to 100 meters. The resulting data are directly related to the emission source. Quality assurance guidelines were followed for inlet placement according to the distance specifications given in table 7-2 in the handbook. A modified version of this table that only includes the species to be measured is given in Table 5 .

Table 5: EPA Quality Assurance Standards for Ambient Air Monitoring

\begin{tabular}{|c|c|c|c|}
\hline Pollutant & $\begin{array}{l}\text { Height from } \\
\text { ground to } \\
\text { probe } \\
\text { (meters) }\end{array}$ & $\begin{array}{l}\text { Horizontal and vertical } \\
\text { distance from supporting } \\
\text { structures to probe } \\
\text { (meters) }\end{array}$ & $\begin{array}{l}\text { Distance from trees to } \\
\text { probe of monitoring path } \\
\text { (meters) }\end{array}$ \\
\hline $\mathrm{CO}$ & $\begin{array}{l}3+0.5 ; 3- \\
15\end{array}$ & $>1$ & $>10$ \\
\hline $\mathrm{NO}_{\mathrm{x}}$ & $3-15$ & $>1$ & $>10$ \\
\hline $\mathrm{CO}_{2}$ & NA & NA & NA \\
\hline $\mathrm{O}_{3}$ & $3-15$ & $>1$ & $>10$ \\
\hline $\begin{array}{l}\text { PM } 10 \text { and } \\
2.5\end{array}$ & 2-7 (micro) & $\begin{array}{l}>2 \text { (all scales, horizontal } \\
\text { distance only) }\end{array}$ & $>10$ (all scales) \\
\hline
\end{tabular}

Since the probes protrude from the side of the garage and not from the roof, there must be unrestricted airflow $180^{\circ}$ around the probe and sampler inlets. Even though the site is located near a major roadway, the distance from the inlet location and the roadway meets 
EPA minimum separation distance. The only major variation from EPA design is for the $\mathrm{NO}_{\mathrm{x}}$ measurements. Typically the EPA does not recommend testing for $\mathrm{NO}_{\mathrm{x}}$ on a microscale when trying to determine ambient levels. The goal was the measurement of car exhaust in ambient conditions, so this recommendation was not followed in the final protocol.
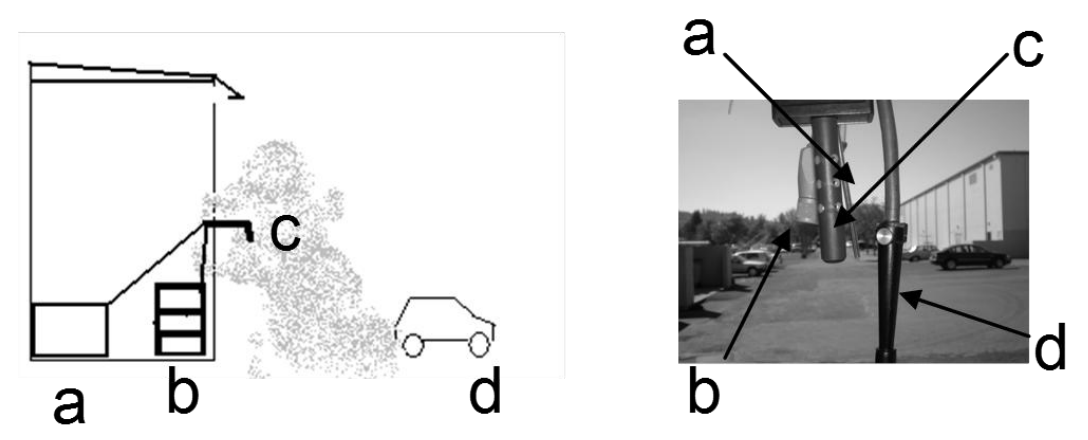

Figure 7: Emission testing/sampling protocol. (left side) Side view. (A) CRDT, (B) $\mathrm{NO}_{\mathrm{X}}, \mathrm{CO}$ and $\mathrm{O}_{3},(\mathrm{C})$ Inlets and $\mathrm{CO}_{2}$, (D) Test Car (right side) View of the inlets looking out to the parking lot. (A) Temperature Probe (B) CRDT inlet (C) $\mathrm{CO}_{2}$ Probe (D) Nephelometer Inlet

To minimize background interference, sampling periods began after the morning rush hour and ended six hours later before the afternoon rush hour (approximately 9:30 am to 3:30 pm).

The inlet for the CRDT had a cyclone with a 2.5 micron (nominal) cut point that was connected to $3 / 8$ inch OD copper tubing sample line. The nephelometer inlet was also fitted with a cyclone that was attached to $1 / 4$ inch OD copper tubing. The $\mathrm{NO}, \mathrm{NO}_{2}, \mathrm{CO}$ and $\mathrm{O}_{3}$ inlet system was $1 / 4$ inch $\mathrm{OD}$ open Teflon tubing. The $\mathrm{CO}_{2}$ sensor and an integral 
temperature probe were attached to the inlets so it would measure the same portion of the plume as the other instruments.

\subsubsection{Fuel}

To minimize uncertainties from using different brands of fuel, B5 provided by Star Oilco, (Portland, OR) and B99 provided by SeQuential Biofuels, Inc. (Salem, OR) were mixed on the spot to produce the test fuels. The chemical properties of the B99 as reported by SeQuential are given in Table 6. This fuel is a fatty acid methyl ester (FAME) made from virgin canola oil produced in western Oregon.

Table 6: Chemical and Physical Properties of SeQuential Biodiesel. ${ }^{108}$

\begin{tabular}{l|l}
\hline \hline Fuel Property & Biodiesel \\
\hline \hline Fuel Standard & ASTM 6751 \\
Fuel composition & C12-C22 FAME \\
Lower Heating Value, Btu/gal & 117,093 \\
Kinetic Viscosity, @ $40^{\circ} \mathrm{C}$ & $1.9-6.0$ \\
Specific Gravity kg/1 @ $60^{\circ} \mathrm{F}$ & 0.88 \\
Density, lb/gal @ $15^{\circ}$ & 7.0328 \\
Water, ppm by wt. & $0.05 \%$ max \\
Carbon, wt $\%$ & 77 \\
Hydrogen, wt $\%$ & 12 \\
Oxygen, by dif. Wt $\%$ & 11 \\
Sulfur, wt $\%$ & $0.0-0.0024$ \\
Boiling Point, ${ }^{\circ} \mathrm{C}$ & $182-338$ \\
Flash Point, ${ }^{\circ} \mathrm{C}$ & $150-170$ \\
Cloud Point, ${ }^{\circ} \mathrm{C}$ & -3 to 12 \\
Pour Point, ${ }^{\circ} \mathrm{C}$ & -15 to 10 \\
Cetane Number & $48-65$ \\
Stoichiometric Air/Fuel Ratio & 13.8 \\
BOCLE scuff, grams wt & $>7,000$ \\
HFRR, microns & 314 \\
Appearance & Pale yellow liquid, slight odor. \\
\hline \hline
\end{tabular}


Table 7: Fuel Mixtures used for Diesel and Biodiesel emissions testing.

\begin{tabular}{l|l|l}
\hline \hline Diesel & Biodiesel & Label \\
\hline \hline $95 \%$ Diesel & $5 \%$ Biodiesel & B5 \\
$75 \%$ Diesel & $25 \%$ Biodiesel & B25 \\
$50 \%$ Diesel & $50 \%$ Biodiesel & B50 \\
$25 \%$ Diesel & $75 \%$ Biodiesel & B75 \\
$<1 \%$ Diesel & $>99 \%$ Biodiesel & B99 \\
\hline \hline
\end{tabular}

The mixtures investigated are listed in Table 7 . Volumetric mixing ratios are reported. After the fuel was introduced to the vehicle, it was driven briskly for 15 minutes before testing.

\subsubsection{Instrumentation}

The gas phase measurements consisted of carbon monoxide (CO), nitrogen monoxide (NO), nitrogen dioxide $\left(\mathrm{NO}_{2}\right)$, and carbon dioxide $\left(\mathrm{CO}_{2}\right)$. $\mathrm{CO}$ was measured using a Thermo Environmental 47 CO Analyzer, and nitrogen monoxide and nitrogen dioxide were measured using a Thermo Environmental 32- $\mathrm{C} \mathrm{NO}_{\mathrm{x}}$ Analyzer. $\mathrm{CO}_{2}$ concentration was measured with a non-dispersive infrared $\mathrm{CO}_{2}$ Gas Sensor (Vernier, $\mathrm{CO}_{2}$-BTA) that sampled passively near the other instruments' inlet, as mentioned above. Laboratory gas calibrations were completed prior to testing to ensure proper instrumental response during testing.

Visible and near IR extinction coefficients were measured using a custom-built cavity ring-down transmissometer. The configuration of the CRDT/N allows for the measurement of the $b_{\text {ext }}$ in the visible and near IR simultaneously and the $b_{\text {scat }}$ with $a \sim 10$ 
second delay. This delay is due to the response time of the nephelometer used (Radiance Research, M903, $\lambda 530)$ and the flow rates through the cavity $(1.974+/-0.009 \mathrm{lpm})$.

The laser source was the fundamental and second harmonic (1064 and $532 \mathrm{~nm}$ ) of an Nd:YAG laser (New Wave Research, MiniLase II, 30 Hz, 6 Amps.) The output of the laser was passed through an adjustable aperture and steered into the cavity using several turning prisms.

The optical cavity length was $94.5 \mathrm{~cm}$ and the ratio of the length of the optical cavity length to the sample length is 1.243 . The mirrors were purged with clean dry air flowing at $0.130 \mathrm{lpm}$. The air samples were filtered by a HEPA-CAP glass microfiber filter (Watman, 90406A) during the clean air cycles to obtain the baseline for the optical measurements. The light transmitted through the concave highly reflective mirrors (General Optics 1"x0.250" Plano-Concave Dual Wavelength R>99.5\% at 1064 and 532 nm) was measured with a visible PMT (Hamamatsu, Inc. R955), and an amplified IR photodiode (ThorLabs PDA255, 700 - $1800 \mathrm{~nm}$ ) after being split by a 45 degree angle of incidence $532 \mathrm{~nm}$ reflective dielectric mirror (transmissive for the $1064 \mathrm{~nm}$ light). The signals were digitized and summed over 128 laser pulses with a digital oscilloscope (Textronix TDS 224, 8-bit resolution, $100 \mathrm{MHz}, 1 \mathrm{Gs} / \mathrm{s}$ ). This signal was then transferred to a personal computer every $\sim 4$ sec for processing using custom Labview VIs. 
A TSI 3080 scanning mobility particle sizer (SMPS) system consisting of a $1 \mu \mathrm{m}$ impactor, a TSI 3081 Long DMA, and a TSI 3776 condensation particle counter CPC, was used to determine the particle size distribution for each mixture. The impactor eliminates particles with aerodynamic diameters larger than $1 \mu \mathrm{m}$.

\subsection{Data Quality and Data Analysis}

Emissions from each fuel mixture were tested on multiple dates. The total useable data total over 3.5 hours for every mixture representing at least 20 car-on cycles. The emission testing cycles included measurements of filtered ambient (clean), ambient, exhaust (caron), and filtered exhaust cycles, each twelve to fifteen minutes in length. During each of the car-on cycles multiple plumes were observed. The plumes were determined by isolating time periods when the $\mathrm{CO}_{2}$ values were at least $50 \mathrm{ppm}$ over the background levels for at least 90 seconds, and were considered valid if the measured wind direction was toward the inlets. All measurements made when the wind direction was between 90 and 270 degrees from the inlets were omitted from analysis. Since measurements were made on different days, the ambient pressure and temperature varied. To compare across days, all measurements were converted to standard temperature and pressure $(273 \mathrm{~K}, 760$ torr) using Equation 9.

$$
M_{\text {stp }}=M_{a m b} * T_{a m b} / 273 * 760 / P_{a m b}
$$


where $\mathrm{M}_{\mathrm{amb}}$ is the ambient measurement, $\mathrm{T}_{\mathrm{amb}}$ is the ambient temperature, and $\mathrm{P}_{\mathrm{amb}}$ is the ambient pressure.

The conversion to standard temperature and pressure was completed using the measured ambient temperature and the barometric pressure obtained at a nearby DEQ monitoring station DEQSEL, located on SE Lafayette Road (average values between 10:00 AM and 3:00 PM were used). These data were downloaded from the Portland Horizons Project website. $^{154}$

After conversion, thirty second averages were calculated and data was sorted based on one of four testing cycles, filtered ambient, ambient, car emissions, and filtered car emissions. The filtered cycles are the particle free baseline values and allow for proper baseline corrections for optical parameters. This is necessary to correct for any instrumental drift over the testing cycle. The particle free cycles were plotted versus time and a proper fit was determined. A separate baseline correction was determined for each test mixture and for each day of testing. This baseline correction was then applied to the extinction measurements.

Every car exhaust cycle was "sandwiched" between filtered cycles and then between ambient cycles to allow for determination of any changes in the ambient properties, unrelated to the car exhaust. The ambient cycles were used to ensure pollutants had 
returned to background levels between testing cycles and to assist with plume determination. The validity of ambient measurements was confirmed by comparing the measured ambient average from each test day to the average measurements of NO and $\mathrm{NO}_{2}$ from the nearby DEQSEL site for the hours the emission testing was conducted. Our average values agreed with those from the test site to within $\pm 3.21 \mathrm{ppb}$ for $\mathrm{NO}$ and \pm 4.71 ppb for $\mathrm{NO}_{2}$ for all test days.

\subsection{SEM analysis}

Visual differences between diesel and biodiesel emission particles were evaluated using SEM by collecting the emissions from several biodiesel blends using SKC DPM cassettes comprising a cellulose support pad and a 37-mm heat-treated quartz filter. (SKC, No. 225-401) These filters meet NIOSH 5040 specifications for sampling DPM. The filter was located at the tailpipe of the idling test vehicle for 25 minutes at a flow of $\sim 1.7$ $\mathrm{L} / \mathrm{min}$. A clean blank sample was also collected under the same conditions, without the vehicle running. All filters were stored at $>32^{\circ} \mathrm{C}$ until analysis was performed.

To visualize particles, a small portion of the filter was trimmed and mounted on a scanning electron microscope (SEM) post. The SEM can be used to scan samples with a beam of electrons that interact with the atoms in the sample and produce a signal. The signal is then detected as a high-resolution image of the sample surface. In order to 
prevent the accumulation of static electricity at the surface and artifacts in images, samples were electrically charged by sputter coating with an ultra-thin coating of gold.

\subsection{Development of Emission Factors}

In order to estimate the emission factors for the measured pollutants, the $\mathrm{CO}_{2}$ balance method described in Hobbs, 2000 and later in Lack, 2009 was used. ${ }^{155,141}$ This method uses concurrent measurements of $\mathrm{CO}_{2}$ and the pollutant of interest in the plume to calculate an emission factor for the pollutant. This method works because carbon dioxide is the main carbon-containing product of fuel combustion and the increase in ambient $\mathrm{CO}_{2}$ from vehicle emissions has been well correlated with an increase in pollutants, including particle number. ${ }^{157}$ Values from identified plumes were included in the emission factor calculation when the regression of the specific parameter with $\mathrm{CO}_{2}$ yielded an $R^{2}$ value above 0.75 . This screening omits any plumes with insufficient data or low signal levels. By isolating measurements where the test vehicle is the only significant $\mathrm{CO}_{2}$ source, the linear correlation between the measurement of $\mathrm{CO}_{2}$ and the pollutant from the plume provides a slope factor. The emission factors for all optical properties and chemical properties were calculated using analogous expressions to Equation 10 and 11 as described in Lack et. al, ${ }^{141}$

$$
\begin{aligned}
& \mathrm{EF}(\text { optical })\left(\mathrm{m}^{2} / \mathrm{kg} \text { fuel }\right)=b_{\text {abs }}\left(\mathrm{Mm}^{-1}\right) / \mathrm{CO}_{2}(\mathrm{ppmv}) \times \mathrm{F}_{\text {fuel }}\left(\mathrm{m}^{2} \mathrm{ppmv} \mathrm{Mm} / \mathrm{kg}\right) \\
& \mathrm{EF}(\text { chemical })(\mathrm{g} / \mathrm{kg} \text { fuel })=\mathrm{NO}_{2}\left(\mu \mathrm{g} / \mathrm{m}^{3}\right) / \mathrm{CO}_{2}(\mathrm{ppmv}) \times \mathrm{F}_{\text {fuel }}(\mathrm{g} \mu \mathrm{g} \mathrm{ppmv} / \mathrm{kg})
\end{aligned}
$$


$\mathrm{F}_{\text {fuel }}$ is a conversion factor that accounts for the fraction of fuel that is carbon and the conversion of $\mathrm{CO}_{2}$ mixing ratio to the concentration of carbon. For this study, the absorption coefficient, $b_{a b s}$ was determined from the difference between the extinction and scattering coefficients measured in the vehicle exhaust. The absorption optical emission factor was then divided by a mass absorption coefficient (MAC) of $7.5 \mathrm{~m}^{2} / \mathrm{g}$, as suggested by Bond et al. for fresh vehicle emissions. ${ }^{99}$ (This conversion has an estimated $\pm 15 \%$ uncertainty.) The resulting value is the emission factor for LAC in grams per kilogram of fuel.

Some uncertainty arises from the carbon content in the various fuel mixtures. The calculated percent carbon for each of the biodiesel mixes is given in Table 8. As the percentage of biodiesel increases, the percentage of carbon decreases because biodiesel is an oxygenated fuel. The percent carbon in the mixtures was calculated by volume percent weighting of the average of published values for carbon content in pure diesel, 0.865 , and biodiesel, 0.795. (Thus the conversion factor $F_{\text {fuel }}$ for biodiesel is different than for petroleum diesel.) 
Table 8: Carbon content in each fuel mixture. This value was used to calculate the $F_{\text {fuel }}$ factor.

\begin{tabular}{l|l|l}
\hline \hline Mixture & Percent Carbon in Fuel & Uncertainty (\%) \\
\hline \hline B5 & 0.860 & 1.6 \\
B25 & 0.846 & 1.6 \\
B50 & 0.827 & 1.8 \\
B75 & 0.808 & 1.9 \\
B99 & 0.789 & 2.0 \\
\hline \hline
\end{tabular}

Uncertainties were determined by arithmetically propagating the percentage uncertainty in the given mixture and the percentage of carbon in the fuel from the published values for diesel and biodiesel. The emission factors calculated can be used to evaluate the impact of biodiesel on both human health and climate. 


\section{Results}

\subsection{Overview}

Emission factors for each fuel mixture and trial were calculated from the correlation slopes of a selected parameter vs. $\mathrm{CO}_{2}$, as described in section 2.5 Plume periods were identified as periods when the $\mathrm{CO}_{2}$ levels were elevated by $50 \mathrm{ppm}$ or more above the ambient background level for at least 90 seconds. An example of this data processing protocol is shown in Appendix A, Figure A.1. Measurements of the pollutant of interest and $\mathrm{CO}_{2}$ throughout each plume were plotted against each other and a linear correlation was determined. If the $\mathrm{R}^{2}$ value for the correlation was above 0.75 , an emission factor was calculated.

The slopes from the linear correlations for each pollutant across all test cycles/plumes were then compiled. Correlation plots between the measured parameters for B5 (532 nm extinction coefficient, $b_{\text {ext, } 532 \mathrm{~nm}}, 530 \mathrm{~nm}$ scattering coefficient, $b_{\text {scat }, 530 \mathrm{~nm}}, 1064 \mathrm{~nm}$ extinction coefficient, $b_{\text {ext, } 1064 \mathrm{~nm}}$, particle count, $\mathrm{NO}$ and $\mathrm{NO}_{2}$ ) and $\mathrm{CO}_{2}$ are shown in Figures 8-13. 


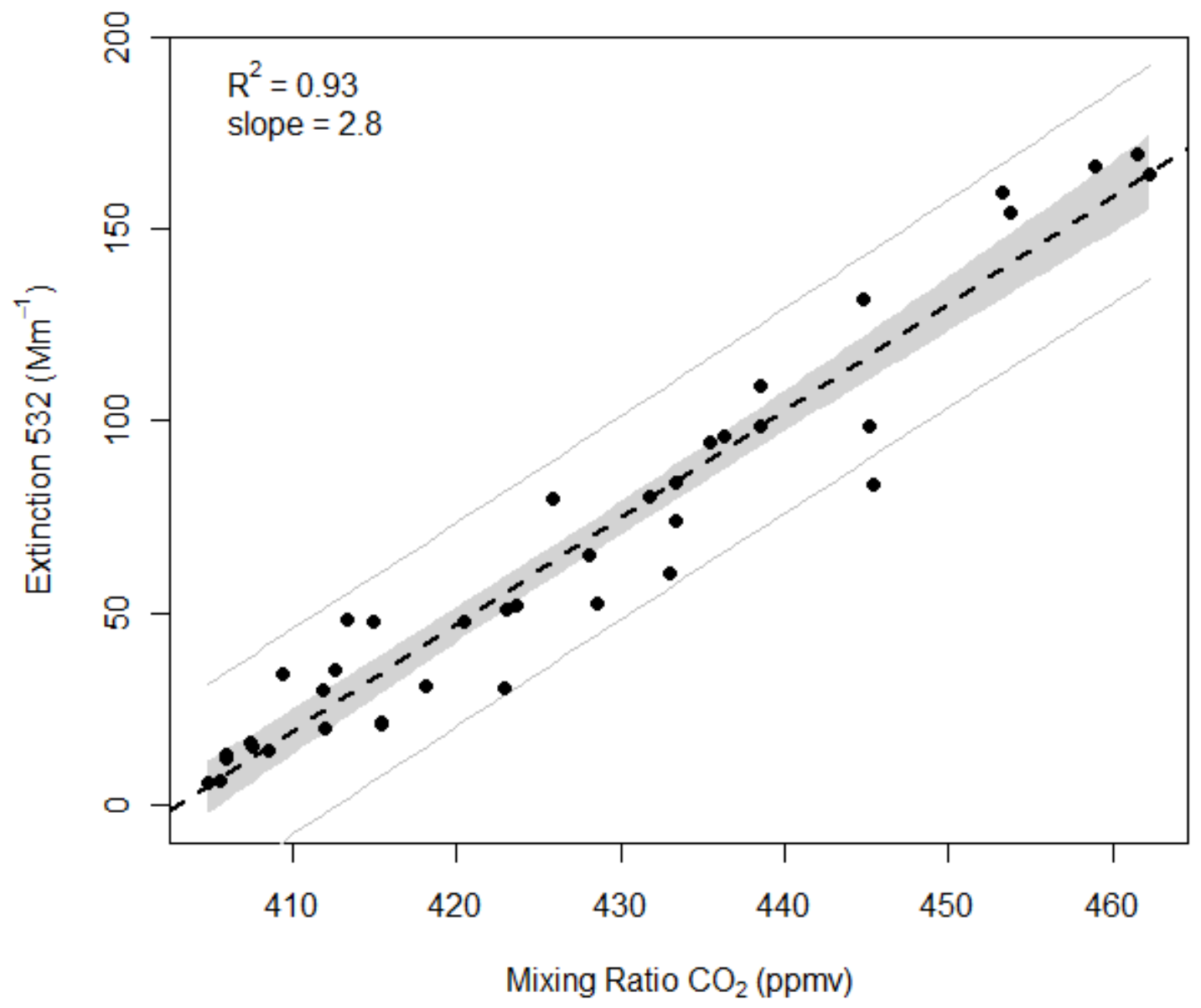

Figure 8: Correlation plot between Extinction $532 \mathrm{~nm}$ and $\mathrm{CO}_{2}$ for all $\mathrm{B5}$ plumes. 


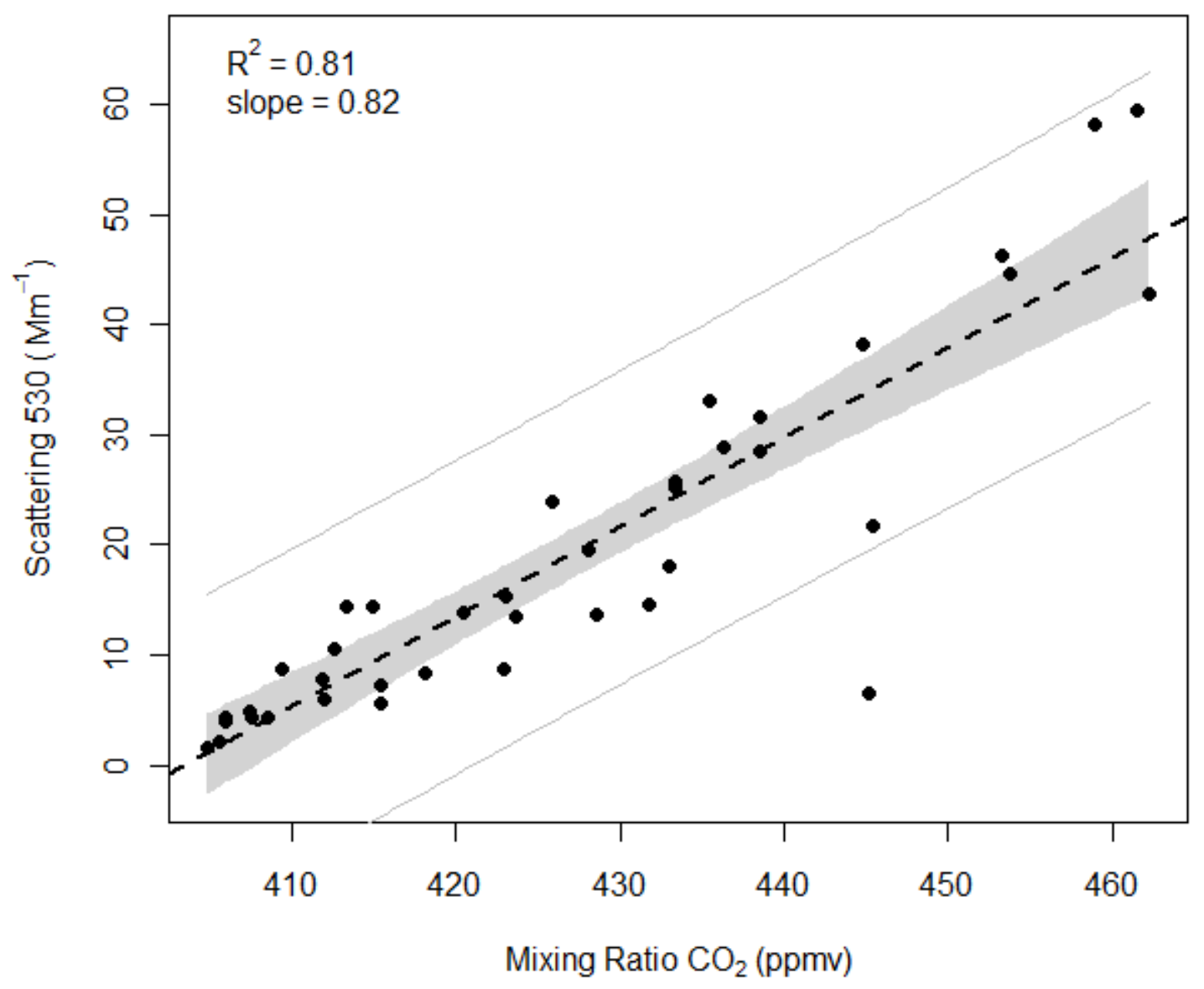

Figure 9: Correlation plot between Scattering $530 \mathrm{~nm}$ and $\mathrm{CO}_{2}$ for all $\mathrm{B} 5$ plumes. 


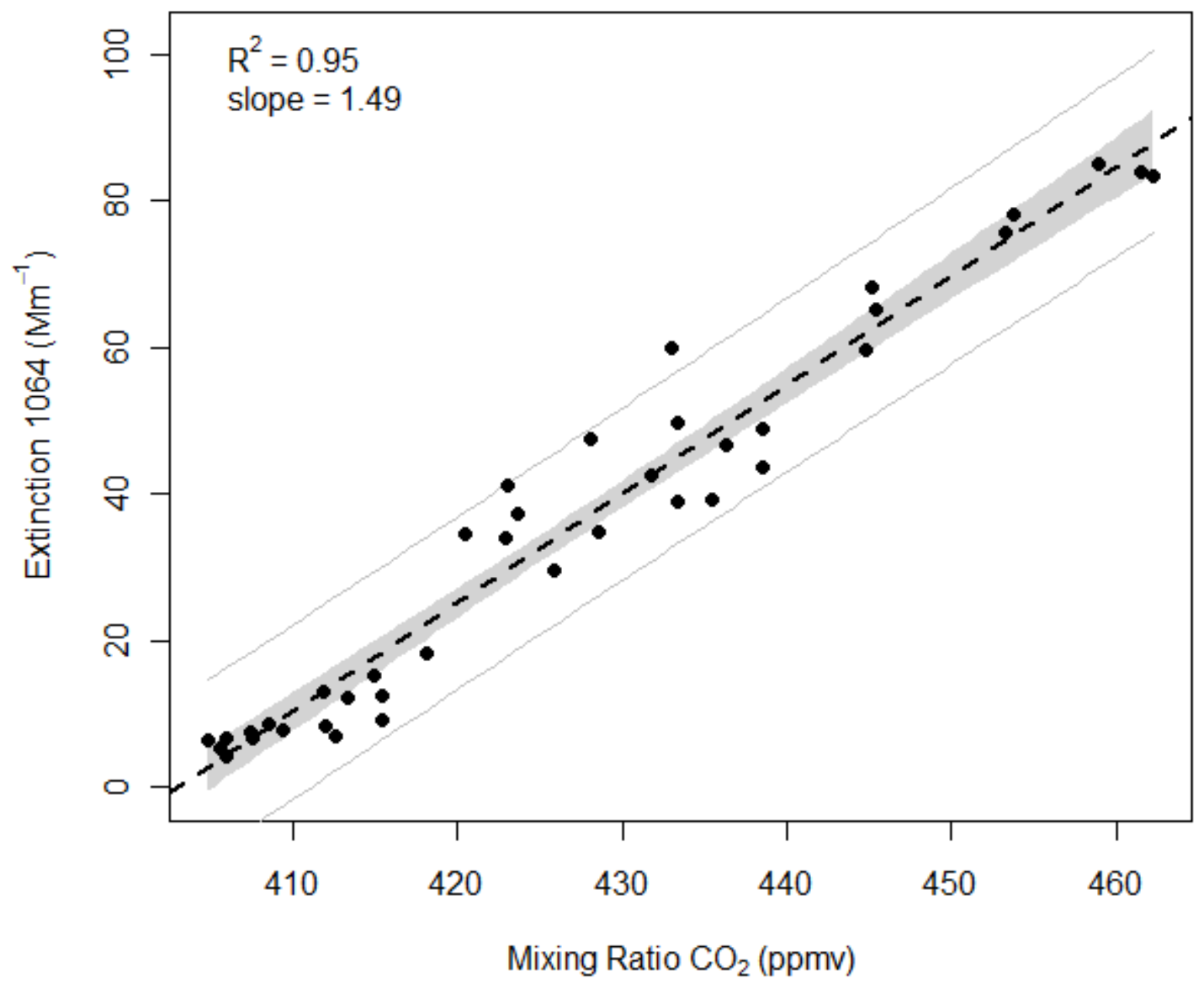

Figure 10: Correlation plot between Extinction $1064 \mathrm{~nm}$ and $\mathrm{CO}_{2}$ for all $\mathrm{B} 5$ plumes. 


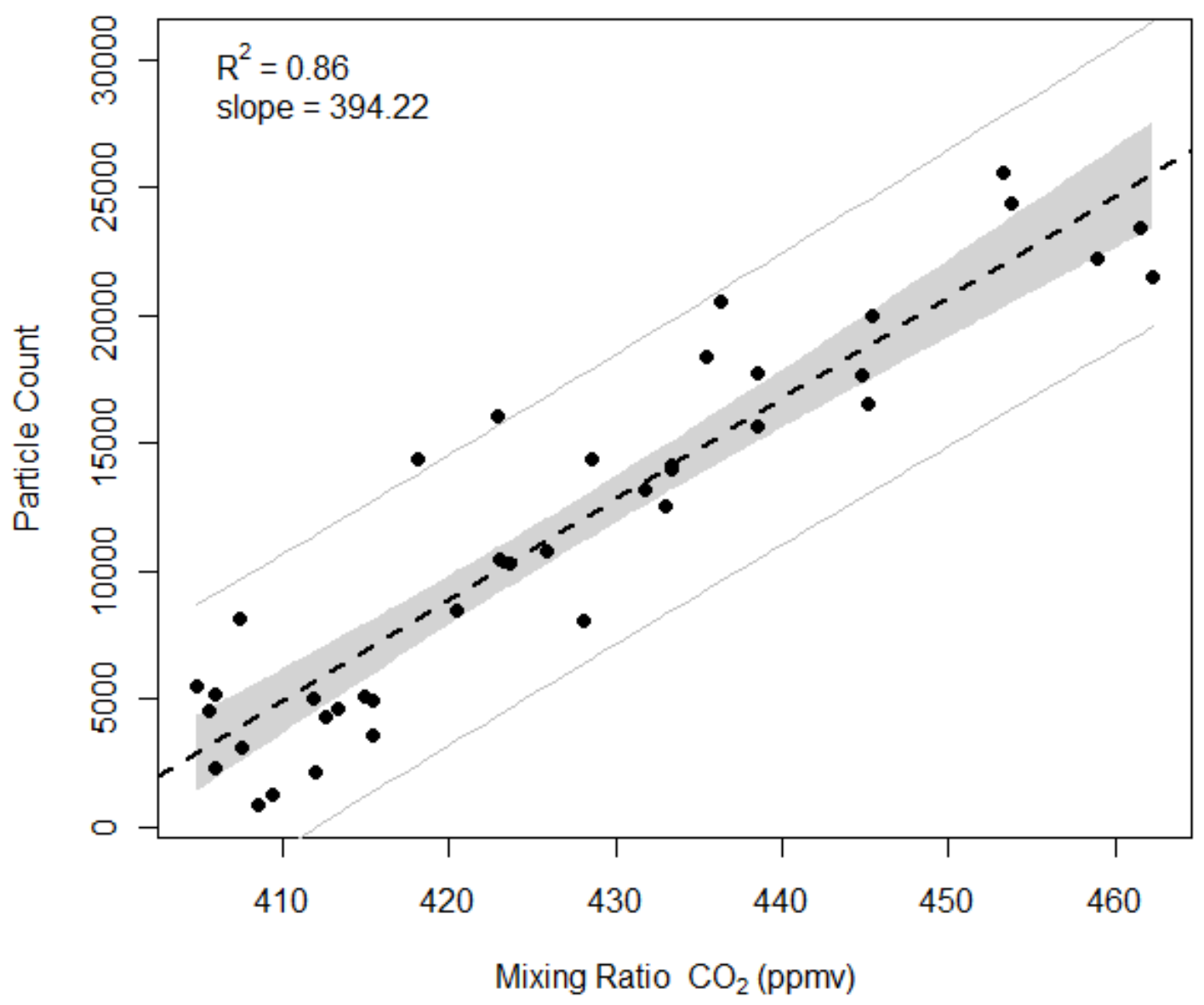

Figure 11: Correlation plot between Particle Count and $\mathrm{CO}_{2}$ for all $\mathrm{B} 5$ plumes. 


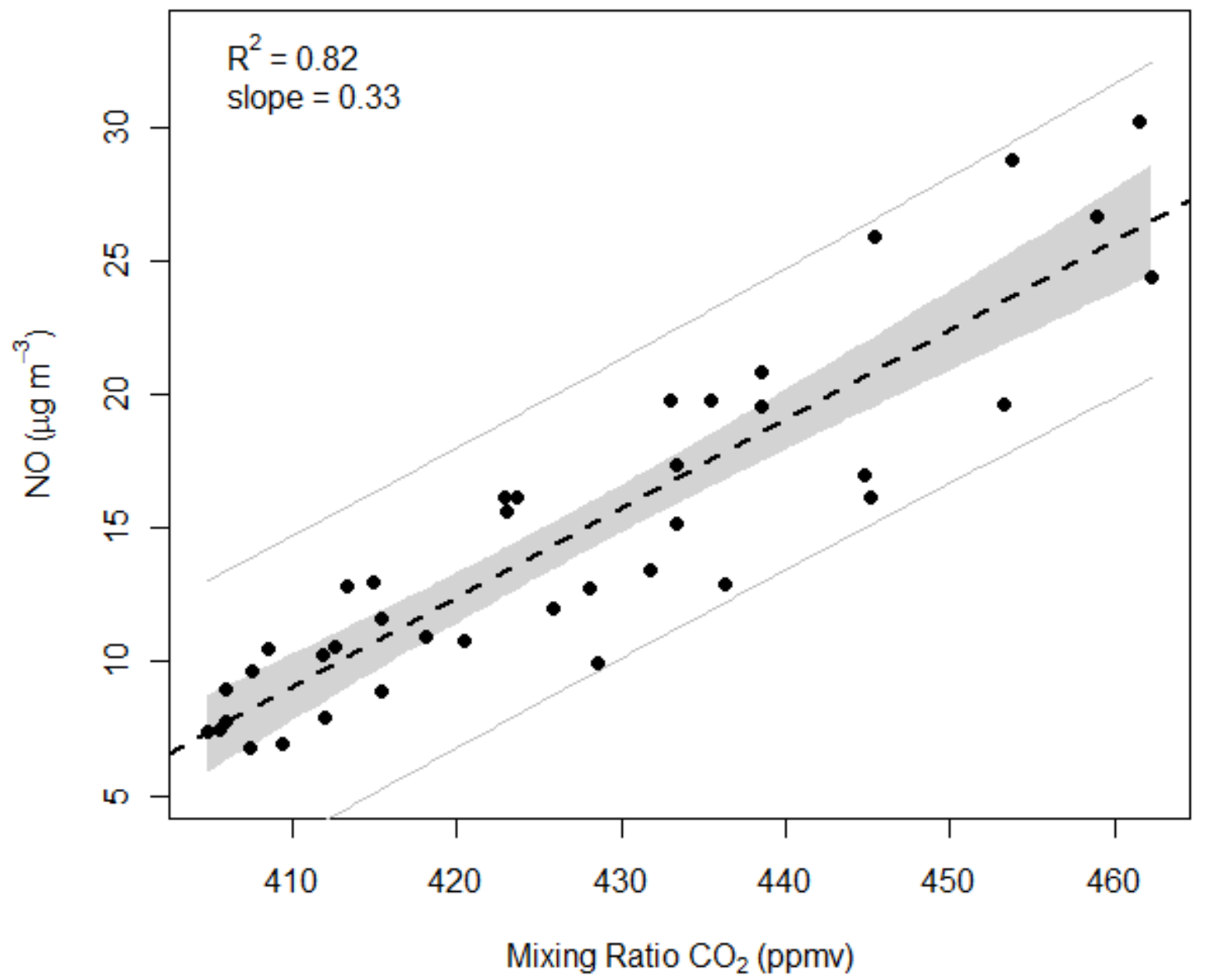

Figure 12: Correlation plot between $\mathrm{NO} \mu \mathrm{gm}^{-3}$ and $\mathrm{CO}_{2}$ for all $\mathrm{B5}$ plumes. 


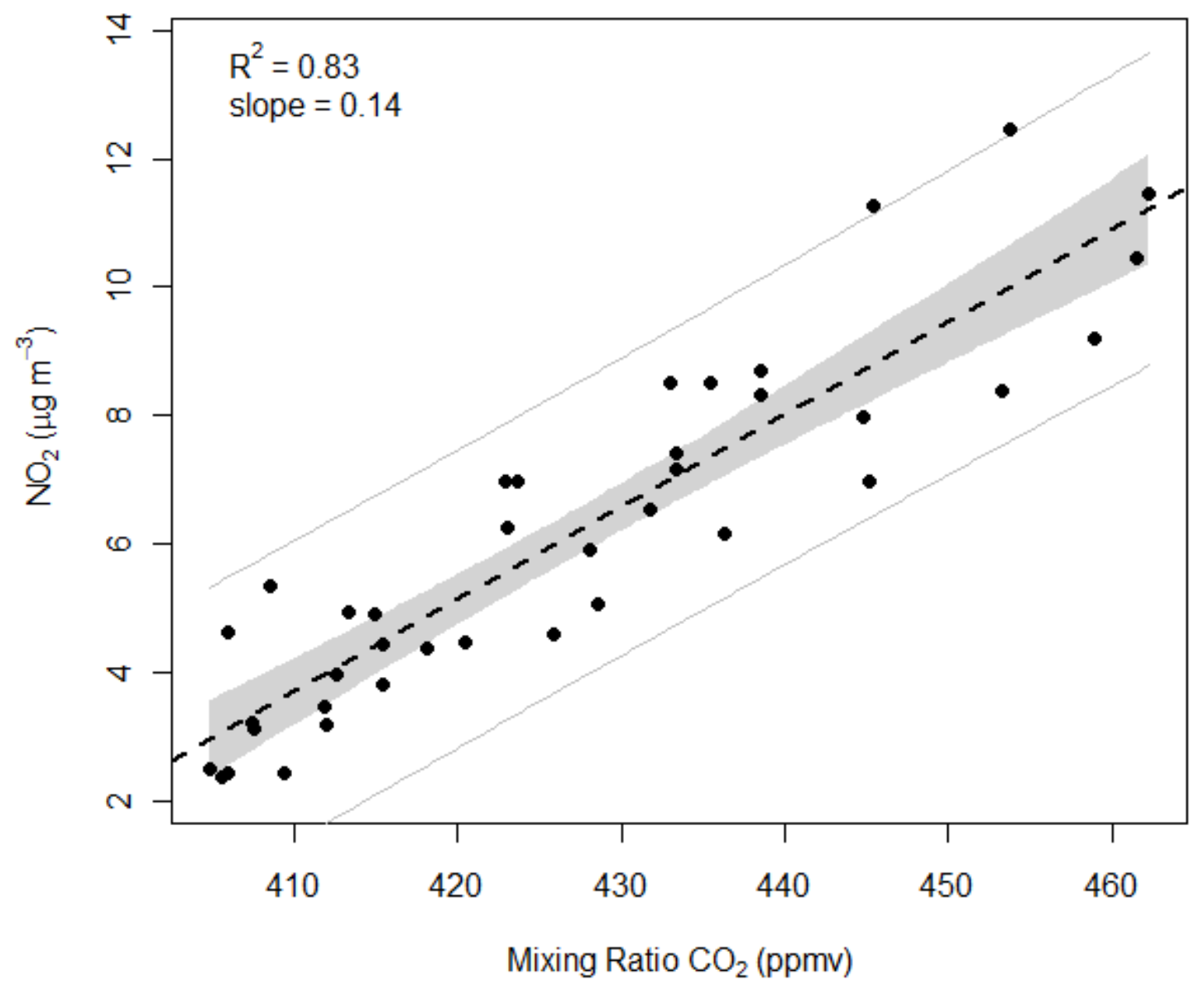

Figure 13: Correlation plot between $\mathrm{NO}_{2} \mu_{\mathrm{gm}}{ }^{-3}$ and $\mathrm{CO}_{2}$ for all $\mathrm{B} 5$ plumes.

In Figures 8 through 13 the correlation line between the measured parameters and carbon dioxide mixing ratio is shown as a dashed line. The slope of the line is used to calculate the emission factor for the given parameter. The $95 \%$ prediction interval is shown as grey shading and the $95 \%$ confidence interval falls between the two grey lines. Correlation plots for all of the parameters and mixtures with $\mathrm{CO}_{2}$ are provided in Appendix A for 
reference. Uncertainties in the calculated emission factors include the standard error of the slope of the correlation as calculated using the statistical software $\mathrm{R}^{201}$, uncertainty in fuel carbon content ( \pm 1.6 to $2.0 \%$ ) and total carbon conversion to $\mathrm{CO}_{2}( \pm 2 \%)$. It is possible that both the linear correlation and the standard error of the slope could be improved by increasing the correlation cut-off to 0.85 . This was not done for these results because there were not enough data for B75 plumes to increase the selectivity to this level.

The $\mathrm{R}^{2}$ values range between 0.75 to 0.94 , consistent with the observed linear relationships between $\mathrm{CO}_{2}$ and emissions for all pollutants and fuel types. The calculated emission factors for the parameters measured in these studies for each of the fuel mixtures are shown in Table 9.

Table 9: Summary of the emission factors obtained from this work.

\begin{tabular}{lllllll}
\hline \hline & $\mathrm{NO}$ & $\mathrm{NO}_{2}$ & $\begin{array}{l}\text { Extinction } \\
(064 \mathrm{~nm} \\
\left(\mathrm{gkg}^{2}\right)\end{array}$ & $\begin{array}{l}\text { Extinction } \\
532 \mathrm{~nm} \\
\left(\mathrm{gkg}^{-1}\right)\end{array}$ & $\begin{array}{l}\text { Scattering } \\
530 \mathrm{~nm} \\
\left(\mathrm{mg}^{-1}\right)\end{array}$ & $\begin{array}{l}\text { Count } \\
\left.\mathrm{x} 10^{14}\right) \\
\left(\mathrm{kg}^{-1}\right)\end{array}$ \\
\hline \hline B5 & $0.54 \pm 0.31$ & $0.21 \pm 0.12$ & $2.41 \pm 0.70$ & $4.53 \pm 1.01$ & $1.43 \pm 0.92$ & $6.38 \pm 4.21$ \\
B25 & $0.6 \pm 0.34$ & $0.23 \pm 0.21$ & $2.45 \pm 1.01$ & $5.33 \pm 1.12$ & $1.81 \pm 0.62$ & $7.25 \pm 6.81$ \\
B50 & $1.02 \pm 0.25$ & $0.31 \pm 0.19$ & $1.50 \pm 0.40$ & $6.13 \pm 1.27$ & $2.48 \pm 0.48$ & $16.9 \pm 8.63$ \\
B75 & $0.71 \pm 0.34$ & $0.22 \pm 0.21$ & $1.32 \pm 1.10$ & $5.45 \pm 1.81$ & $2.27 \pm 0.79$ & $7.58 \pm 7.21$ \\
B99 & $0.65 \pm 0.56$ & $0.21 \pm 0.16$ & $0.99 \pm 0.81$ & $4.12 \pm 1.05$ & $1.79 \pm 1.20$ & $8.27 \pm 3.60$ \\
\hline \hline
\end{tabular}

Figures 14 through 17 show the results from Table 9 in graphical format. 


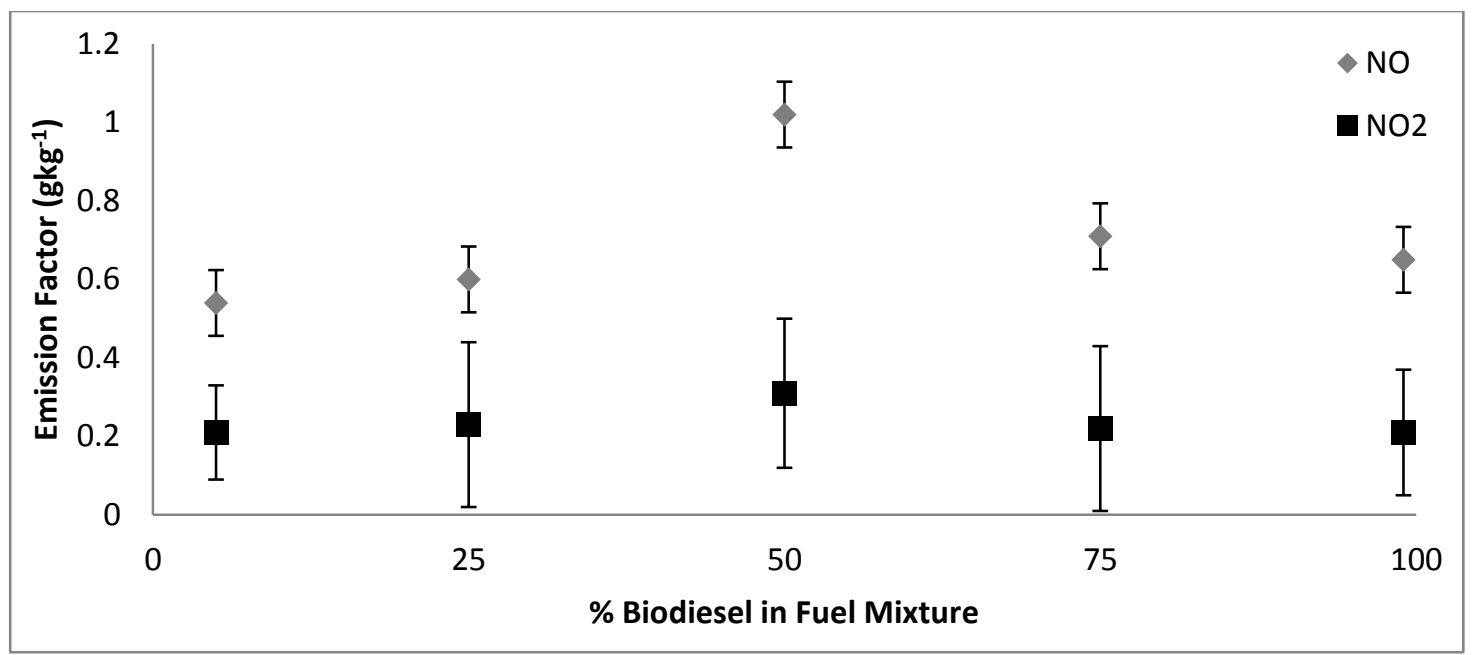

Figure 14: Emission Factors for $\mathrm{NO} \mathrm{gkg}^{-1}$ and $\mathrm{NO}_{2} \mathrm{gkg}^{-1}$.

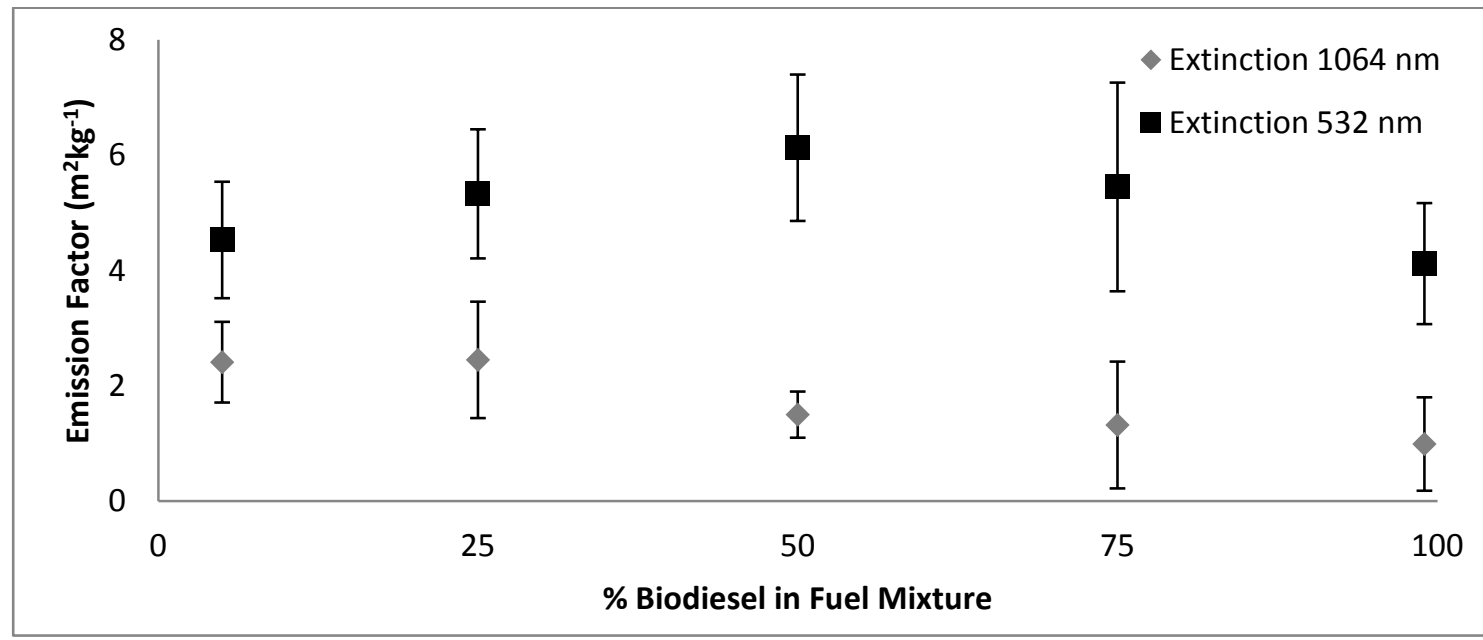

Figure 15: Emission Factors for Extinction $1064 \mathrm{~nm}$ and Extinction $532 \mathrm{~nm}\left(\mathrm{~m}^{2} \mathrm{~kg}^{-1}\right)$ 


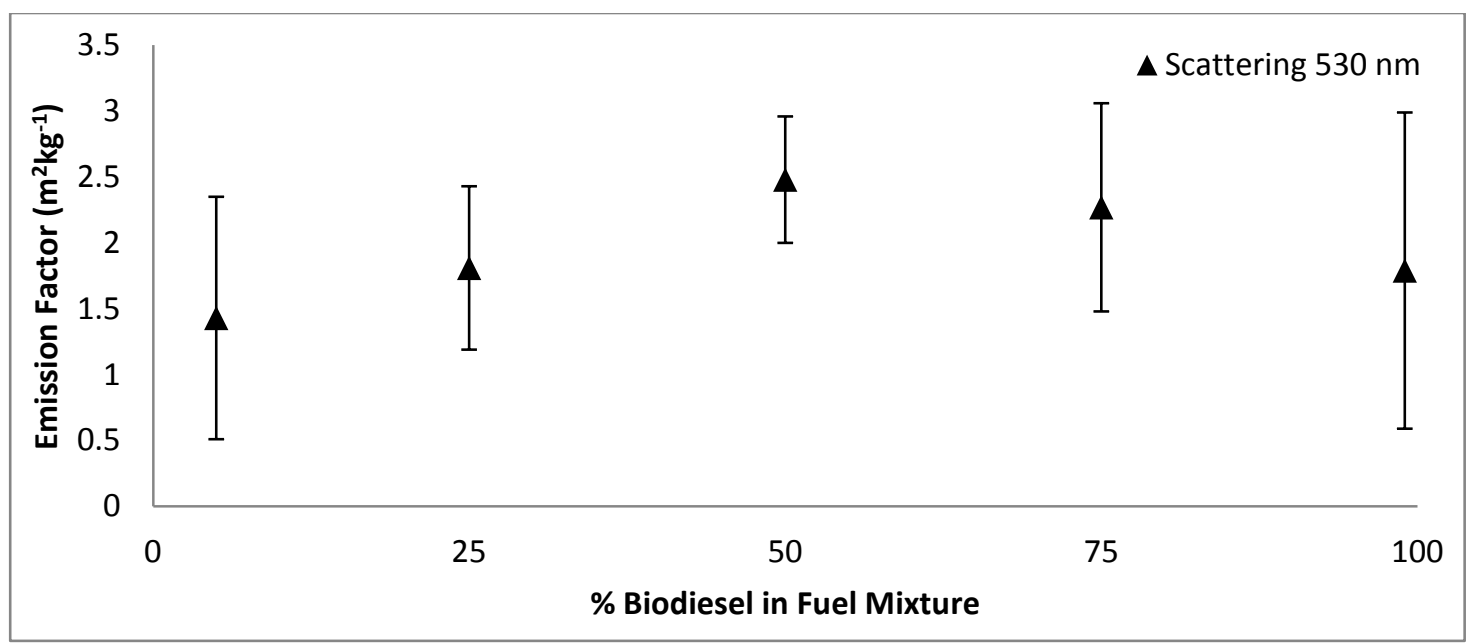

Figure 16: Emission Factors for Scattering $530 \mathrm{~nm}\left(\mathrm{~m}^{2} \mathrm{~kg}^{-1}\right)$

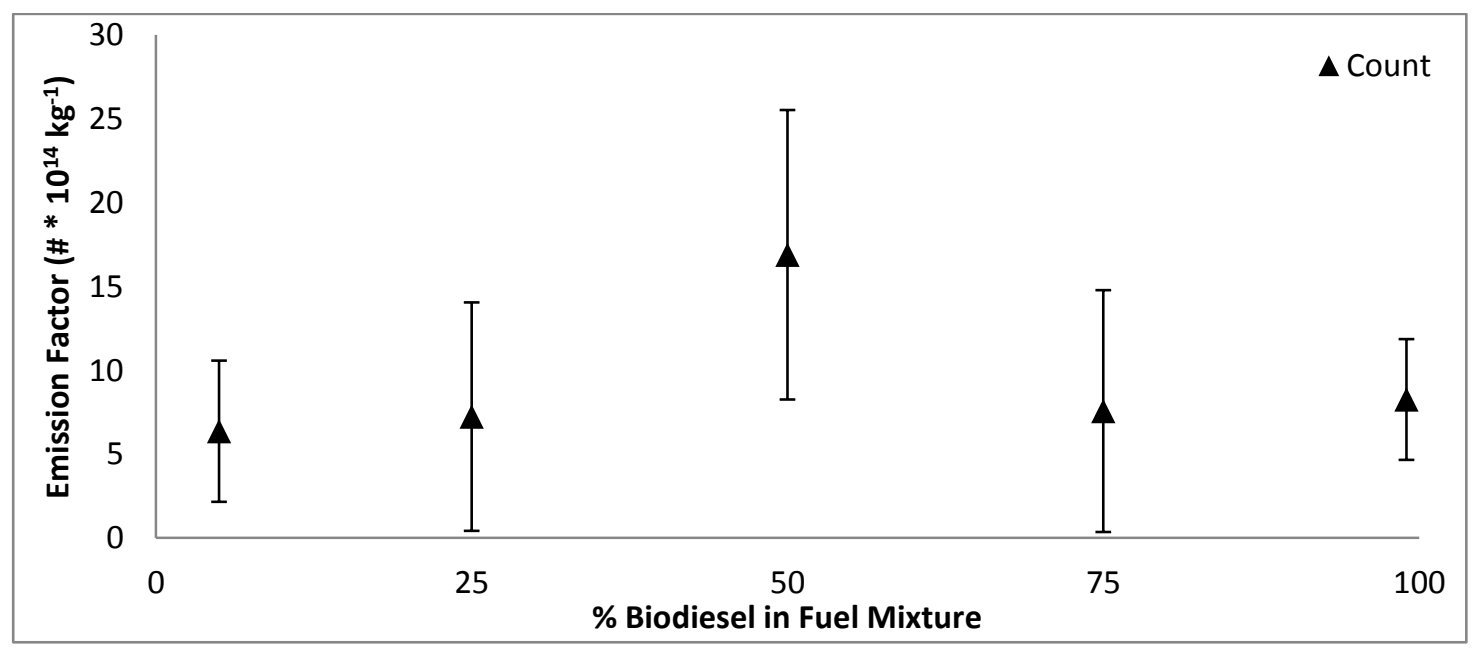

Figure 17: Emission factors for Particle Count $\left(\# * 10^{14} \mathbf{k g}^{-1}\right)$

Emission factors for particle number, 532 extinction, 530 scattering, $\mathrm{NO}$ and $\mathrm{NO}_{2}$ were all highest for the B50 mixture. The 1064 extinction tended to decrease with increased biodiesel content. These trends are investigated in the following sections. 


\subsection{Particle Number and Size and Extensive Optical Property Emission Factors}

Scattering and extinction coefficients are extensive properties and depend on the particle concentration. A greater number of particles, especially larger particles, will increase the extinction and scattering. Composition is also important: fresh soot will increase absorption while sulfate particles would only exhibit scattering. If particles are heterogeneous, morphology can have an impact: for a soot core with a non-absorbing organic coating for example, Bond 2006, demonstrated that absorption, and therefore extinction, can be enhanced by up to $30-50 \%$ due a lensing effect. The scattering shell acts like a lens, focusing more photons onto the absorbing core. ${ }^{99}$

\subsubsection{Results}

For this study extinction at $532 \mathrm{~nm}$ and $1064 \mathrm{~nm}$, particle count, and scattering at 530 were measured. The B99 mixture had the smallest emission factor for extinction at 532 $\mathrm{nm}$ and at $1064 \mathrm{~nm}$. For the $1064 \mathrm{~nm}$ extinction, the trend was linear and tended to decrease with increased biodiesel content. For the extinction at $532 \mathrm{~nm}$, the trend was not linear and the emission factor peaked at the B50 mixture. The scattering measurement and the particle count had similar trends with the maximum extinction factor occurring at the B50 mixture, and the smallest emission factor at B5.

The B5 mixture had the smallest emission factor for particle count, indicating that using biodiesel can increase the overall number of particles emitted. However, the trend was not linear or even monotonic, with the B50 mixture showing larger particle number 
emission factors than either B5 or B99. Larger particle emission factors are often linked with engines running at higher temperatures and pressures because these combustion conditions favor the production of higher number concentrations. Tsolakis (2006) and Pagan (1999) found that the increase in particle number when using biodiesel was related to the increase in fuel injection pressure due to the higher viscosity of biodiesel fuel. ${ }^{20,121}$ Tsolakis hypothesized that the increase in injection pressure optimized fuel atomization and air-fuel mixing, creating locally supersaturated zones with enhanced particle nucleation, leading to a higher number of smaller particles.

A review of the SPMS data collected reveals more information regarding the size of particles emitted for each type of fuel. The SMPS was operated during the car on and car off ambient cycles for a 90 second run time with a 15 second ramp-up between runs. The start times for each run were compared with the time series emission data and when an emission plume, identified by a spike in $\mathrm{CO}_{2}$, overlapped the SMPS run time, the data was analyzed to obtain particle size distributions. This method of sampling was only intended to provide a general size distribution for each fuel, not data for emission factor calculations. Figures 18 to 22 and Tables 11 to 15 show number and volume size distribution plots and a summary of size data statistics for each mixture. The cut-off values for the instrument are shown as dashed lines in the figures. In Tables 11 through 15 , the particle density was assumed to be $1 \mathrm{~g} / \mathrm{cm}^{3}$ for the whole size distribution, which 
may be questionable for the emissions from vehicles, but allows for a comparison between mixtures.

Diesel emissions are typically characterized by a bimodal size distribution with peaks in the nucleation mode $(<30 \mathrm{~nm})$ and the Aitken or accumulation mode $(>30 \mathrm{~nm})$. The majority of the mass from emitted particles comes from the accumulation mode particles and the majority of the number concentration comes from particles in the nucleation mode. Diesel exhaust particles are usually all found under $1000 \mathrm{~nm}$. The nucleation mode particles consist mostly of volatile condensates and contain very little solid material. The accumulation mode particles are primarily carbon or ash solids mixed with condensates and adsorbed material. Number distributions for diesel emissions depend heavily on the specific vehicle tested, the testing cycle, age of the vehicle and sampling method used. Reported values span several orders of magnitude and range from $10^{3}$ to $10^{9}$ particles per $\mathrm{cm}^{3}$. In this study a bimodal distribution was seen for all of the mixtures, with the dominant mode varying based on the different fuel mixture tested.

\section{$\underline{\text { B99 }}$}

Particles with diameters under $50 \mathrm{~nm}$ dominated the particle number for B99. With fewer accumulation mode particles present in the emissions the dominant pathway for emitted vapors was most likely nucleation because the surface area available for condensation 
and adsorption was limited. Since these particles are small, they contribute relatively little to the mass compared with particles over $100 \mathrm{~nm}$ as seen in Figure 18.
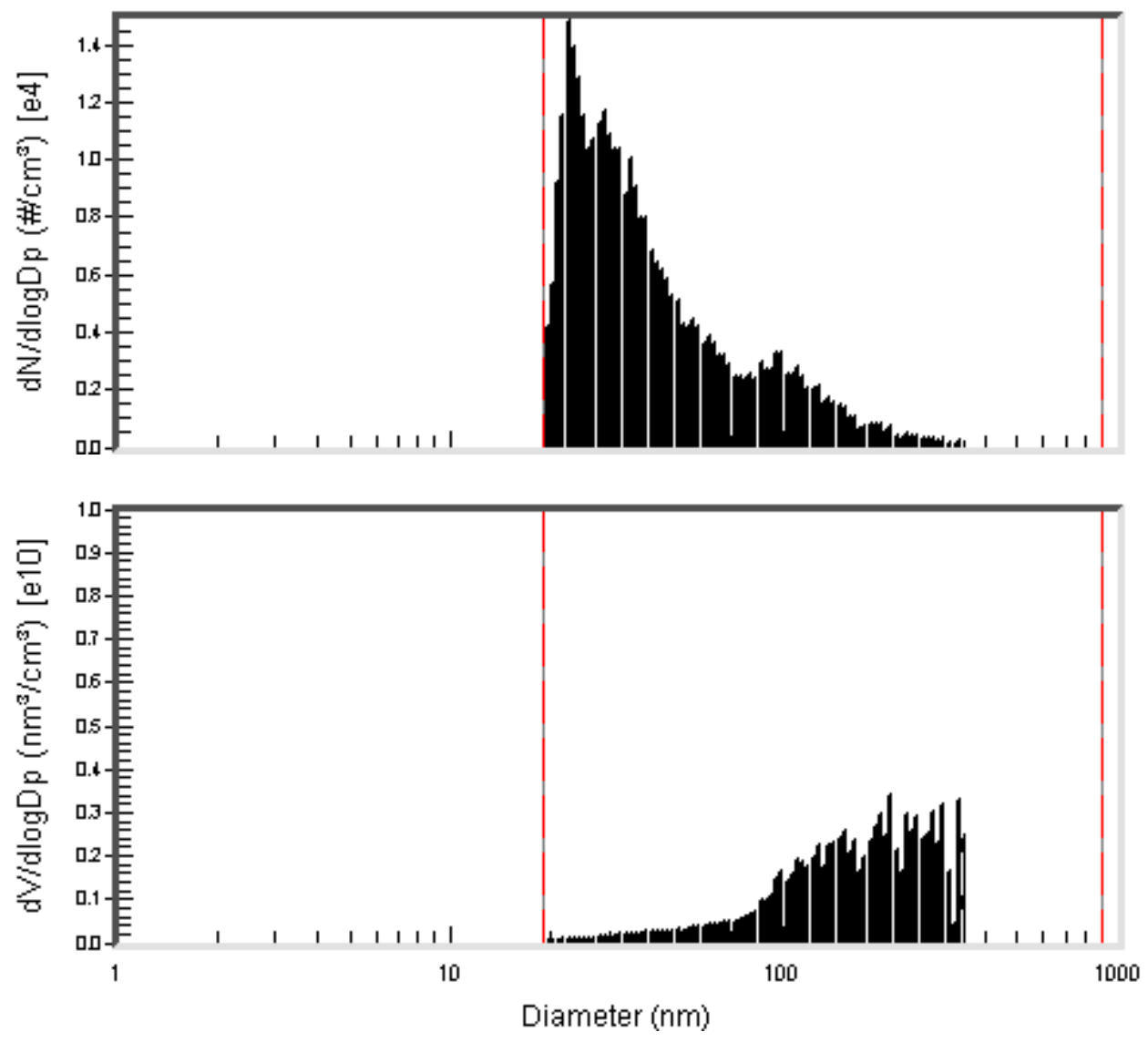

Figure 18: Number and Volume distributions for B99.

The total number concentration from the SMPS scan compares well to the corresponding CPC total number concentration for the same time span for B99. The size cutoff of the SMPS was smaller $(1 \mu \mathrm{m})$ compared to the CPC $(\sim 4 \mu \mathrm{m})$ so the concentrations are not expected to be exactly equal. The average number concentration from the $\mathrm{CPC}$ was 7,182 particles per $\mathrm{cm}^{3}$ compared with the SMPS total concentration of 5,260 particles 
per $\mathrm{cm}^{3}$. Overall B99 emissions are dominated by particles in the Aitken mode, but nucleation mode particles $(<20 \mathrm{~nm})$ are present in greater quantities than for the other mixture emissions, as shown below. A summary of the size data statistics for this particular representative B99 plume are given in Table 10.

Table 10: Size Data Statistics for B99.

\begin{tabular}{llllll}
\hline \hline & Number & Diameter & Surface & Volume & Mass \\
\hline \hline Median (nm) & 34 & 58.9 & 118.1 & 175.3 & 175.3 \\
Mean $(\mathrm{nm})$ & 49.5 & 82.4 & 132.8 & 181.7 & 181.7 \\
Geo. Mean $(\mathrm{nm})$ & 40.3 & 62.9 & 107.2 & 159.5 & 159.5 \\
Mode $(\mathrm{nm})$ & 22.5 & 34.6 & 126.3 & 209.1 & 209.1 \\
Geo. St. Dev. & 1.79 & 2.07 & 2.01 & 1.74 & 1.74 \\
Total Conc. & $5.26 \times 10^{3}$ & 0.260 & $6.75 \times 10^{7}$ & $1.49 \times 10^{9}$ & 1.49 \\
& $\left(\# / \mathrm{cm}^{3}\right)$ & $\left(\mathrm{mm} / \mathrm{cm}^{3}\right)$ & $\left(\mathrm{nm}^{2} / \mathrm{cm}^{3}\right)$ & $\left(\mathrm{nm}^{3} / \mathrm{cm}^{3}\right)$ & $\left(\mu \mathrm{g} / \mathrm{m}^{3}\right)$ \\
\hline \hline
\end{tabular}

\section{$\underline{\mathrm{B} 75}$}

The emissions from the B75 mixture were also dominated by particles in the Aitken mode with some contribution of particles in the nucleation mode, but there were more particles greater than $100 \mathrm{~nm}$, which fall in the accumulation mode. The number distribution for B75, shown in Figure 19, indicates that the peak in the Atiken range occurs around $30 \mathrm{~nm}$ and the peak in the accumulation mode is around $90 \mathrm{~nm}$. 

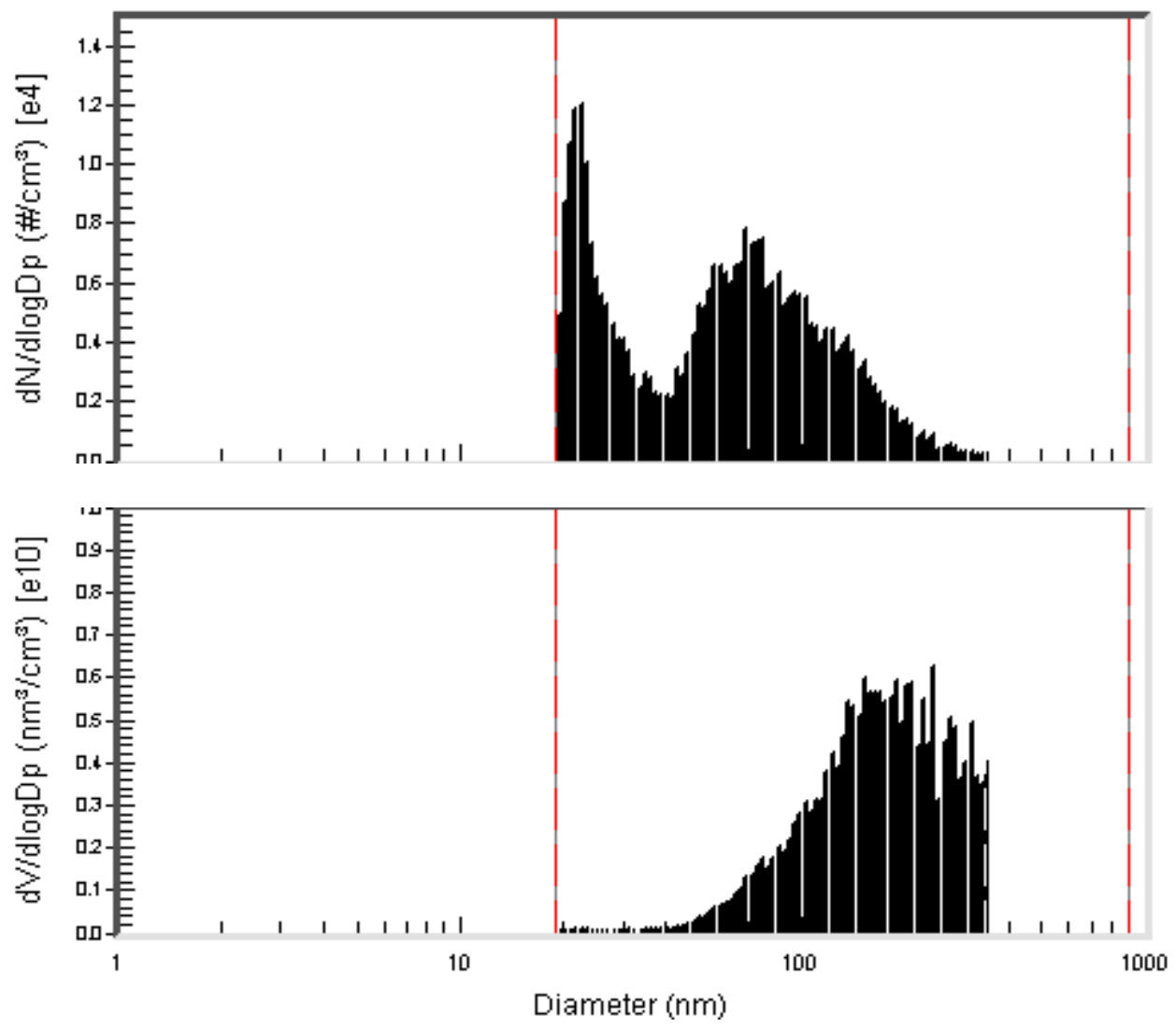

Figure 19: Number and Volume Distribution for B75 Plume.

For the SMPS measurement shown in Figure 15 the number concentration from the CPC was 8,573 particles per $\mathrm{cm}^{3}$ and the SMPS total concentration was 5,150 particles per $\mathrm{cm}^{3}$. This difference may have been caused by the smaller range measured by the SMPS or differences in the residence time between emissions and measurement. 
Table 11: Size distribution statistics for $\mathbf{B 7 5}$.

\begin{tabular}{llllll}
\hline \hline & Number & Diameter & Surface & Volume & Mass \\
\hline \hline $\begin{array}{l}\text { Median } \\
(\mathrm{nm})\end{array}$ & 59.4 & 94.1 & 134.3 & 171.4 & 171.4 \\
$\begin{array}{l}\text { Mean }(\mathrm{nm}) \\
\text { Geo. Mean }\end{array}$ & 70.6 & 107.2 & 145.7 & 181.8 & 181.8 \\
$\begin{array}{l}\mathrm{nm}) \\
\text { Mode }(\mathrm{nm})\end{array}$ & 55.6 & 88.7 & 127.2 & 164.6 & 164.6 \\
Geo. St. & 22.5 & 76.4 & 135.8 & 241.4 & 241.4 \\
Dev. & 1.92 & 1.73 & 1.6 & 1.6 \\
Total Conc. & $\begin{array}{l}5.15 \times 10^{3} \\
\left(\# / \mathrm{cm}^{3}\right)\end{array}$ & $\begin{array}{l}0.364 \\
\left(\mathrm{~mm} / \mathrm{cm}^{3}\right)\end{array}$ & $\begin{array}{l}1.22 \times 10^{8} \\
\left(\mathrm{~nm}^{2} / \mathrm{cm}^{3}\right)\end{array}$ & $\begin{array}{l}2.97 \times 10^{9} \\
\left(\mathrm{~nm}^{3} / \mathrm{cm}^{3}\right)\end{array}$ & $\begin{array}{l}2.97 \\
\left(\mu \mathrm{g} / \mathrm{m}^{3}\right)\end{array}$ \\
\hline \hline
\end{tabular}

The number of particles in the accumulation mode for B75 was much larger than for B99 which could indicate a higher concentration of solid particles. The rate of adsorption and condensation is proportional to the surface area of available particulate matter. When a larger number of solid agglomerates are present there is a higher chance of vapors adsorping and condensing onto existing particles. As this process occurs the saturation ratio decreases which further decreases the likelihood of nucleation occuring. The slightly smaller particle number emission factor for B75 when compared with B99 may be related to the amount of solid formed during combustion.

The increased uncertainty for B75 emission factors (Table 10) may be related to the small number of acceptable emission plumes measured. Only four plumes met the criteria outlined for inclusion in the emission factor calculation and the correlation coefficient between $\mathrm{CO}_{2}$ and the particle count was only 0.80 , the lowest of all of the $\mathrm{R}^{2}$ values obtained. Based on the uncertainty and the small sample size, this emission factor should 
be investigated again to verify the value, but will be used to assist in hypothesizing the differences between the mixtures.

\section{$\underline{\mathrm{B} 50}$}

The number distribution of particles in B50 emissions were dominated by particles in the upper size range of the Aitken mode and lower size range of the accumulation mode (70 to $120 \mathrm{~nm}$ ). There were also consistently and significantly more particles when compared with emissions from the other fuel mixtures. In contrast to the B99 and B75 emissions, the primary peak for the B50 emissions occurred in the accumulation mode and the secondary peak was in the Atiken mode. As noted above, a higher number of accumulation mode particles may indicate a larger number of solid soot (in the 30-100 $\mathrm{nm}$ range) or ash particles (in the $30-40 \mathrm{~nm}$ range) being formed during combustion. Increases in ash and soot are a signature of incomplete combustion and/or combustion of fuel with impurities. 

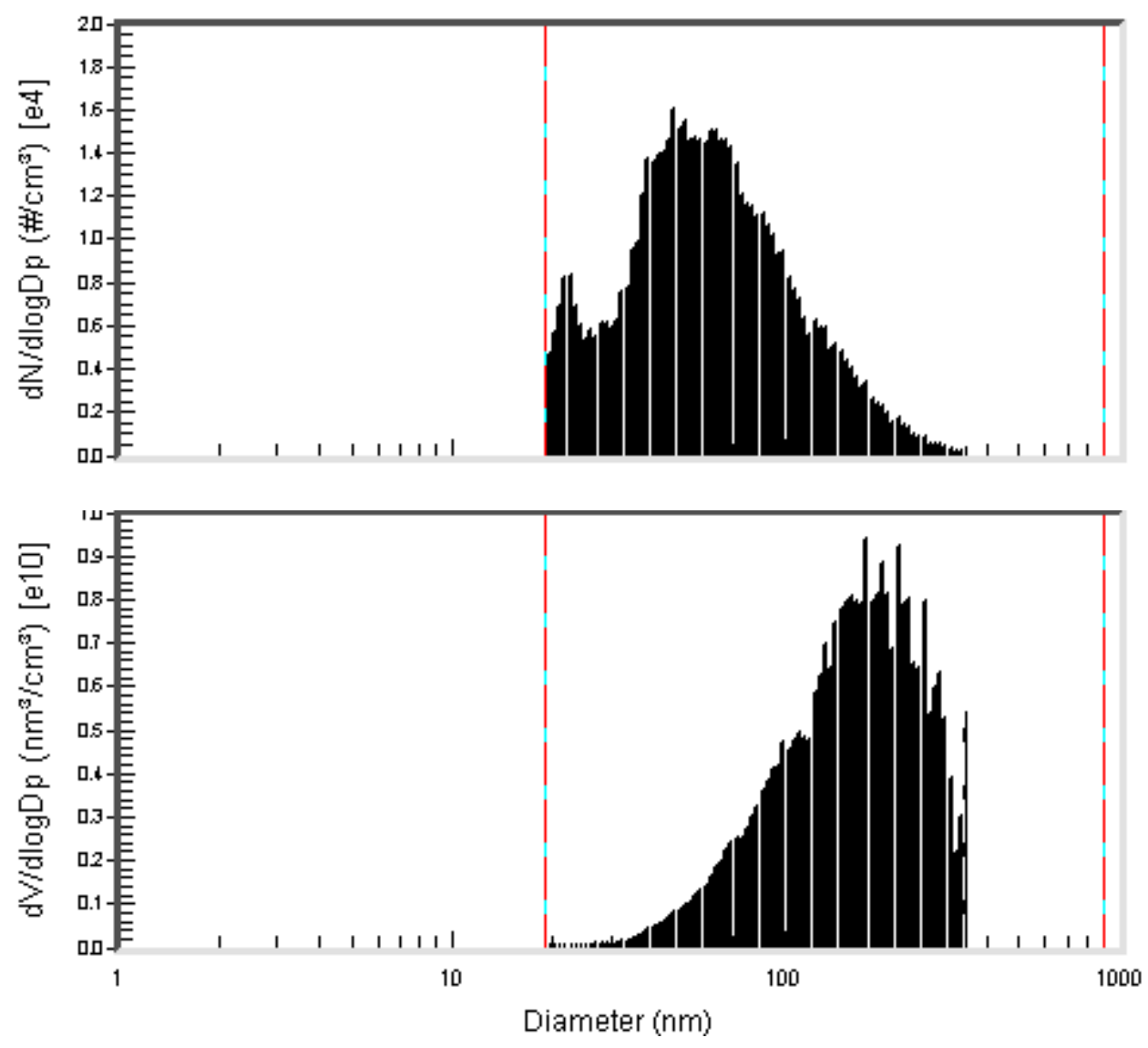

Figure 20: Number and Volume Distribution for B50.

The SMPS and CPC measurement agreed fairly well for B50 emissions. The total number concentration from the SMPS was 9,350 particles per $\mathrm{cm}^{3}$ and the CPC measured 12,239 particles per $\mathrm{cm}^{3}$ over the same time span for B50. Table 12 outlines the particle size data for B50. 
Table 12: Size Data Statistics for B50.

\begin{tabular}{llllll}
\hline \hline & Number & Diameter & Surface & Volume & Mass \\
\hline \hline Median $(\mathrm{nm})$ & 57 & 81.7 & 121.4 & 163.9 & 163.9 \\
Mean $(\mathrm{nm})$ & 69.3 & 97.9 & 134 & 171.3 & 171.3 \\
Geo. Mean $(\mathrm{nm})$ & 58.5 & 82.4 & 115.6 & 153.4 & 153.4 \\
Mode (nm) & 46.1 & 68.5 & 174.7 & 174.7 & 174.7 \\
Geo. St. Dev. & 1.77 & 1.81 & 1.76 & 1.64 & 1.64 \\
Total Conc. & $\begin{array}{l}9.35 \times 10^{3} \\
\left(\# / \mathrm{cm}^{3}\right)\end{array}$ & $\begin{array}{l}0.648 \\
\left(\mathrm{~mm} / \mathrm{cm}^{3}\right)\end{array}$ & $\begin{array}{l}1.99 \times 10^{8} \\
\left(\mathrm{~nm}^{2} / \mathrm{cm}^{3}\right)\end{array}$ & $\begin{array}{l}4.45 \times 10^{9} \\
\left(\mathrm{~nm}^{3} / \mathrm{cm}^{3}\right)\end{array}$ & $\begin{array}{l}4.45 \\
\left(\mu \mathrm{g} / \mathrm{m}^{3}\right)\end{array}$ \\
\hline \hline
\end{tabular}

$\underline{B 25}$

Particle number concentration for all size ranges were smaller for B25 emissions compared to B50, B75 or B99 emissions, with the greatest decrease in the very small size ranges. Similar to B50, it is likely that an increased number of larger sized solid particles provided surfaces for the condensation and adsorption of nucleation mode particles and vapors. Since the Aitken mode peak is small in comparison to B50 it is also likely that there were fewer volatile condensates to begin with. The volume and number distributions for a representative B25 plume are shown in Figure 21. 

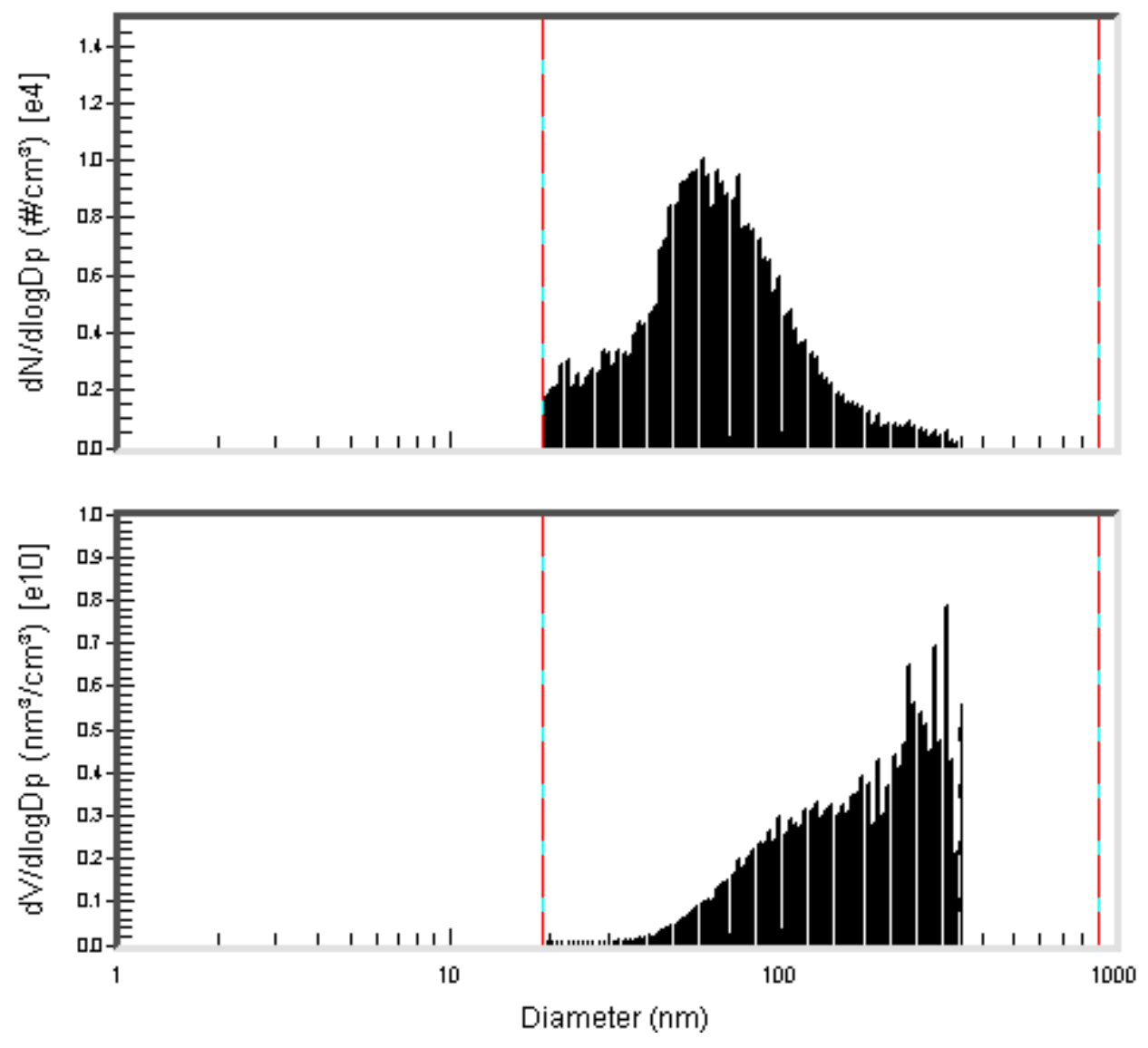

Figure 21: Number and Volume Distribution for B25.

The CPC total concentration was 4,210 particles per $\mathrm{cm}^{3}$ and the SMPS was 4,990 particles per $\mathrm{cm}^{3}$ for the same time span. The average size of B25 particles was similar to the other middle mixtures, larger than B99 and smaller than B5, as seen in Table 13. The 
overall particle number emission factor was lower than all other mixtures with a higher biodiesel percentage.

Table 13: Size Data Statistics for B25.

\begin{tabular}{llllll}
\hline \hline & Number & Diameter & Surface & Volume & Mass \\
\hline \hline $\begin{array}{l}\text { Median } \\
(\mathrm{nm})\end{array}$ & 61.5 & 81.4 & 117.3 & 181.5 & 181.5 \\
$\begin{array}{l}\text { Mean }(\mathrm{nm}) \\
\text { Geo. Mean }\end{array}$ & 72.7 & 100.9 & 141.6 & 187.7 & 187.7 \\
$\begin{array}{l}\text { (nm) } \\
\text { Mode }(\mathrm{nm})\end{array}$ & 62.4 & 85.1 & 120 & 165.4 & 165.4 \\
$\begin{array}{l}\text { Geo. St. } \\
\text { Dev. }\end{array}$ & 1.71 & 73.7 & 98.2 & 310.6 & 310.6 \\
Total Conc. & $\begin{array}{l}4.99 \times 10^{3} \\
\left(\# / \mathrm{cm}^{3}\right)\end{array}$ & $\begin{array}{l}0.362 \\
\left(\mathrm{~mm} / \mathrm{cm}^{3}\right)\end{array}$ & $\begin{array}{l}1.15 \times 10^{8} \\
\left(\mathrm{~nm}^{2} / \mathrm{cm}^{3}\right)\end{array}$ & $\begin{array}{l}2.71 \times 10^{9} \\
\left(\mathrm{~nm}^{3} / \mathrm{cm}^{3}\right)\end{array}$ & $\begin{array}{l}2.71 \\
\left(\mu \mathrm{g} / \mathrm{m}^{3}\right)\end{array}$ \\
\hline \hline
\end{tabular}

\section{$\underline{\mathrm{B} 5}$}

A larger portion of $\mathrm{B} 5$ emissions are particles in the $80 \mathrm{~nm}$ to $150 \mathrm{~nm}$ size range. The overall number of particles is smaller than for the other fuels, but the calculated mass is larger. This is in-line with current research on the size distributions from diesel fuel. Figure 22 shows a representative volume and number distribution for one of the B5 plumes measured. 

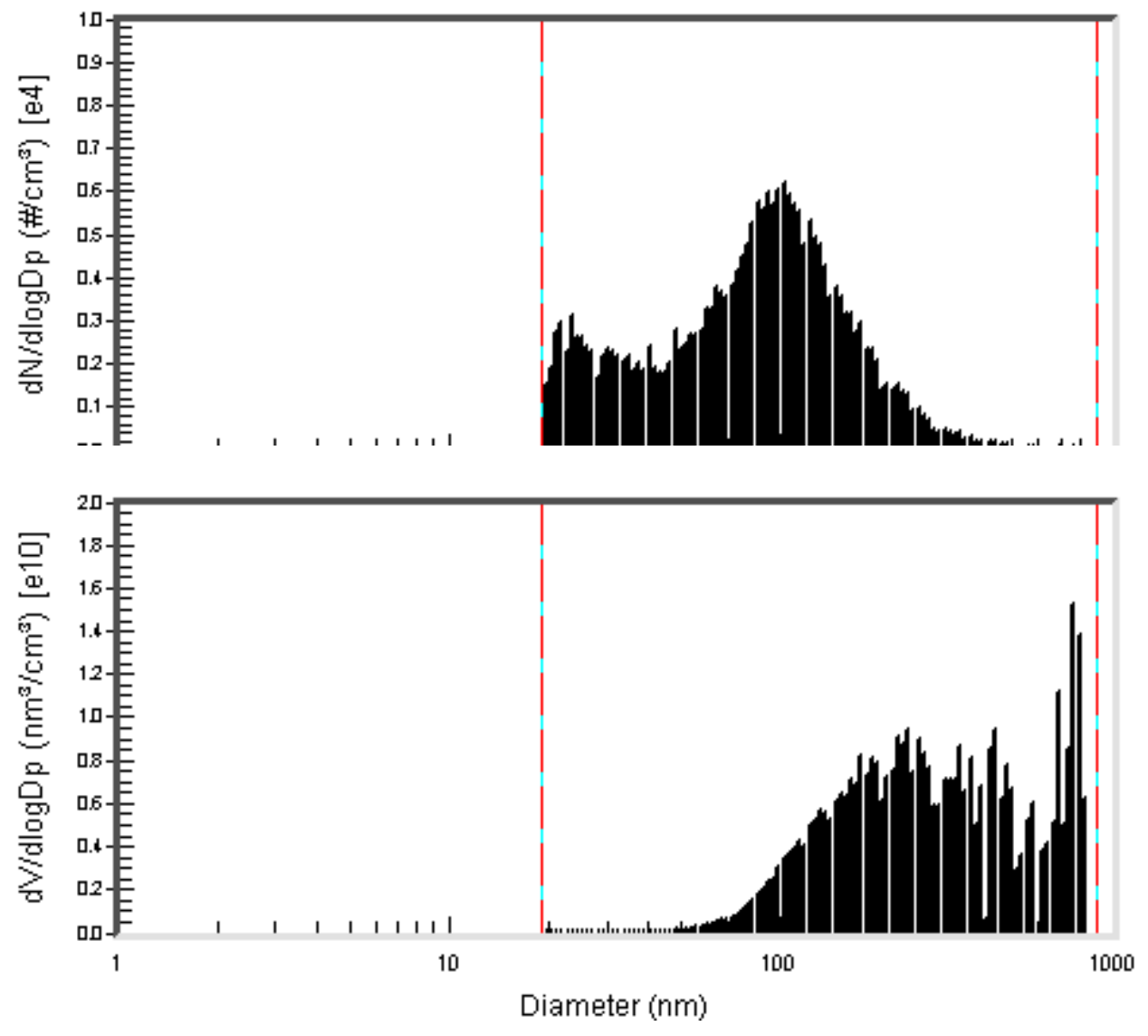

Figure 22: Number and Volume Distribution for B5.

Table 14 shows the size distribution statistics for the same B5 plume. 
Table 14: Size Data Statistics for B5.

\begin{tabular}{llllll}
\hline \hline & Number & Diameter & Surface & Volume & Mass \\
\hline \hline Median $(\mathrm{nm})$ & 86.8 & 122.7 & 175.2 & 274.7 & 274.7 \\
Mean $(\mathrm{nm})$ & 98.7 & 149.8 & 227.6 & 346.4 & 346.4 \\
Geo. Mean $(\mathrm{nm})$ & 78.7 & 122.3 & 183.8 & 282.6 & 282.6 \\
Mode $(\mathrm{nm})$ & 101.8 & 121.9 & 174.7 & 763.5 & 763.5 \\
Geo. St. Dev. & 1.99 & 1.9 & 1.91 & 1.93 & 1.93 \\
Total Conc. & $3.64 \times 10^{3}$ & 0.359 & $\begin{array}{l}1.69 \times 10^{8} \\
\left(\mathrm{~nm} / \mathrm{cm}^{3}\right)\end{array}$ & $\begin{array}{l}6.41 \times 10^{9} \\
\left(\mathrm{~nm}^{3} / \mathrm{cm}^{3}\right)\end{array}$ & $\begin{array}{l}6.41 \\
\left(\mu \mathrm{g} / \mathrm{m}^{3}\right)\end{array}$ \\
\hline \hline
\end{tabular}

A decrease in particle size was observed as the biodiesel percentage was increased. This trend is similar to trends observed in the literature, but could use additional confirmation. The middle mixtures have two apparent modes of particles with the small mode becoming increasingly more significant as the biodiesel percentage increases. As the mixtures pass through a 50/50mixture, there is an increase in both sizes, probably indicating some interaction between the fuel mixture and the engine performance.

\subsubsection{Discussion}

As expected the extinction emission factors varied based on the particle number, size distribution of particles and particle composition. However a common trend was not seen between all of the parameters. Extinction at 1064 decreased linearly as the biodiesel content increases while extinction at 532 had a peak at B50 and the lowest extinction at B99 followed by B5. Scattering emission factors had a similar trend to the particle count emission factors with B50 being the highest, B5 the lowest followed by B99. The 
different trends appear to be related to both particle composition and size. As the content of biodiesel increases in the fuel, the organic content of the emissions is also expected to increase. Organic compounds tend to have a wavelength dependent extinction signature, with a higher extinction in shorter wavelength light and very little extinction in the near IR. Additionally smaller particles tend to have lower extinctions at longer wavelengths. The combination of more organic content and smaller particles may be responsible for the decreasing $1064 \mathrm{~nm}$ extinction signature. The extinction at $532 \mathrm{~nm}$ seems to be more related to total particle number and particle size than the content of the emission particles. The mixture with the highest particle count in the accumulation size range tended to have the highest $532 \mathrm{~nm}$ extinction.

The B50 mixture had the largest particle count overall and in both the accumulation and Aitken mode . The increase in particles is associated with increasing extinction and scattering and reflected in the results. The B50 particle number emission factor was two times higher than all other fuels indicating that there was an increase in both the amount of solid and vapor phase particulate emission formed. When this trend is investigated alongside the other mixtures, B50 emissions have larger peaks in both the accumulation and Aitken modes as seen in Figure 16. The accumulation mode peak occurs at a smaller size than the B5 peak, indicating that the particulate has had less time to age or that the particles formed were smaller in size than B5 particles. One possible reason for this emission signature is that biodiesel is more polar than diesel so even when the fuels are 
well mixed, separation between the two fuels is possible. If this separation occurs on a micro-emulsion level the fuel injected into the combustion chamber could have various areas that are biodiesel rich and areas that are diesel rich. The biodiesel rich areas would have higher oxygen content and tend to lead to the formation of primary hydrocarbon or other volatiles. The diesel rich areas would tend to lead to more incomplete combustion and higher soot formation. The mixture would typically be injected sooner than diesel alone, giving any soot formed more time to oxidize before leaving the combustion chamber. Additionally, mixing the two fuels with different polarities can result in precipitation of high molecular weight oxidation products as insoluble particles which would tend to increase ash formation.

The emissions from B99 had only a small number of larger particles compared with the other fuel emissions tested; indicating the overall mass concentration from the B99 emissions would be lower than the other biodiesel mixtures. This is consistent with trends observed in literature for both the particle size distribution and particle mass emissions of pure biodiesel.

The larger particles and therefore larger calculated mass for B5 compared with the other mixtures highlights the importance of measuring not only the total mass but also particle size distribution and composition. Radiative forcing in the atmosphere and toxicity to humans are linked to both particle size and composition, a mass measurement (note that 
the mass inferred using a uniform density deterministically decreases with increasing biodiesel content) would have missed the increase in the total particle number and the shift in the GMD to a smaller size observed here.

\section{3 $\mathrm{NO}_{\mathrm{X}}$ Emissions}

$\mathrm{NO}_{\mathrm{X}}$ emissions from diesel vehicles are thought to be formed by one of two proposed mechanisms, thermal or prompt. Thermal $\mathrm{NO}_{\mathrm{X}}$ formation occurs via the disproportionation shown in Reaction 2.

$$
\mathrm{N}_{2}+\mathrm{O}_{2} \leftarrow \rightarrow 2 \mathrm{NO}
$$

As the temperature in the engine increases, this reaction shifts to the right and rapid cooling of the exhaust as it leaves the combustion chamber causes the gases to be 'trapped' in the high temperature equilibrium concentration state. The Thermal $\mathrm{NO}_{\mathrm{X}}$ pathway is the primary contributor to $\mathrm{NO}_{\mathrm{X}}$ emissions from petroleum diesel combustion in a diesel engine. However, when hydrocarbon radicals react with nitrogen in the combustion chamber, nitrogen containing fragments that can react with atmospheric nitrogen are formed via the prompt pathway. This type of NOx formation occurs in fuel rich environments. The accepted pathway for the formation of prompt NOx is given in Reactions 3-7. 


$$
\begin{aligned}
& \mathrm{CH}+\mathrm{N}_{2} \leftarrow \rightarrow \mathrm{HCN}+\mathrm{N} \\
& \mathrm{CH}_{2}+\mathrm{N}_{2} \leftarrow \rightarrow \mathrm{HCN}+\mathrm{NH} \\
& \mathrm{N}+\mathrm{O}_{2} \leftarrow \rightarrow \mathrm{NO}+\mathrm{O} \\
& \mathrm{HCN}+\mathrm{OH} \leftarrow \rightarrow \mathrm{CN}+\mathrm{H}_{2} \mathrm{O} \\
& \mathrm{CN}+\mathrm{O}_{2} \leftarrow \rightarrow \mathrm{NO}+\mathrm{CO}
\end{aligned}
$$

It has been suggested that unsaturated methyl esters can cause a higher number of hydrocarbon radicals in the fuel rich zones of diesel spray compared to saturated methyl esters. ${ }^{160} \mathrm{An}$ increase in hydrocarbon radicals leads to an increase in the amount of $\mathrm{HCN}$ and thus $\mathrm{NO}_{\mathrm{x}}$ formed. The fuel blends of diesel and biodiesel in the middle range may also produce more of the fuel rich areas and thus hydrocarbon radicals, leading to more NO formation.

Published values for $\mathrm{NO}_{\mathrm{X}}$ emissions range from $0.45 \mathrm{gkg}^{-1}$ to $15.87 \mathrm{gkg}^{-1}$, with the higher values being observed in exhaust from older or poorly maintained vehicles. The ranges of emission factors found in this study are on the lower end of published values for light duty diesel vehicles. This finding is reasonable because the test vehicle is a newer model vehicle and has been on a regular maintenance schedule. 
All biodiesel blends had a higher $\mathrm{NO}_{\mathrm{X}}$ emission factor when compared with $\mathrm{B} 5$. When the results from this study are compared with the engine dynamometer study results described earlier, a similar trend is found for $\mathrm{NO}_{\mathrm{X}}$, as shown in Figure $19 .{ }^{102}$ Only B5, B25 and B95 were included in the comparison. The similarity in the trend lends credibility to our experimental protocol. The EPA relationship, shown in Equation 12 is also plotted in Figure 23 The EPA relationship was developed from a compilation of emission testing completed on vehicles fueled with B0, B20 and B100.

$$
\mathrm{NO}_{\mathrm{x}}=\mathrm{NO}_{\mathrm{xD}} \mathrm{e}^{0.0009794(\% \mathrm{~B})}
$$

Comparison between the EPA results and B5, B25 and B95 results from this work show a similar relationship between percentage of biodiesel in fuel mixtures and measured $\mathrm{NO}_{\mathrm{X}}$ emissions. This similarity indicates that the ambient sampling method used in this work is capturing the same emission signature as the methods summarized in the EPA study. 


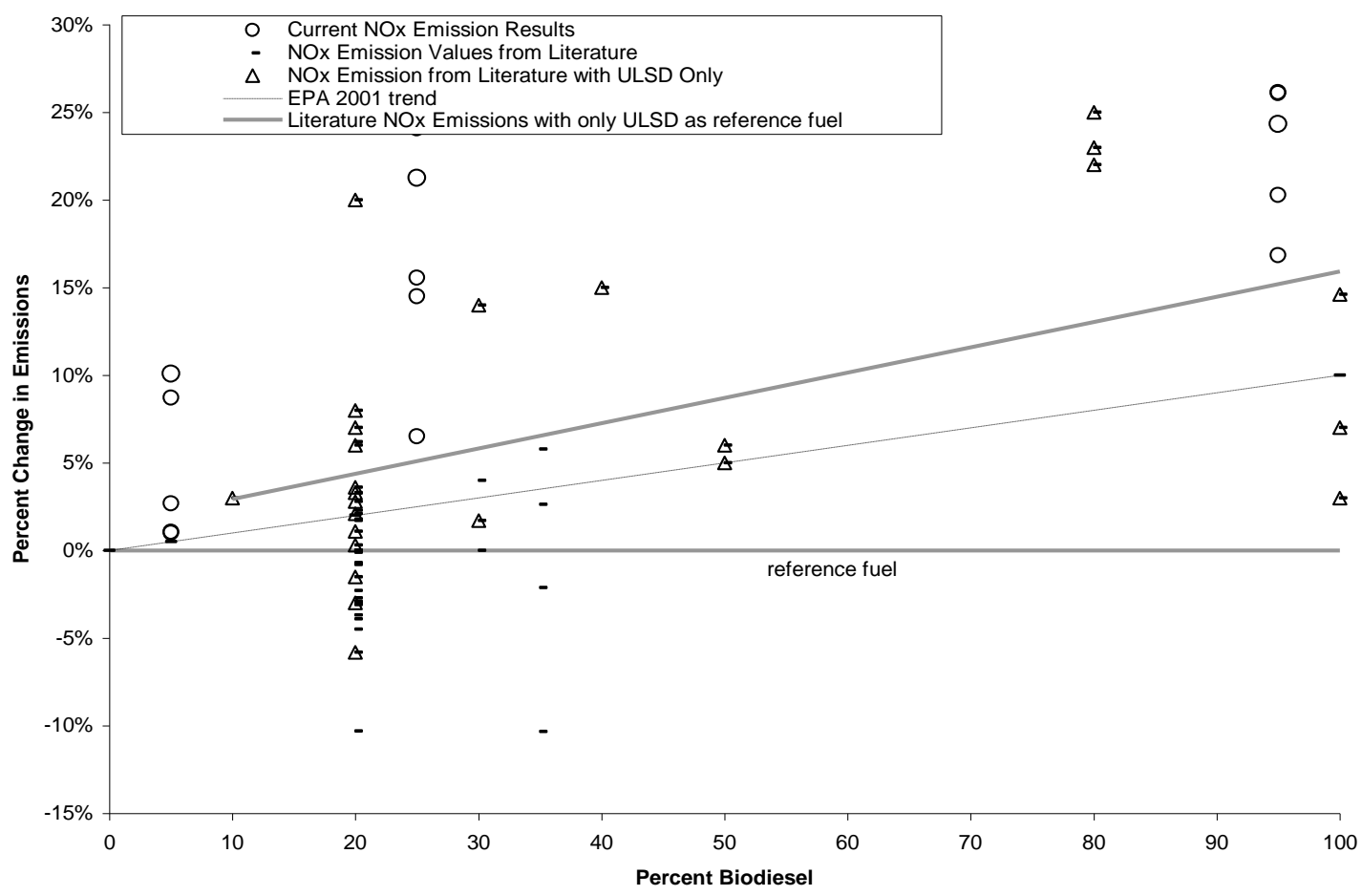

Figure 23: Comparison of percent change in $\mathrm{NO}_{\mathrm{x}}$ emissions with biodiesel use from this study and literature data. Only B5, B25 and B95 were used for this comparison.

When the middle range mixtures are considered, a non-monotonic increase in the $\mathrm{NO}_{\mathrm{X}}$ obtained with increasing biodiesel content is observed, this may be in contradiction to (or in addition to) the assessment of the literature results provided by EPA.

This significant difference in the behavior of measured properties at "middle" concentrations was observed for all emission tests conducted in this study, except for the $1064 \mathrm{~nm}$ extinction. The EPA relationship was established without a large body of experimental data in this range. Considering fuel properties and engine function, a large 
increase in $\mathrm{NO}_{\mathrm{x}}$ for the 50/50 blend is not unreasonable. The combination of biodiesel's higher cetane number, which creates an earlier fuel injection, and higher oxygen availability have been shown to contribute to higher combustion temperatures and therefore more NO formation for fuel blends. An increase in NO formation due to diffuse combustion is also expected in regions with oxygen-fuel ratios around the stochiometric ratio. ${ }^{159}$ For biodiesel this ratio is $\sim 2.81$ and for diesel it is $\sim 3.58$. The 50/50 blend of biodiesel and diesel has the largest stochiometric oxygen-fuel ratio range of all of the mixtures tested. A large aromatic content can also contribute to higher NO formation because there are increased $\mathrm{CH}$ radicals. The $\mathrm{B} 50$ mixture contains twice the aromatics from the diesel used compared to the B99 mixture, which may also help explain the higher $\mathrm{NO}_{\mathrm{X}}$ values observed from the $\mathrm{B} 50$ mixture.

\subsection{Absorption and LAC Emission Factors}

To calculate the absorption emission factors, the extinction emission factor for a given mixture was subtracted from the scattering emission factor for that pollutant. These are shown along with the LAC emission factors in Table 15. The LAC emission factors were calculated from the absorption emission factors using the recommended MAC conversion factor for fresh fossil-fuel combustion aerosol of $7.5 \pm 1.2 \mathrm{~m}^{2} \mathrm{~g}^{-1}$ at $550 \mathrm{~nm} .{ }^{99}$ This

calculation assumes that all of the absorbing material is soot. ${ }^{141}$ 
Table 15: Calculated Absorption and LAC emission factors.

\begin{tabular}{lll}
\hline \hline Mixture & $\begin{array}{l}\text { Absorption } \\
532 \mathrm{~nm}\left(\mathrm{~m}^{2} \mathrm{~kg}^{-1}\right)\end{array}$ & $\begin{array}{l}\text { LAC } \\
\left(\mathrm{gkg}^{-1}\right)\end{array}$ \\
\hline \hline B5 & $3.10 \pm 1.37$ & $0.41 \pm 0.47$ \\
B25 & $3.52 \pm 1.28$ & $0.47 \pm 0.40$ \\
B50 & $3.65 \pm 1.36$ & $0.49 \pm 0.40$ \\
B75 & $3.18 \pm 1.97$ & $0.42 \pm 0.64$ \\
B99 & $2.33 \pm 1.59$ & $0.31 \pm 0.70$ \\
\hline \hline
\end{tabular}

Published emission factors for PM for diesel vehicles range between 0.25 and $10.50 \mathrm{gkg}^{-}$

1. The upper end values are from heavy duty, older or improperly running vehicles. The values found in this study are on the low side for light duty diesel vehicles, but still within the published range for vehicles of this type. The middle mixtures were consistently higher than either B5 or B99.

The general trend of decreasing LAC emissions with increasing biodiesel content was not seen in these experiments. When only the B5 and B99 LAC emission factors are considered, there is approximately a 75\% decrease in LAC emissions. This is consistent with the EPA study. However, the relationship between biodiesel content and LAC emissions was not found to be linear or even monotonic, as with the other properties. The elevated emissions in the middle mixtures may be related to the increased number of particles emitted in conjunction with less efficient combustion of the 50/50 mixture. During the testing, the vehicle operator noted that the test vehicle was 'running rough' when fueled with the B50 mixture indicating that the fuel may have caused the engine to operate less efficiently. 
A factor to consider when evaluating these results is that all absorbing particles are assumed to be fresh soot in the LAC emission factor calculation. While fresh soot likely makes up the majority of the B5 mixture, it is possible that the higher percentage biodiesel fuels have emissions with either fresh soot coated with non-absorbing material or absorbing organic carbon material called brown carbon. Soot particles coated with non-absorbing or less absorbing material tend to have increased absorption due to the increase in photons focused on the absorbing particle by the scattering shell material. A number of studies have examined the influence of non-absorbing coatings on the mass absorption coefficient of soot. Results indicate that these coatings can enhance the MAC by $30-50$ percent for particles in the Aitken size range. ${ }^{36}$ Alder et al. (2010) compared computationally derived MAC values for diesel soot particles and coatings created by the organic carbon from incomplete combustion. ${ }^{118}$ The findings indicate that for calculations using the Rayliegh-Deby-Gans Theory (RDG) for soot particles in Aitken range ( 25 $\mathrm{nm})$, the MAC increased by $28-34 \%$ when the same particles were coated with an equal diameter of OC. If the emissions from the higher percentage biodiesel fuel does consist of non-absorbing organic carbon coatings, the LAC emission factors for these fuels would be lower than what is reported here. 


\subsection{Intensive Optical Properties}

Using the optical emission factors calculated for extinction and scattering at $532 \mathrm{~nm}$ and extinction at $1064 \mathrm{~nm}$, the single scattering albedo and Ångström exponent were calculated. Calculating these intensive properties from emission factors rather than the base measurements helps to reduce the background interference for these parameters.

The single scattering albedo represents the relative magnitude of scattering versus absorption for an aerosol. The single scattering albedos are given in Table 16. Fresh diesel light absorbing carbon typically has a single scattering albedo between 0.38 and $0.50^{134}$. Higher single scattering albedos indicate that scattering is more dominant than absorption. This could be a result of scattering decreasing or absorption increasing, and may also indicate the presence of more non-black absorbing aerosols. A chamber study by Schnaiter et al., 2003 showed that soot coated with organic matter had a higher single scattering albedo than pure soot. ${ }^{151}$ All $\omega_{532}$ for this experiment were between 0.32 and 0.43 indicating the fresh emission particles were highly absorbing, but that scattering became more important with biodiesel content. The B99 had the largest single scattering albedo, indicating there may be more "white" organic material in the emissions from this fuel. 
The Ångström exponent Å gives an indication of particle size. Values greater than two are typically found for particles under $100 \mathrm{~nm}$ and Angstrom exponents less than one are associated with particles over $500 \mathrm{~nm} .{ }^{37}$ For this experiment, $\AA$ increased with the content of biodiesel in the fuel. This is consistent with the formation of a larger number of smaller particles with increased percentage of biodiesel in the fuel mixture, but diesel PM is already quite small, so we suggest an alternative interpretation to this data.

Table 16: Calculated Ångström Exponent and Single Scattering Albedo.

\begin{tabular}{lll}
\hline \hline Mixture & Single Scattering Albedo & $\begin{array}{l}\text { Angstrom Exponent } \\
\mathrm{E}_{532} / \mathrm{E}_{1064}\end{array}$ \\
\hline \hline B5 & $0.32 \pm 0.68$ & $0.91 \pm 0.37$ \\
B25 & $0.34 \pm 0.40$ & $1.12 \pm 0.46$ \\
B50 & $0.40 \pm 0.28$ & $2.03 \pm 0.34$ \\
B75 & $0.42 \pm 0.48$ & $2.05 \pm 0.90$ \\
B95 & $0.43 \pm 0.72$ & $2.06 \pm 0.86$ \\
\hline \hline
\end{tabular}

Diesel particle emissions generally contain a substantial fraction of black carbon. The extinction for these small particles is dominated by absorption, which has a weak wavelength dependence with an Ångström exponent close to one. ${ }^{39}$ Higher Ångström exponent values may indicate stronger absorption at shorter wavelengths, produced by a stronger spectral dependence from non-BC organics or BC coated with a less absorbing material. ${ }^{67}$ A 2004 filter based study by Kirchstetter et al. measured aerosol light absorption by particles from biomass burning and motor vehicles. ${ }^{160}$ The motor vehicle exhaust particles had Ångström exponents near one, and the biomass emissions had Ångström exponents that were 2 or greater. When the organic component of the biomass 
emissions was removed by extraction with acetone, the spectral dependence was strongly diminished, indicating that organic matter can increase the Ångström exponent. In this study, the emissions from B5 and B25 mixtures have Ångström exponents close to 1, typical for black carbon emissions. The mixtures with a larger fraction of biodiesel have values closer to 2 , indicating there may be more absorbing organic matter in the emissions. Additionally, Gyawali et al. (2009) have demonstrated that BC cores that are coated in scattering shells can have an AAE that deviates from the typically assumed value of $1 .{ }^{162}$

The Ångström exponent is plotted versus the single scattering albedo in Figure 24. In this way, the emission signature from the different mixture fuels can be compared to one another. As the biodiesel percentage increases, both the single scattering albedo and the Ångström exponent increase. The B5 and B25 have intensive property values closer to typical diesel emissions, while the mixtures B50 and above have more of the signature of black carbon mixed with absorbing organic aerosol. 


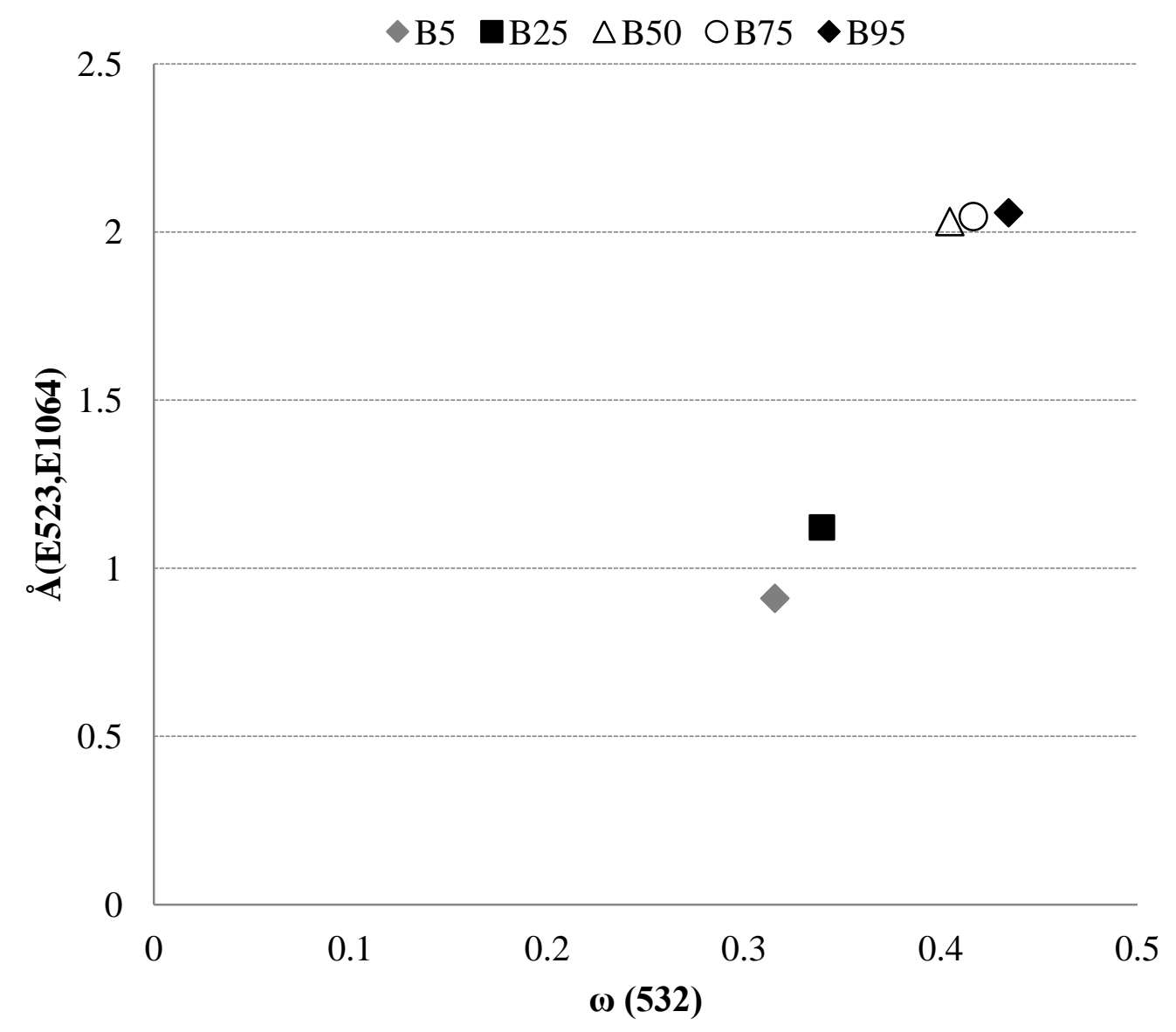

Figure 24: Angstrom Exponent vs. Single Scattering Albedo.

To further solidify the conclusion that the larger percentage of biodiesel in the fuel mixture results in particles with increased organic content, optical properties would need to be measuered at additional wavelengths, especially an ultraviolet wavelength where brown carbon would be expected to absorb more strongly. The Ångström exponent is expected to increase as the distance between the wavelengths increases for organic absorbing material. 


\subsection{SEM Results}

The percentage of biodiesel in the fuel blend affected the structure of the emission particles in the samples collected for this study. Combustion soot particles typically show an aggregated morphology while emissions from low temperature flames or fuels combusted under non-stochiometric conditions tend to have emissions with a higher organic fraction resulting in liquid or bead like appearance. ${ }^{132,126}$ In SEM images, the organic fraction usually causes the filter fibers to appear to be swollen and the particles appear as bumps or beads along the fibers.

Particles from a B5 sample are shown in Figure 25 (on the left). These emission particles appear to be more fractal than the B50 particles (on the right). The B5 particles show similar fractal like characteristics to those typically seen for fresh soot particles. The particles from the B50 emissions appear more bead-like and are almost completely coating the filter fibers. 

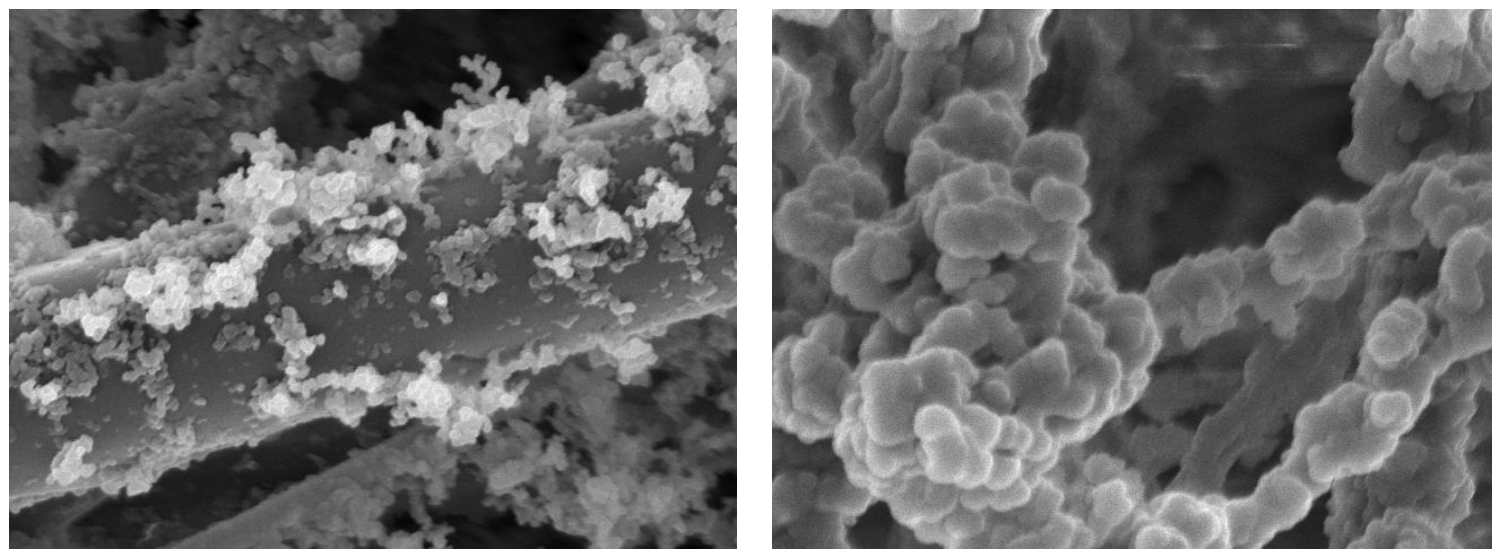

Figure 25: B5 and B50 emission particles as imaged with an SEM. These particles were coated for 90 seconds and are shown at a $1 \mu \mathrm{m}$ scale.

Figure 26 shows SEM images from the remainder of the mixtures. Again, all of the images are at a $1 \mu \mathrm{m}$ scale. Starting at the top and moving down the images show B25, B75 and B99 respectively. The lower percent biodiesel particles (B25) appear to be smaller fractal chains of individual particles. B75 and B99 have smaller particle sizes but the fractal network look more extensive and clumped. 

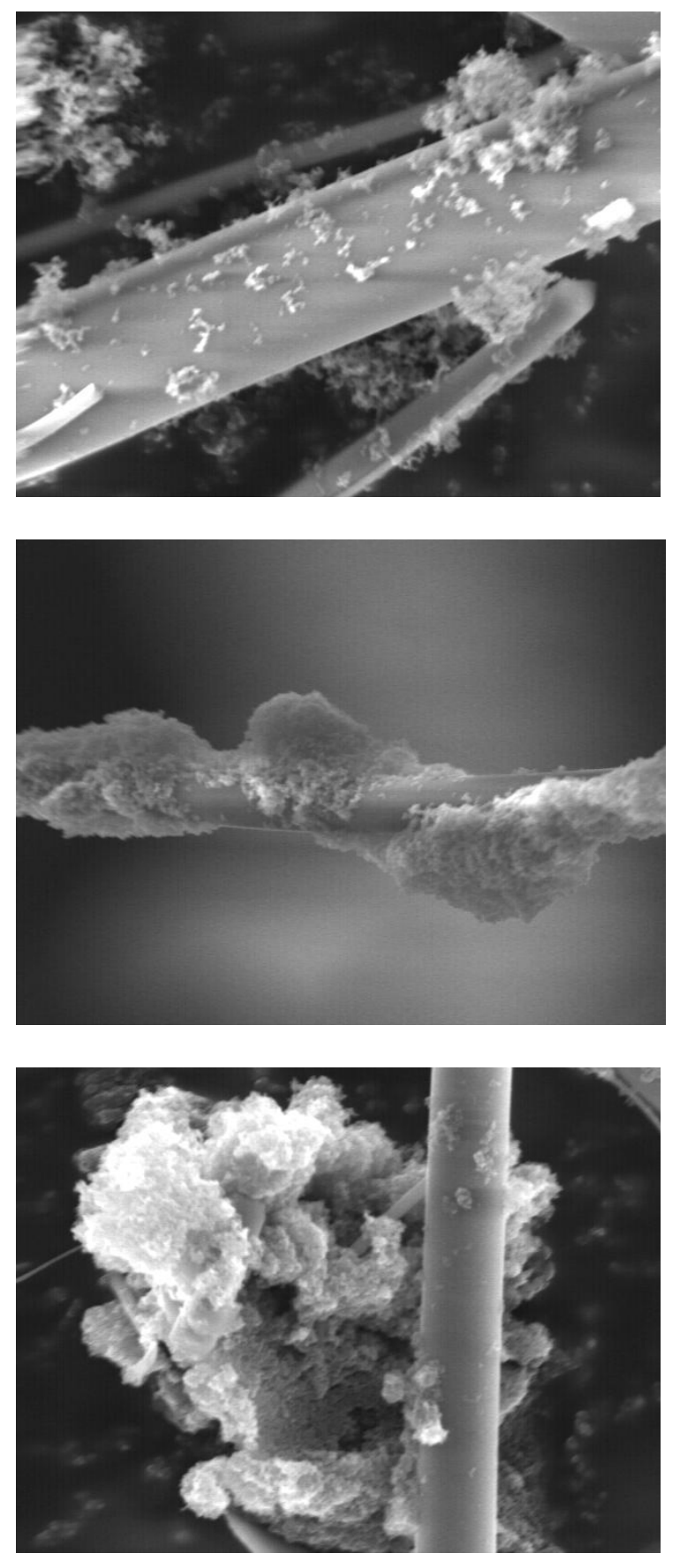

Figure 26: B25, B75 and B99 emission particles as imaged with an SEM. These particles were coated for 90 seconds and are shown at a $1 \mu \mathrm{m}$ scale. 
Overall, B50 appears the most like organic carbon emissions while B5 and B25 emissions most resemble fresh diesel emissions. ${ }^{132}$

\subsection{Conclusions}

The goal of this research project was to investigate biodiesel particulate emissions based on the number and optical property emissions with a novel instrumentation and sampling protocol. Incorporating the CRDT with other instruments allowed for a more complete understanding of particle composition and the various fates of particles in the atmosphere once emitted. The CRDT instrument is sensitive to the small changes in absorption between the different mixtures allowing for a more complete understanding of how the emissions of the various mixtures tested differ. Additionally the CRDT can make measurements in near real-time which allows for sampling under ambient conditions.

Based on results from this study, it is clear that combustion conditions in a given engine vary based on the percentage of biodiesel used in the diesel fuel. The decrease in particulate mass emissions as a function of increasing biodiesel concentration seen in previous studies may be related to a decrease in the mean particle size, not in a reduction in particle number emissions. The optical property emission factors indicate that the increased biodiesel content in the fuel results in emissions that have a higher percentage of organic matter, and it is likely that the organic matter acts as a coating on soot particles 
formed during combustion, which enhanced extinction measurements. Increased emissions with higher extinction emission factors can contribute to a decrease in visibility.

The light extinction caused by scattering and absorption by particles and gases is related to visibility effects. In this study, the B50 mixture had the highest extinction emission factor for all of the mixtures studies. The LAC emissions from B50 were also highest, but this value may be artificially elevated by the assumption that all of the emission particles were fresh soot. The intensive optical property emission factors indicate that the emissions from B50, B75 and B99 have the signature of mixed aerosol, specifically fresh soot coated in non-absorbing organic material. This finding, that B5 and B25 have more of a soot emission signature and B50-B99 are increasingly more organic is supported by SEM measurements. Adjusting the MAC by $\sim 30 \%$ would reduce the LAC emission factors from B50-B99 and B5 and B25 would then have the largest LAC emissions. Light absorption by aerosols heats the local atmosphere because absorbed energy is reradiated as long wave radiation or non-radiatively coupled to the air that the particles are suspended in. Interactions with gases or aerosols that are able to absorb the long wave radiation will result in a localized warming of the atmosphere. ${ }^{54}$

The extent that emissions from a vehicle impact climate is related to the optical properties of the particles and to particle lifetime in the atmosphere. The longer emission particles 
are in the atmosphere, the more impact the particles will have. A large particle that is quickly removed from the atmosphere via dry deposition will only have a localized impact very close to the emission source. Smaller particles that are less likely to follow an immediate deposition pathway can travel further distances and have a regional or global impact. Typically particles grow through coagulation and condensation until they follow a wet or dry deposition pathway.

The size ranges for diesel emissions are typically between $10 \mathrm{~nm}$ and $500 \mathrm{~nm} .{ }^{56}$ For particles in the approximate $40 \mathrm{~nm}$ to $300 \mathrm{~nm}$ size ranges one of the main removal pathways is as cloud condensation nuclei $(\mathrm{CCN}) .{ }^{142} \mathrm{CCN}$ are aerosol particles that facilitate the condensation of water vapor and formation of cloud droplets at various levels of water vapor saturation. However, the ability of a particle to act as a CCN is related to both the size of the particle and the particle composition. ${ }^{138}$ The higher the organic content in the particle regardless of the size, the lower the overall hygroscopicity of the particle. In this study the B99 mixture has the smallest number concentration of particles in the $\mathrm{CCN}$ range, with the majority of B99 particle numbers smaller than the typical CCN particle. Based on the intensive optical property emission factors, B99 also had the most organic signature. This indicates that emissions from pure biodiesel are less likely to act as $\mathrm{CCN}$ than emissions from the other mixtures near the emission source. Based on the size distributions and the intensive optical property measurements, increasing the diesel concentration in the fuel mixture increases the likelihood for the 
emissions to form CCN particles also increases. Large numbers of particles with a high $\mathrm{CCN}$ formation likelihood can increase indirect radiative forcing due to increased cloud formation and may negatively alter the hydrologic cycle. ${ }^{64}$

The mixture with the lowest biodiesel content, B5 had the smallest particle number emission factor for all mixtures tested. The size distribution for this plume indicated that this mixture also had the largest mean particle diameter. These findings indicate that the use of biodiesel and diesel fuel mixtures in diesel vehicles is likely to increase exposure to nucleation, Aitken and accumulation mode particles under $100 \mathrm{~nm}$. So, while the overall mass emission factors may be smaller when biodiesel is mixed with diesel, the potential for increased exposure to higher particle numbers is greater.

The mixture with the highest particle number emission factor was B50, indicating that mixing two different fuels results in sub-optimal combustion conditions for both of the fuels. $\mathrm{B} 50$ also had the highest $\mathrm{NO}_{\mathrm{X}}$ emissions and the highest extinction. This combination of high particle numbers in all size ranges, increased extinction and increased $\mathrm{NO}_{\mathrm{X}}$ emissions indicated that using either $\mathrm{B} 5$ or $\mathrm{B} 99$ fuel is a better option than mixing the two fuels for this particular emission scenario. 


\subsection{Recommendations for Future Research}

This study has demonstrated that mass based emission studies do not adequately address emissions from vehicles by particle number, size or general composition all of which directly affect both human health and climate. The majority of data available regarding biodiesel particulate emissions are from mass based particulate measurements. Mass based emissions answer questions about the ability of a fuel to meet current regulatory standards, but miss important information about particle size and composition needed to understand how changing a fuel will ultimately impact human health or climate. This study provided useful information regarding the various emission properties from biodiesel, but it is only a starting point, and more meaningful scientific research on biodiesel emissions are still needed.

Based on the findings presented here, it is clear that two additions to the measurements taken would greatly enhance current information on biodiesel emissions. First, particle size distribution measurements should be completed so that actual emission factors can be determined for each of the size bins. The size of particles impacts how particles act in the atmosphere and in the human body, so a more complete understanding of the potential size distributions on various mixtures of biodiesel will allow for more accurate

modeling of health and climate impacts. Second, the addition of scattering measurements at $1064 \mathrm{~nm}$ and $355 \mathrm{~nm}$ and an extinction measurement at $355 \mathrm{~nm}$ would allow for a more robust determination of the intensive optical properties of the emissions. This will 
help in determining how emissions will influence climate and provide a general understanding of the particle composition. 


\section{References}

(1) Adams, P. J.; Seinfeld, J. H.; Koch, D. M. J. Geophys. Res. 1999, 104, 791-713, 823

(2) Almeida, S. M.; Pio, C. A.; Freitas, M. C.; Reis, M. A.; Trancoso, M. A. Atmospheric Environment 2006, 40, 2058-2067

(3) Andreae, M. O.; Crutzen, P.J. Science 1997, 276, 1052-1056

(4) Bond, T., C.; Bhardwaj, E.; Dong, R.; Jogani, R.; Jung, S.; Roden, C. Global Biogeochem. Cycles 2007, 21, GB2018, doi:10.1029/2006GB002840

(5) Buzcu, B.; Fraser, M. P. Atmospheric Environment 2006, 40, 2385-2400

(6) Heald, C. L. J. Geophys. Res 2006, 111 D12106, doi:10.1029/2005JD006548

(7) Krejci, R.; Strom, J.; de Reus, M.; Williams, J.; Fischer, H.; Andreae, M. O.; Hansson, H. C. Atmospheric Chemistry and Physics 2005, 5, 1527-1543

(8) Nyanganyura, D.; Maenhaut, W.; Mathuthua, M.; Makarau, A.; Meixner, F. X. Atmospheric Environment 2007, 41, 2644-2659

(9) Reddy, M. S.; Venkataraman, C. Current Science 1999, 76, 1005-1011

(10) Satheesh, S. K.; Moorthy, K. K. Atmospheric Environment 2005, 39, 2089-2110

(11) Seinfeld, J. H.; Carmichael, G. R.; Arimoto, R.; Conant, W. C.; Brechtel, F. J.; Bates, T. S.; Cahill, T. A.; Clarke, A. D.; Flatau, P.; Huebert, B. J.; Masonis, S. J.; Quinn, P. K.; Russell, L. M.; Russell, P. B.; Shimizu, A.; Shinozuka, Y.; Song, C.; Tang, Y.; Uno, I.; Weber, R. J.; Woo, J. H.; Zhang, X. Y. Bull. Am. Meteorol. Soc 2004, 85, 367-380

(12) Shine, K. P.; Forster, P. M. D. Global and Planetary Change 1999, 20, 205-225

(13) Smirnov, V. V. Izvestiya Atmospheric and Oceanic Physics 2006, 42, 663-687

(14) Thornes, J. E. (2002), IPCC, 2001, edited by J. J. McCarthy, O. F. Canziani, N. A. Leary, D. J. Dokken and K. S. White (eds). Cambridge University Press, Cambridge, UK, and New York, USA, 2001 Int. J. Climatol., 22: 1285-1286. doi: 10.1002/joc.775IPCC

(15) Krzyzanowski, M., Kuna-Dibbert, B., Schneider, J., Editors. World Health Organization 2005 
(16) Kunzli, N., Kaiser, R., Medina, S., Studnicka, M., Chanel, O., Filliger, P., Herry, M., Horak, F., Puybonnieux-Texier, V., Quenel, P., Schneider, J., Seethaler, R., Vergnaud, J.C., Sommer, H. Lancet 2000, 356 795-801

(17) Schlesinger, R. B., Kunzli, N., Hidy, G.M., Gotschi, T., Jerrett, M. Inhalation Toxicology 2006, 18, 95-125

(18) NARSTO; P. McMurry; M. Shepherd; J. Vickery, Eds. Particulate Matter Assessment for Policy Makers: A NARSTO Assessment. ; Cambridge University Press: Cambridge, England, 2004

(19) Pahl, G. Biodiesel: Growing a new energy economy; Chelsea Green Publishing: White River Jct., VT, 2004

(20) Tsolakis, A. Energy and Fuels 2006, 20 1418-1424

(21) Park, K., Kittelson, D.B., McMurry, P.H. Aerosol Science and Technology 2004, 38 881-889

(22) Rodriguez, S.; Van Dingenen, R.; Putaud, J. P.; Dell'Acqua, A.; Pey, J.; Querol, X.; Alastuey, A.; Chenery, S.; Ho, K. F.; Harrison, R.; Tardivo, R.; Scarnato, B.; Gemelli, V. Atmospheric Chemistry and Physics 2007, 7, 2217-2232

(23) Poschl, U. Angewandte Chemie-International Edition 2005, 44, 7520-7540

(24) Miller, R. L.; Tegen, I.; Perlwitz, J. Journal of Geophysical ResearchAtmospheres 2004, 109

(25) Nemesure, S., Wagener, R., Schwartz, S.E. Journal of Geophysical Research 1995, 100 26105-26116

(26) Penner, J. E., Andreae, M,. Annegarn, H., Barrie, L., Feichter, J., Hegg, D., Jayaraman, A., Leaitch, R., Murphy, D., Nganga, J., Pitari, G. In Climate Change 2001: the Scientific Basis; Cambridge University Press 2001

(27) Ramanathan, V., Garmichael, G. Nature Geoscience 2008, 221-227

(28) Akasaka, Y., Suzuki, T., Sakaural, Y.; Society of Automotive Engineers: Warrendale, PA 1997

(29) Baik, D. S. International Journal of Automotive Technology 2006, 7, 653-658 
(30) Baik, D. S.; Han, Y. C. Journal of Mechanical Science and Technology 2005, 19, 870-876

(31) Bunger, J., Krahl, J. Baum, K., Schroder, O., Muller, M., Westphal, G., Ruhnau, P., Schulz, T.G., Hallier, E. Archives of Toxicology 2000, 74, 490-498

(32) Chung, A., Lall, A. A.,Paulson, S. E. Atmospheric Environment 2008, 42, 906915

(33) Corporan, E.; Reich, R.; Monroig, O.; DeWitt, M. J.; Larson, V.; Aulich, T.; Mann, M.; Seames, W. Journal of the Air \& Waste Management Association 2005, $55,940-949$

(34) Dorado, M. P., Ballesteros, E., Arnal, J.M., Gomez, J., Lopez, F.J. Fuel 2003, $821311-1315$

(35) Durbin, T. D.; Norbeck, J. M. Environmental Science \& Technology 2002, 36, 1686-1691

(36) Howes, P., Rideout, G.; National Biodiesel Board, MSED Report\#95-26743-1: Ottawa, Ontario, 1988

(37) Knothe, G.; Sharp, C. A.; Ryan, T. W. Energy \& Fuels 2006, 20, 403-408

(38) Krahl, J., Munack, A., Grope, N., Ruschel, Y., Schrőder, O., J. Bünger, J. Clean 2007, 35 417-426

(39) Leung, D. Y. C.; Luo, Y.; Chan, T. L. Energy \& Fuels 2006, 20, 1015-1023

(40) Lin, Y. C.; Lee, W. J.; Wu, T. S.; Wang, C. T. Fuel 2006, 85, 2516-2523

(41) Peterson, C.; Reece, D. Transactions of the Asae 1996, 39, 805-816

(42) Peterson, C. L.; Taberski, J. S.; Thompson, J. C.; Chase, C. L. Transactions of the Asae 2000, 43, 1371-1381

(43) Sharp, C., Howell, S., Jobe, J.; SAE Tech Pap Ser, No. 2000-01-1968., 2000

(44) Swanson, K. J., Madden M.C., Ghio, A.J. Environmental Health Perspectives 2007, 115, 496-499

(45) Turrio-Baldassarri, L., Battistelli, C.L., Conti, L., Crebelli, R., De Berardis, B., AIamiceli, A.L., Gambino, M., Iannaccone, S. Science of the Total Environmental 2004, 327 147-162 
(46) Wang, W. G., Lyons, D.W., Clark, N.N., Gautan. M., Norton, P.M.

Environmental Science and Technology 2000, 34 933-939

(47) Yuan, C. S.; Lin, H. Y.; Lee, W. J.; Lin, Y. C.; Wu, T. S.; Chen, K. F. Journal of the Air \& Waste Management Association 2007, 57, 465-471

(48) Lough, G. C.; Schauer, J. J.; Lawson, D. R. Atmospheric Environment 2006, 40, 4137-4149

(49) Park, R. J.; Jacob, D. J.; Kumar, N.; Yantosca, R. M. Atmospheric Environment 2006, 40, 5405-5423

(50) Rodriguez, S.; Van Dingenen, R.; Putaud, J. P.; Martins-Dos Santos, S.; Roselli, D. Atmospheric Environment 2005, 39, 6734-6746

(51) Schulz, M., et al. Atmos. Chem. Phys 2006, 6, 5225-5246

(52) Seinfeld, J. H.; Pandis, S. N. Atmospheric Chemistry and Physics: From Air Pollution to Climate Change. ; Wiley New York, 1998

(53) Coakley Jr., J. A.; Cess, R. D.; Yurevich, F. B. Journal of Atmospheric Science 1983 40, 116-138

(54) Houghton, J. T., et. al, Ed. Radiative Forcing of Climate Change and an Evaluation of the IPCC IS92 Emission Scenarios; Cambridge Univ. Press: New York, 1994

(55) Haywood, J.; Boucher, O. Reviews of Geophysics 2000, 38, 513-543

(56) Lane, T. E.; Pandis, S. N. Environmental Science \& Technology 2007, 41, 39843990

(57) Jacobson, M. Z. Journal of Geophysical Research-Atmospheres 2001, 106, 15511568

(58) Haywood, J. M.; Shine, K. P. Geophysics Research Letters 1995, 22 603-606

(59) Ghan, S. J.; Easter, R. C. Atmospheric Chemistry and Physics 2006, 6, 41634174

(60) Jacobson, M. Z. Nature 2001, 409, 695-697

(61) Chen, W.-T.; H. Liao; Seinfeld, J. H. J. Geophys. Res 2007, 112 
(62) Bates, T. S.; Anderson, T. L.; Baynard, T.; Bond, T.; Boucher, O.; Carmichael, G.; Clarke, A.; Erlick, C.; Guo, H.; Horowitz, L.; Howell, S.; Kulkarni, S.; Maring, H.; McComiskey, A.; Middlebrook, A.; Noone, K.; O'Dowd, C. D.; Ogren, J.; Penner, J.; Quinn, P. K.; Ravishankara, A. R.; Savoie, D. L.; Schwartz, S. E.; Shinozuka, Y.; Tang, Y.; Weber, R. J.; Wu, Y. Atmospheric Chemistry and Physics 2006, 6, 16571732

(63) Schulz, M., et al. Atmos. Chem. Phys 2006, 6, 5225-5246

(64) McFiggans, G.; Artaxo, P.; Baltensperger, U.; Coe, H.; Facchini, M. C.; Feingold, G.; Fuzzi, S.; Gysel, M.; Laaksonen, A.; Lohmann, U.; Mentel, T. F.; Murphy, D. M.; O'Dowd, C. D.; Snider, J. R.; Weingartner, E. Atmospheric Chemistry and Physics 2006, 6, 2593-2649

(65) Horvath, H. Journal of Environmental Radioactivity 2000, 51, 5-25

(66) Cattani, E.; Costa, M. J.; Torricella, F.; Levizzani, V.; Silva, A. M. Atmospheric Research 2006, 82, 310-327

(67) Samet, J. M.; Dominici, F.; Curriero, F. C.; Coursac, I.; Zeger, S. L. N Engl J Med 2000, 343, 1742-1749

(68) Dockery, D. W.; Pope, C. A. I.; Xu, X.; Spengler, J. D.; Ware, J. H.; Fay, M. E.; al., e. N Engl J Med 1993, 329, 1753-1759

(69) Pope, C. A. I. Environ. Health. Prespect. 2000, 108, 731-723

(70) Pope, C. A. I. Aerosol Sci. Tech 2000, 32, 4-14

(71) Frampton, M. W.; Stewart, J. C.; Oberdörster, G.; Morrow, P. E.; Chalupa, D.; Pietropaoli, A. P.; Frasier, L. M.; Speers, C. M.; Cox, C.; Huang, L. S.; Utell, M. J. Environ Health Perspect 2006, 114, 51-58

(72) Delucchi, M. A.; Prepared by Institute of Transportation Studies, University of California Davis: Davis, CA, 1999

(73) Oberdorster, G.; Oberdorster, E.; Oberdorster, J. Environmental Health Perspectives 2005, 113, 823-839

(74) Lippmann, M.; Frampton, M.; Schwartz, J.; Dockery, D.; Schlesinger, R. B.; Koutrakis, P.; Froines, J.; Nel, A.; Finkelstein, J.; Godleski, J.; Kaufman, J.; Koenig, J.; Larson, T.; Luchtel, D.; Liu, L.-J. S.; Oberdorster, G.; Peters, A.; Sarnat, J.; Sioutas, C.; Suh, H.; Sullivan, J.; Utell, M.; Wichmann, E.; Zelikoff, J. Environmental Health Perspectives 2003, 111, 1074-1092 
(75) Sarnat, J. A.; Kourtrakis, P.; Suh, H. H. Environmental Health Perspectives 2001, 109, 1053-1061

(76) Schlesinger, R. B.; Kunzil, N.; Hidy, G. M.; Gotschi, T.; Jerrett, M. Inhal. Toxicol. 2006, 18, 95-125

(77) Zhu, Y.; Hinds, W. C.; Kim, S.; Sioutas, C. Journal of Air and Waste Management Association 2002, 52, 1032-1042

(78) Delfino, R. J.; Sioutas, C.; Malik, S. Environ Health Perspect 2005, 113, 934946

(79) Pekkanen, J.; Timonen, K. L.; Mirme, A.; Ruuskanen, J.; A., R. Environ Res 1997, 74, 24-33

(80) Penttinen, P.; Timonen, K. L.; Tittannen, P.; Mirme, A.; Ruuskanen, J.;

Pekkanen, J. Environ Health Perspect 2001, 109, 319-323

(81) Sioutas, C.; Delfino, R. J.; Singh, M. Environmental Health Perspectives 2005, $113,947-955$

(82) Yamakoshi, K.; Umezawa, N.; Ryu, A.; Arakane, K.; Miyata, N.; Goda, Y. J. Am. Chem. Soc 2003, 125, 12803-12809

(83) Xia, T.; Korge, P.; Weiss, J. N.; Li, N.; Venkatesen, M. I.; Sioutas, C.; Nel, A. Environ Health Perspect 2004, 112, 1347-1358

(84) Li, N.; Sioutas, C.; Cho, A.; Schmitz, D.; Misra, C.; Sempf, J.; Wang, M.;

Oberley, T.; Nel, A. Environ Health Perspect 2003, 111, 455-460

(85) Cadle, S.; Mulawa, P.A.; Ball, J.; Donase, C.; Weibel, A.; Sagebiel, J.; Knapp, K.T.; Snow, R.;Environ. Sci. Technol 1997, 31, 3405

(86) Eiguren-Fernandez, A.; Miguel, A. H.; Jaques, P.; Sioutas, C. Aerosol Sci. Tech 2004, 38, 174-181

(87) Glovsky, M. M.; Miguel, A. G.; G.R., C. Allergy Asthma Proc 1997, 18, 163-166

(88) Wichmann, H.; Spix, C.; Tuch, T.; Wolke, G.; Peters, A.; J., H.; al., e. Res Rep Health Eff Inst 2000, 98, 5-86

(89) Chu, S. H.; Paisie, J. W. Atmospheric Environment 2006, 40, S206-S211

(90) Lonati, G.; Giugliano, M. Atmospheric Environment 2006, 40, S264-S274 
(91) Kittelson, D. B. Journal of Aerosol Science 1998, 29, 525 - 536

(92) Lall, R.; Thurston, G. D. Atmospheric Environment 2006, 40, S333-S346

(93) Imhof, D.; Weingartner, E.; Prevot, A. S. H.; Ordonez, C.; Kurtenbach, R.; Wiesen, P.; Rodler, J.; Sturm, P.; McCrae, I.; Ekstrom, M.; Baltensperger, U. Atmospheric Chemistry and Physics 2006, 6, 2215-2230

(94) Knothe, G., Van Gerpen, J., Krahl, J., Editors The BIodiesel Handbook; AOCS Press: Champaign, IL, 2005

(95) Icingur, Y., Altiparmak, D., Energy Conservation and Management 2001, 44, 389-397

(96) Kis, V. K.; Posfai, M.; Labar, J. L. Atmospheric Environment 2006, 40, 5533 5542

(97) Streets, D. G.; Bond, T. C.; Lee, T.; Jang, C. J. Geophys. Res 2004, 109

(98) Bagley, S. T., Gratz, L.D., Johnson, J.H., McDonnald, J.F. Environmental Science and Technology 1998, 32 1183-1191

(99) Bond, T. C.; Bergstrom, R. W. Aerosol Science and Technology 2006, 40, 27-67

(100) Wolf, M. E.; Hidy, G. M. Journal of Geophysical Research-Atmospheres 1997, $102,11113-11121$

(101) Myhre, G., Bellouin, N., Berglen, T.F., Berntsen, T.K., Boucher, O., Grini, A., Isaksen, I.S.A., Johnsrud, M., Mishchenko, M.I., Stordal, F., Tanre, D. Tellus Series B-Chemical and Physical Meteorology 2007, 59 115-129

(102) US-EPA; U.S. Environmental Protection Agency (U.S. EPA), 2002; EPA420$\mathrm{P}-02-001$

(103) Watson, J. G. J. Air Waste Manag. 200252 628-713

(104) Ganesh, D., Nagarajan, G., Ibrahim, M.M. Fuel 2008, 87, 3497-3503

(105) Agarwal, D.; Sinha, S.; Agarwal, A. K. Renewable Energy 2006, 31, 2356-2369

(106) Soltic, P., Edenhauser, D., Thurnheer, T., Schreiber, D., Sankowski, A. Fuel 2008, Volume 88, 1-8 
(107) Riberio, N. M., Pinto, A.C., Quintella, A.M., da Rocha, G.O., Teixeria, L.S.G., Guarrieiro, L.L.N, Rangel, M. d. C., Velogo, M. C., Rezende, M. J. C., de Cruz, R.S., de Oliveria, A. M., Torres, E. A., de Andrade, J. B. Energy \& Fuels 2007, 2433-2445

(108) SeQuential Biofuels, Biodiesel Specification Document 2006

(109) Morawska, L., Johnson, G., Ristovsk, Z.D., Agranovski, V. Atmospheric Environment 1999, 33 1983-1990

(110) Clayton, C. A.; Perritt, R. L.; Pellizzari, E. D.; Thomas, K. W.; Whitmore, R. W.; Wallace, L. W.; al., e. J Expo Anal Environ Epidemiol 1993, 3, 227-250

(111) Patashnick, H., Rupprecht, E. Journal of Air and Waste Management Association 1991, 41, , 1079-1083

(112) Clarke, A. Atmos. Env. 1987, 21, 1455-1465

(113) Lack, D. A.; Lovejoy, E. R.; Baynard, T.; Pettersson, A.; Ravishankara, A. R. Aerosol Science and Technology 2006, 40, 697-708

(114) Alebic-Juretic, A.; Zetzsch, C.; Doka, O.; Bicanic, D. Review of Scientific Instruments 2003, 74, 503-505

(115) Dwivedi, D., Agarwal, A.K., Sharma, M. Atmospheric Environment 2006, 5586-5595

(116) Wang, W. G.; Lyons, D. W.; Clark, N. N.; Gautam, M.; Norton, P. M. Environmental Science \& Technology 2000, 34, 933-939

(117) Pang, X. B.; Shi, X. Y.; Mu, Y. J.; He, H.; Shuai, S. J.; Chen, H.; Li, R. L. Atmospheric Environment 2006, 40, 7057-7065

(118) Adler, G., Riziq, A. A., Erlick, C., and Rudich, Y., 2010 P. Natl. Acad. Sci. USA, 107, 6699-6704

(119) Patashnick, H., Rupprecht, G., Ambs, J.L., Meyer, M.B. Aerosol Science and Technology 2001, 34 42-45

(120) Hinds, W. C. Aerosol Technology 2nd. ed.; Wiley: New York 1999

(121) Pagan, J. SAE Trans. J. Fuels Lubricants 1999, 108, 4, 557- 562

(122) Wang, S. C., Flagan, S.C. Aerosol Science and Technology 1990, 13 230-240

(123) Knutson, E. O., Whitby, K.T. Journal of Aerosol Science 1975, 6 443-451 
(124) Agarwal, J. K., Sem, G.J. Journal of Aerosol Science 1980, 11 343-357

(125) Slowik, J. G.; Stainken, K.; Davidovits, P.; Williams, L. R.; Jayne, J. T.; Kolb, C. E.; Worsnop, D. R.; Rudich, Y.; DeCarlo, P. F.; Jimenez, J. L. Aerosol Science and Technology 2004, 38, 1206-1222

(126) Kittelson, D. B. Journal of Aerosol Science 1998, 29, 575-588

(127) Sioutas, C., Abt, E., Wolfson, J.M., P. Koutrakis, P. Aerosol Science and Technology 1999, 30 84-92

(128) Finlayson-Pitts, B. J., Pitts,J.N. Chemistry of the upper and lower atmosphere, ; Academic Press 2000

(129) Schneider, J.; Hock, N.; Weimer, S.; Borrmann, S.; Kirchner, U.; Vogt, R.; Environ Sci Technol 2005,39, 6153-61

(130) Ziemba, L. D.; Dibb, J. E.; Griffin, R.; Anderson, C.; Whitlow, S. I.; Lefer, B. L.; Rappengluck, B.; Flynn, J. Atmospheric Environment 2008. 44, 4081-4089, doi:10.1016/j.atmosenv.2008.12.024

(131) Baynard, T.; Lovejoy, E. R.; Pettersson, A.; Brown, S. S.; Lack, D.; Osthoff, H.; Massoli, P.; Ciciora, S.; Dube, W. P.; Ravishankara, A. R. Aerosol Science and Technology 2007, 41, 447-462

(132) Verma, S.; Boucher, O.; Reddy, M. S.; Upadhyaya, H. C.; Le Van, P.;

Binkowski, F. S.; Sharma, O. P. Journal of Geophysical Research-Atmospheres 2007, 112

(133) O'Keefe, A.; Deacon, D. A. G. Rev. Sci. Instrum 1988

(134) Bulatov, V.; Fisher, M.; Schechter, I. Analytica Chimica Acta 2002, 466, 1-9

(135) Atkinson, D. B. Analyst 2003, 128, 117-125

(136) Moosmuller, H.; Varma, R.; Arnott, W. P. Aerosol Science and Technology 2005, 39, 30-39

(137) Radney, J.G.; Bazargan, M.H.; Wright, M.E.; Atkinson, DB (2009). Aerosol Science And Technology 2009, 43,71-80

(138) Satheesh, S. K.; Srinivasan, J.; Vinoj, V.; Chandra, S. Atmospheric Environment 2006, 40, 3008-3010 
(139) Seinfeld, J. H.; Pankow, J. F. Annual Review of Physical Chemistry 2003, 54, $121-140$

(140) Mazzoleni, C.; Kuhns, H. D.; Moosmu“ller, H.; Keislar, R. E.; Barber, P. W.; Robinson, N. F.; Watson, J. G.; Nikolic, D. J. Air \& Waste Manage. Assoc. 2004, 54, 5711-5726

(141) Lack, D., Lerner, B., Granier,C., Baynard, T., Lovejoy, E., Massoli, P., Ravishankara, A.R., Williams, E. Geophysical Research Letters 2008, 35

(142) Riziq, A. A.; Erlick, C.; Dinar, E.; Rudich, Y. Atmospheric Chemistry and Physics Discussions 2006, 6, 12347-12387

(143) Vasic, A. M.; Weilenmann, M. Environ. Sci. Technol. 2006, 40, 149-154

(144) Bond, T. C.; Anderson, T. L.; Campbell, D. Aerosol Sci. Technol. 1999, 30, $582-600$

(145) Lesins, G., Chylek, P., Lohmann, U. Journal of Geophysical Research 2002, 107

(146) Slowik, J. G.; Cross, E. S.; Han, J. H.; Davidovits, P.; Onasch, T. B.; Jayne, J. T.; WilliamS, L. R.; Canagaratna, M. R.; Worsnop, D. R.; Chakrabarty, R. K.; Moosmuller, H.; Arnott, W. P.; Schwarz, J. P.; Gao, R. S.; Fahey, D. W.; Kok, G. L.; Petzold, A. Aerosol Science and Technology 2007, 41, 295-314

(147) Lapuerta, M.; Martos, F.J.; Herreros, J.M.; J Aerosol Sci 2007, 38, 455-66

(148) Lefer, B.; Rappenglück, B. Atmospheric Environment 2008, 44,3997-4004, doi:10.1016/j.atmosenv.2010.05.053

(149) Rappenglück, B.; Perna, R.; Zhong, S.; Morris, G. A. Journal of Geophysical Research 2008, 113, D17315, doi:10.1029/2007JD009745

(150) Wright, M.E., Atkinson, D.B., Ziemba, L., Griffin, R., Hiranuma, N., Brooks, S.D., Lefer, B., Flynn, J., Perna, R., Rappenglück, B., Luke, W., Kelley, P.

Atmospheric Environment, 2008, 10.1016/j.atmosenv.2008.12.055

(151) Bates, T. S., Quinn, P. K., Coffman, D., Schulz, K., Covert, D. S., Johnson, J. E., Williams, E. J., Lerner, B. M., Angevine, W. M., Tucker, S. C., Brewer, W. A., and Stohl, A.: J. Geophys. Res., 2008 113, D00F01, doi:10.1029/2008JD010023

(152) Massoli, P., T.S. Bates, P.K. Quinn, D.A. Lack, T. Baynard, B.M. Lerner, S.C. Tucker, J. Brioude, A. Stohl, and E.J. Williams, J. Geophys. Res., 2009, 114, D00F07, doi:10.1029/2008JD011604, 2009 
(153) Atkinson, DB, Massoli, P, O’Neill, NT, Quinn, PK, Brooks, SD, Lefer, B. Atmospheric Chemistry and Physics, 2010 10, 51-61

(154) George, L. A., Parra, J., Sitbon, P., ; Portland State University - Center for Environmental Atmospheric Research (CEAR), Portland, OR., 2005. ; Vol. 2008

(155) Hobbs, P. V., Garrett, T.J. Journal of the Atmospheric Sciences 2000, 57 25702590

(156) Krahl, J., Baum, K., Uackbarth, U., Jeberien, H.E., Munack, A., Schutt, C., Schroder, O., Walter, N., Bunger, J., Muller, M.M., Weigel, A. American Society of Agricultural Engineers 200144 179-191

(157) Kinast, J.A.; NREL/SR-510-31460, March, 2003

(158) Waynick J.A.; NREL/TP-540-39096; November 2005

(159) Frame, E.A.; Bessee, G.B.; Marbach, H.W. Biodiesel Interim Report TRLRF No.317 to U. S. Army TARDEC,1997, Contract No. DADK70-92-C-0059

(160) Kirchstetter, T.W.; Novakov, T.; Hobbs, P.V. J. Geophys. Res., 2004 109, 21208

(161) Schnaiter, M.; Horvath, H.; Mohler, O.; Naumann, K. H.; Saathoff, H.; and Schock, O. W. J. Aerosol Sci., 2003,34, 1421- 1444

(162) Gyawali1, M.; Arnott1, W. P. ; Lewis, W. P. ; Moosmuller, H. Atmos.Chem. Phys., 2009, 9, 8007-8015

(163) Heikkil, J; Virtanen, A.; Rnkk, T.; Keskinen, J.; Aakko-Sa, T.; Environ. Sci. Technol. 2009, 43 (24), 9501-9506

(164) Bünger, J.; Krahl, J.; Franke, H.U.; Munack, A.; Hallier, E. Mutat Res 1998;415:13-23 


\section{Appendix A: Support Figures and Data}

\section{A.1 Sample of Field Data}

A sample of the emission test data is given in Figure A1. The four types of test cycles can be seen in the plot. The Condensation Particle Counter (CPC) was attached to the cavity, so both the optical properties and the count data have clean air cycles. The gas phase measurements were not attached, and do not have a filtered baseline.

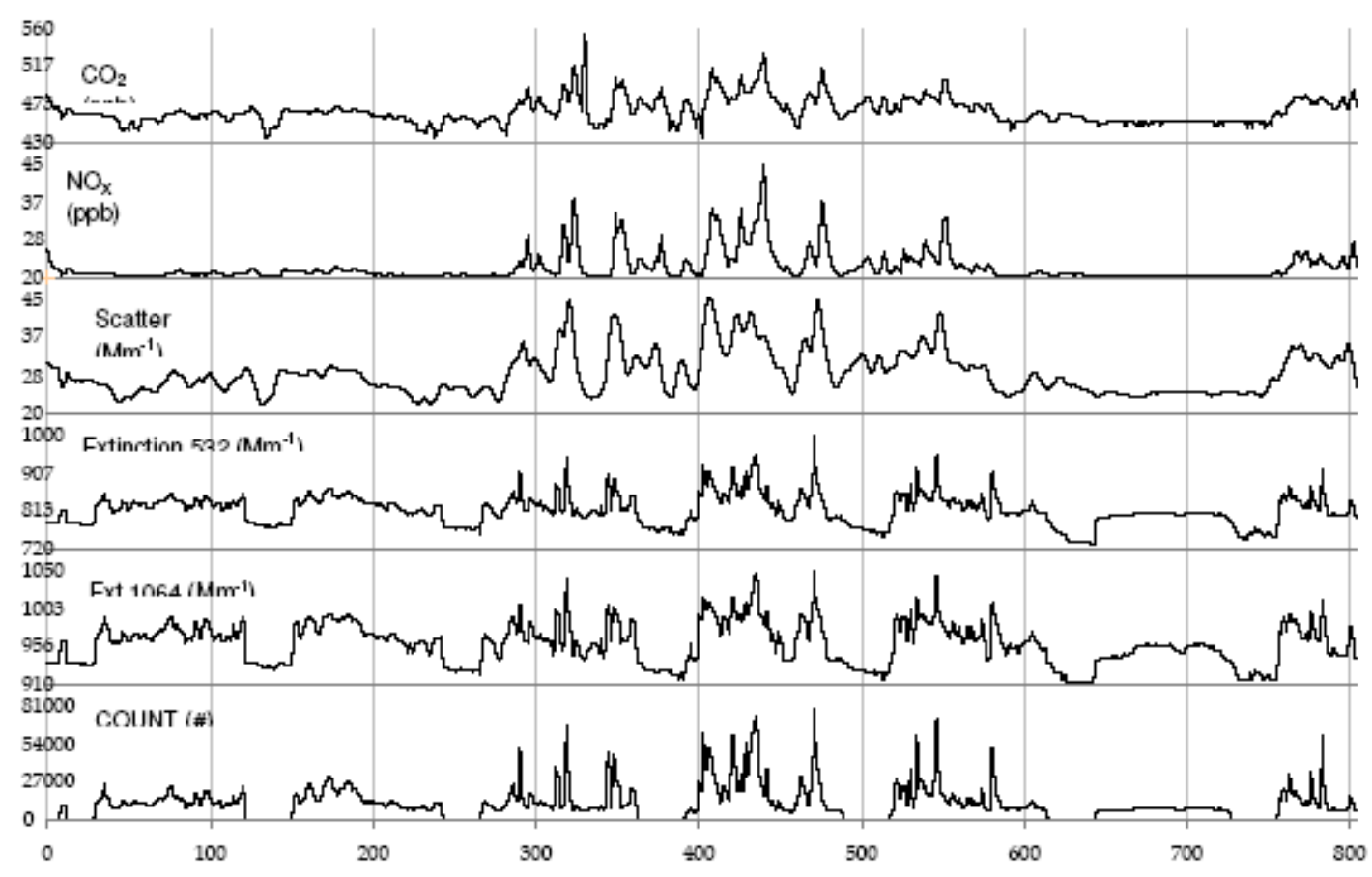

Figure A.1 Sample of field data. The four test cycles are indicated. 


\section{A.2 Correlation Plots for Emission Factor Determination}

Correlation plots between the measured parameters for each mixture and $\mathrm{CO}_{2}$ are provided for reference in the following section. The slope of the line is used to calculate the emission factor for the given parameter. The $95 \%$ prediction interval is shown as grey shading and the $95 \%$ confidence interval falls between the two grey lines. All plots are presented by fuel mixture in the following parameter order: $532 \mathrm{~nm}$ extinction coefficient, $b_{\text {ext, } 532 \mathrm{~nm}}, 530 \mathrm{~nm}$ scattering coefficient, $b_{\text {scat }, 530 \mathrm{~nm}}, 1064 \mathrm{~nm}$ extinction coefficient, $b_{\text {ext,1064 nm }}$, particle count, $\mathrm{NO}$ and $\mathrm{NO}_{2}$.

B5

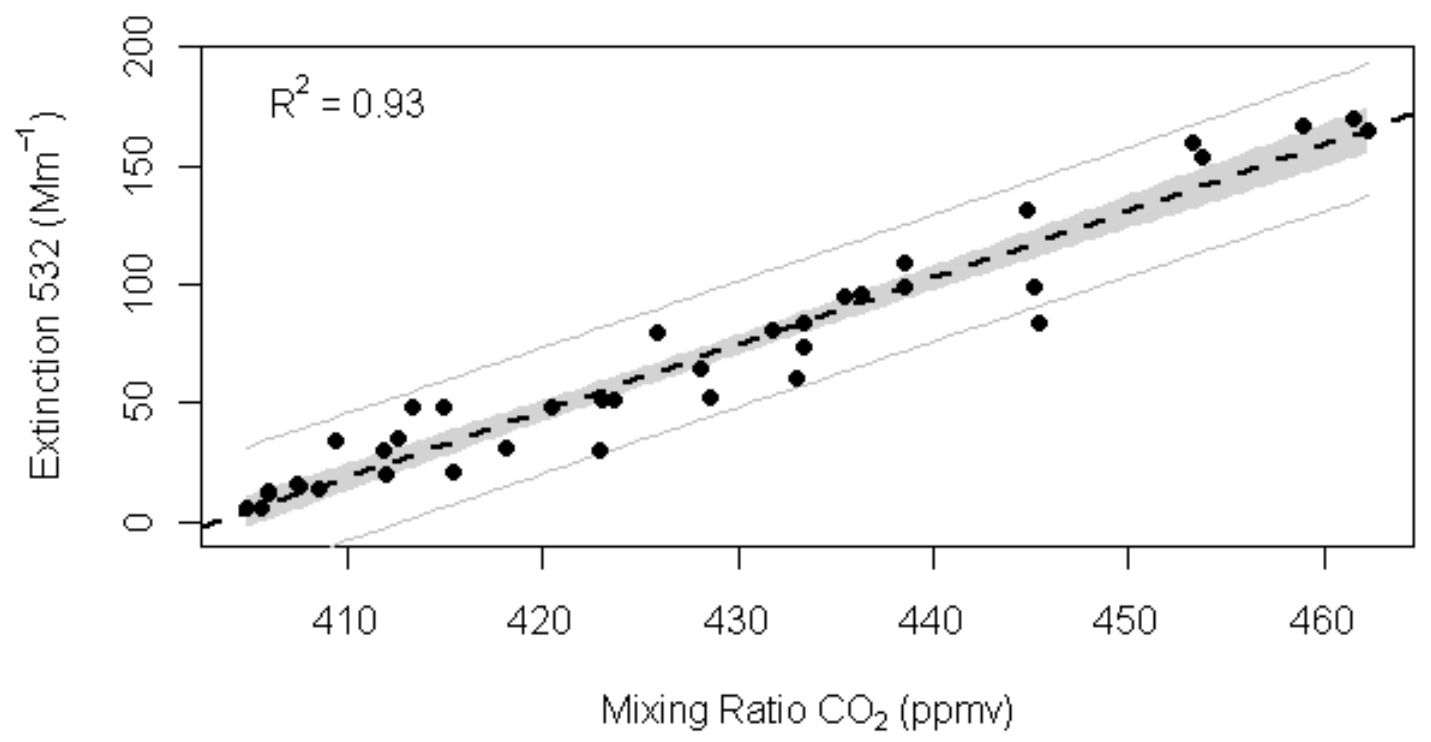

Figure A2: Correlation plot between Extinction $532 \mathrm{~nm}$ and $\mathrm{CO}_{2}$ for all $\mathrm{B} 5$ plumes. 


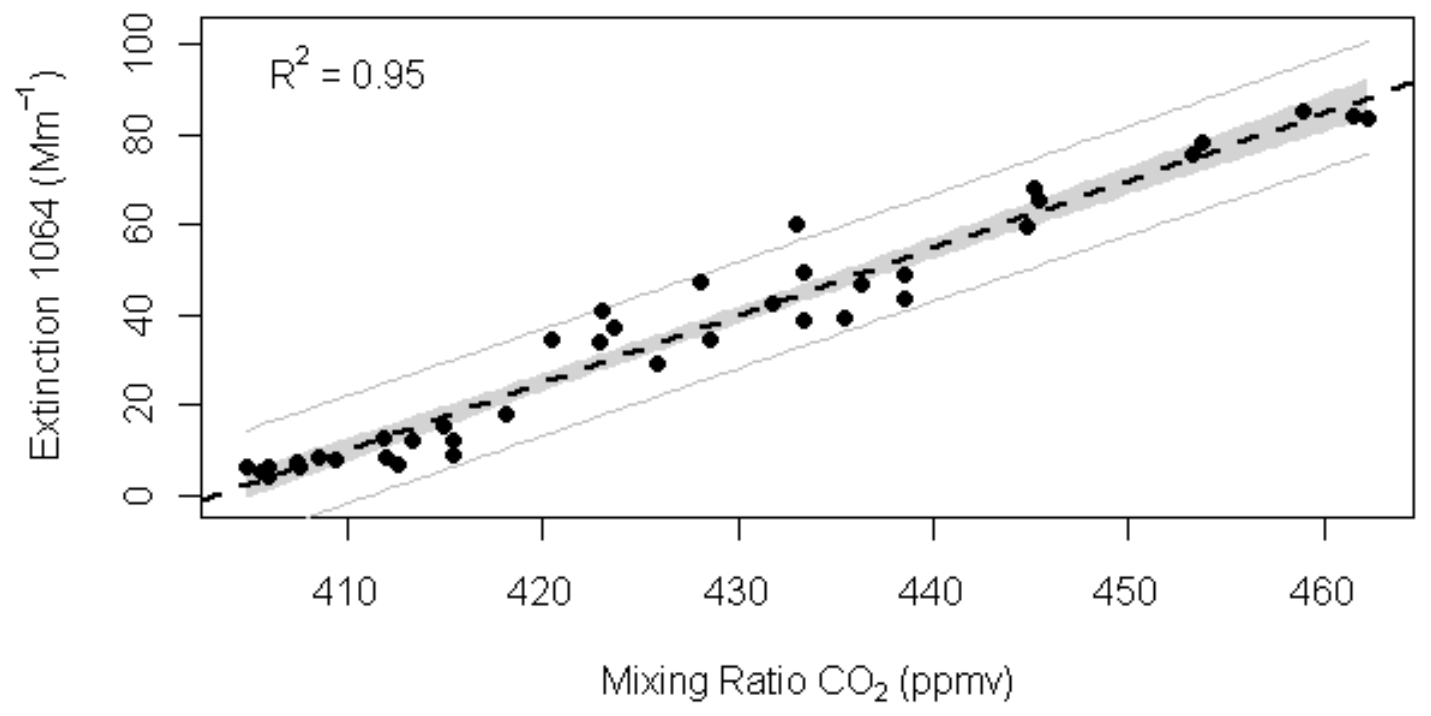

Figure A3: Correlation plot between Extinction $1064 \mathrm{~nm}$ and $\mathrm{CO}_{2}$ for all $\mathrm{B5}$ plumes.

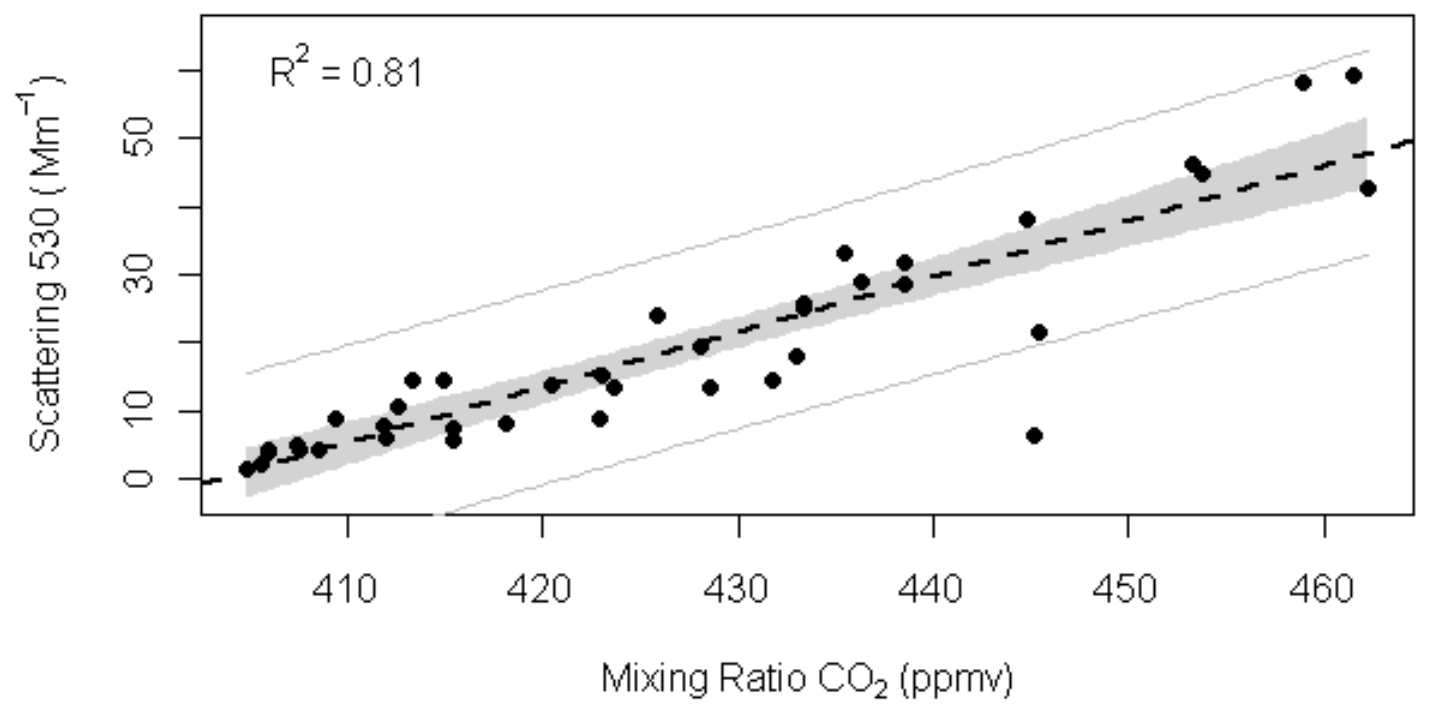

Figure A4: Correlation plot between Scattering $530 \mathrm{~nm}$ and $\mathrm{CO}_{2}$ for all $\mathrm{B5}$ plumes. 119 


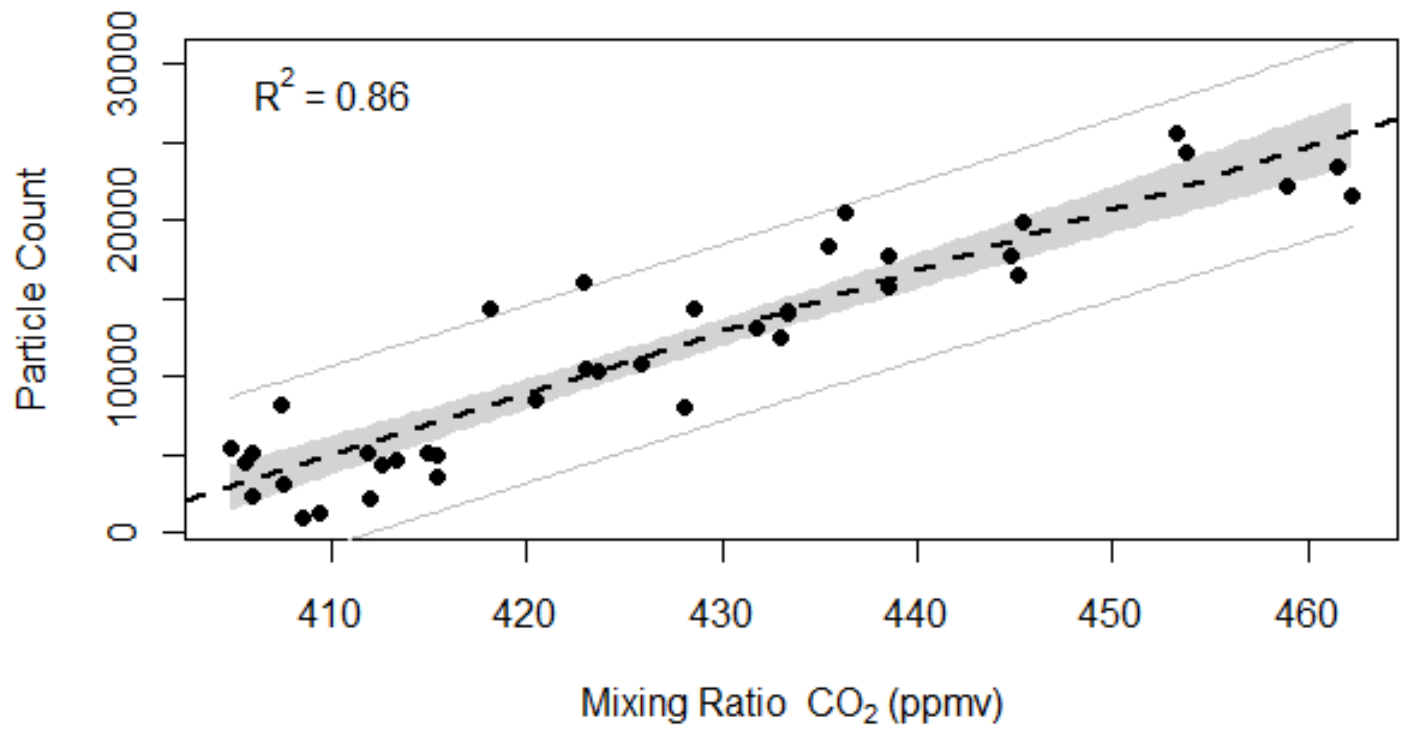

Figure A5: Correlation plot between Particle Count and $\mathrm{CO}_{2}$ for all $\mathrm{B} 5$ plumes.

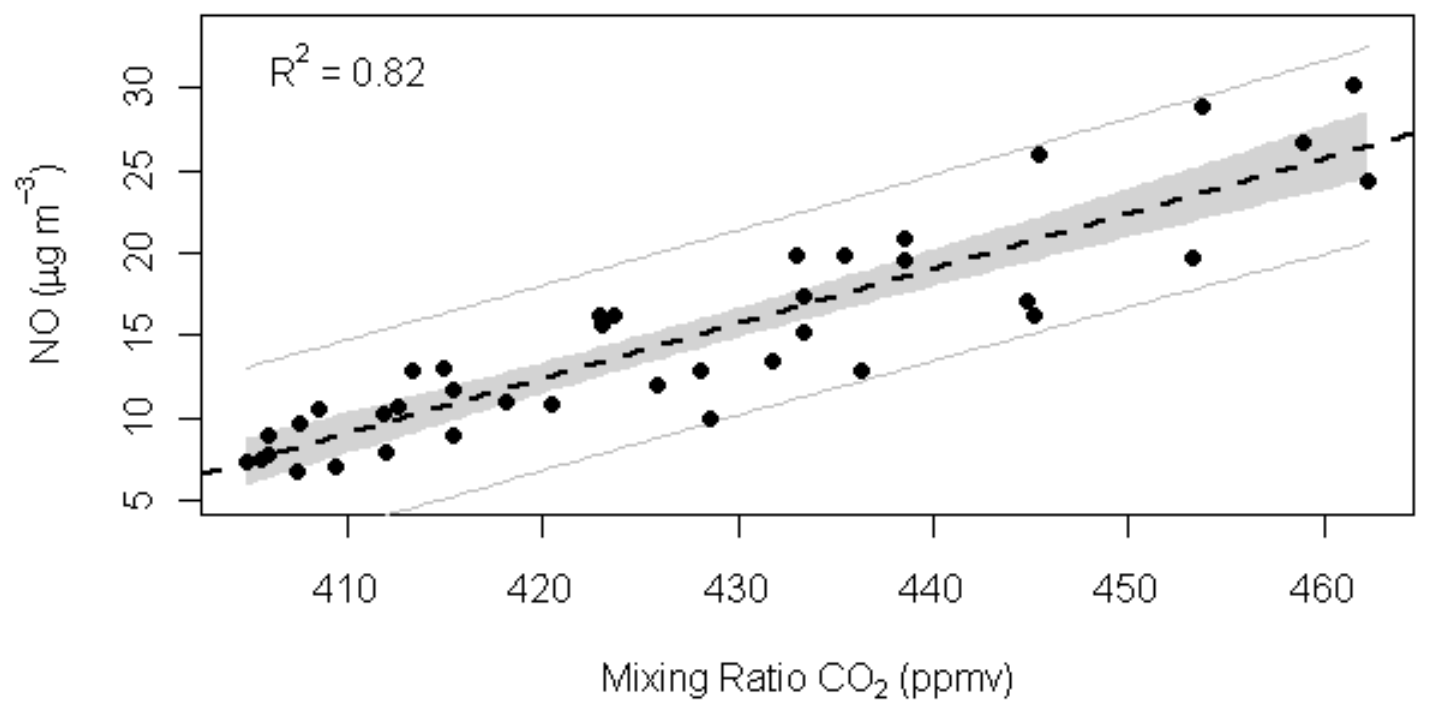

Figure A6: Correlation plot between $\mathrm{NO} \mu \mathrm{gm}^{-3}$ and $\mathrm{CO}_{2}$ for all $\mathrm{B} 5$ plumes. 


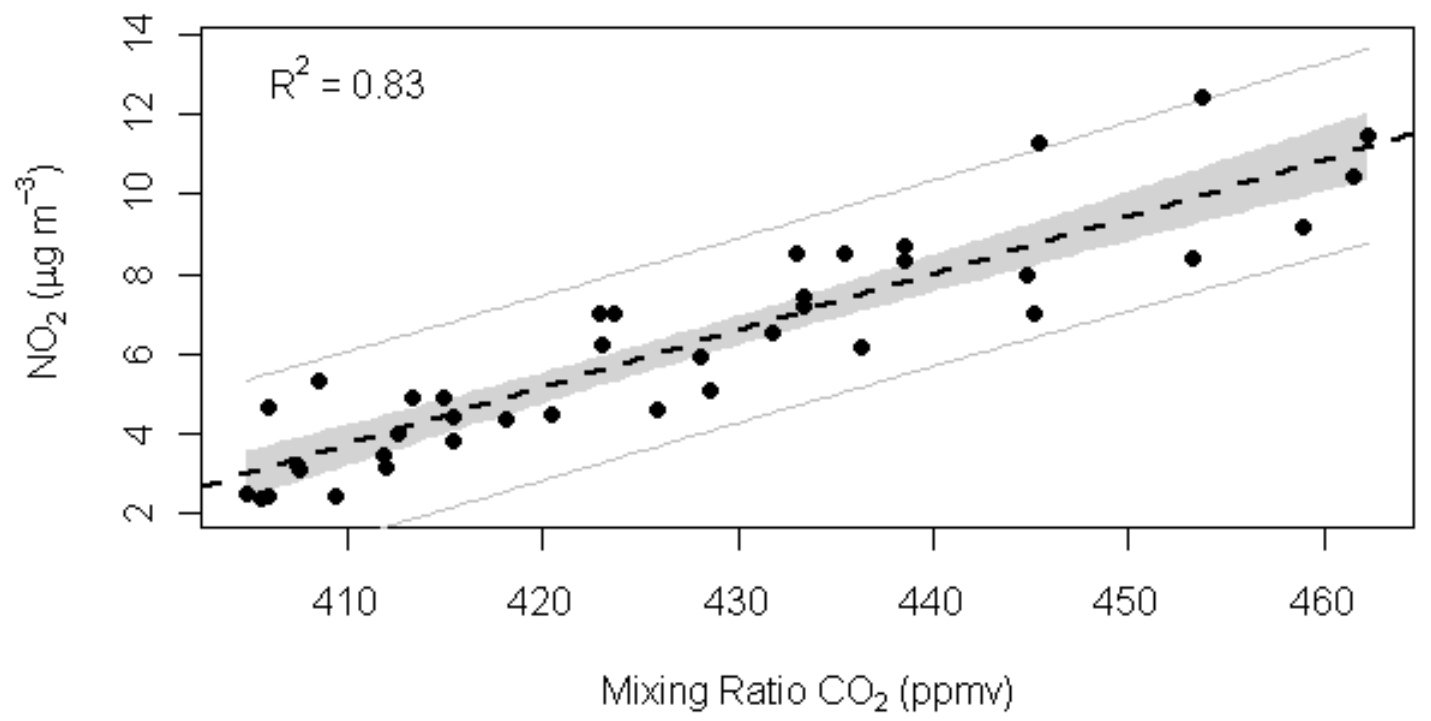

Figure A7: Correlation plot between $\mathrm{NO}_{2} \mu_{\mathrm{gm}}{ }^{-3}$ and $\mathrm{CO}_{2}$ for all $\mathrm{B5}$ plumes 


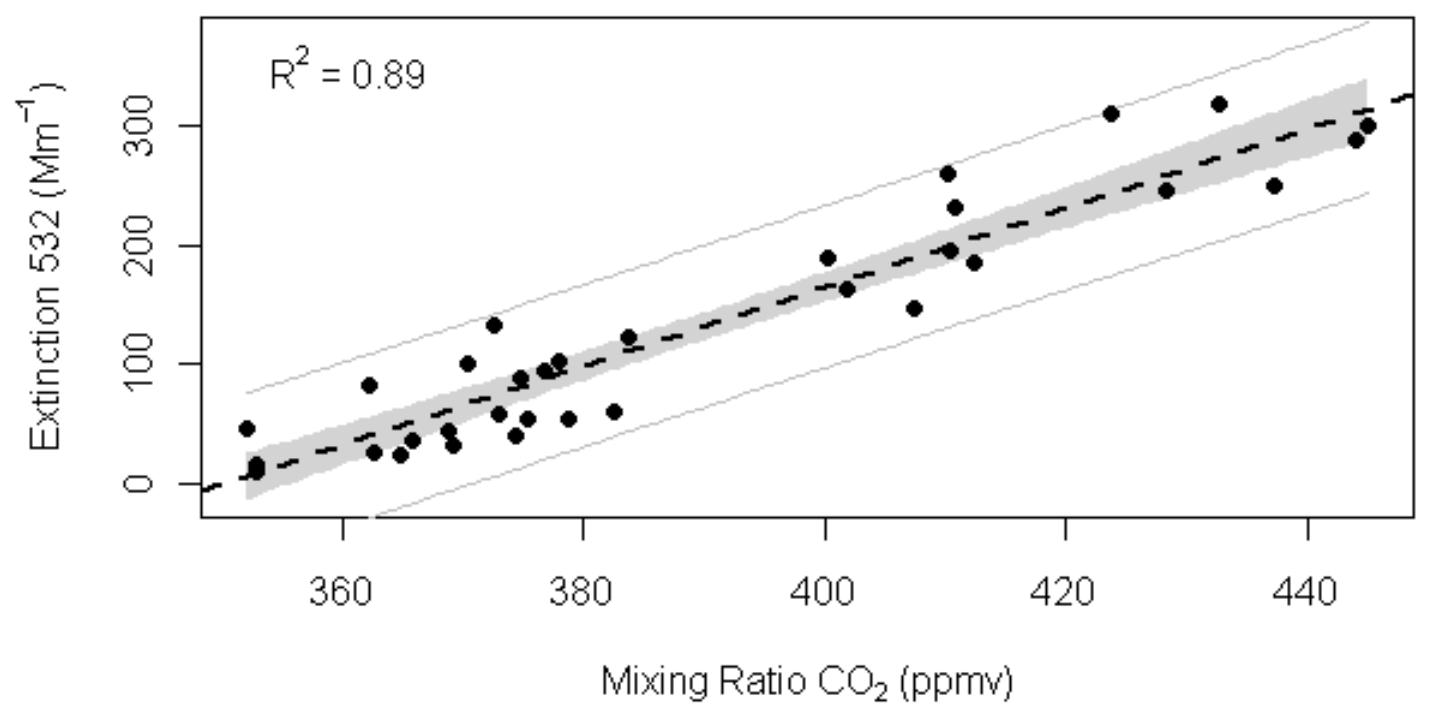

Figure A8: Correlation plot between Extinction $532 \mathrm{~nm}$ and $\mathrm{CO}_{2}$ for all $\mathrm{B} 25$ plumes. 


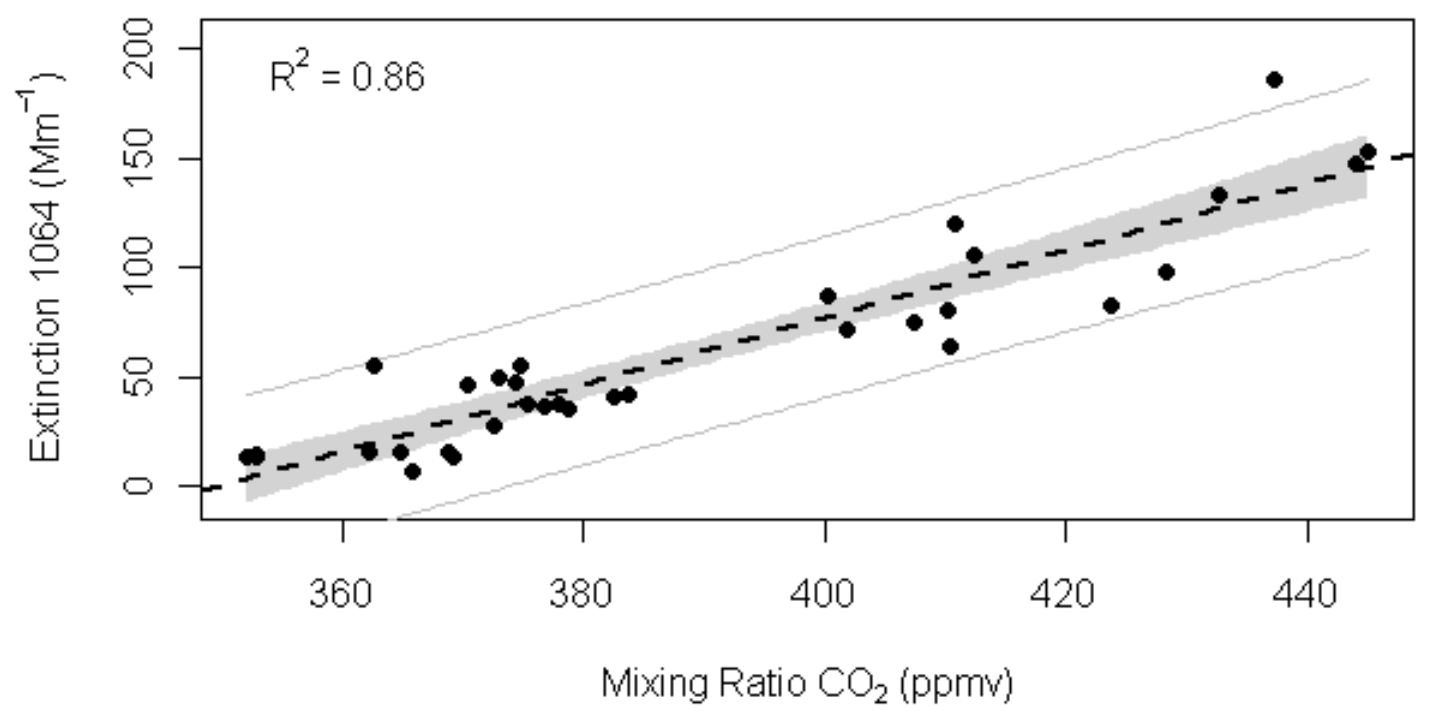

Figure A9: Correlation plot between Extinction $1064 \mathrm{~nm}$ and $\mathrm{CO}_{2}$ for all $\mathrm{B} 25$ plumes.

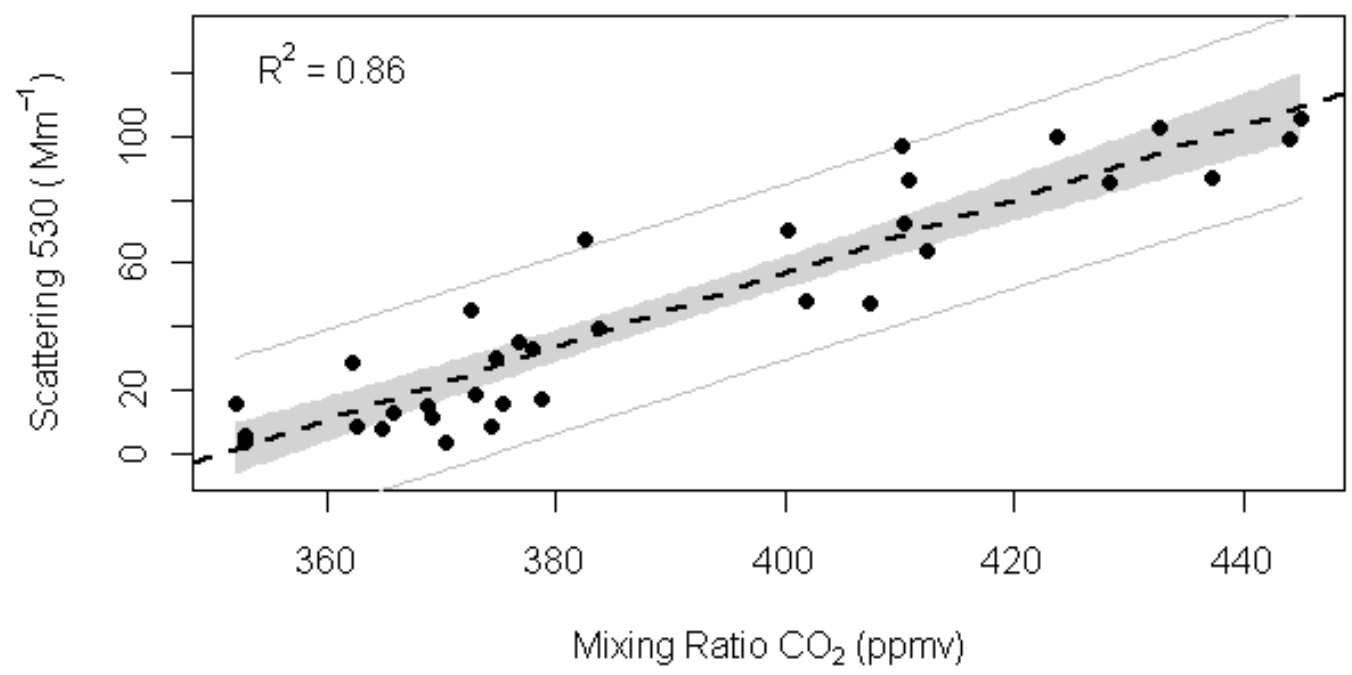

Figure A10: Correlation plot between Scattering $530 \mathrm{~nm}$ and $\mathrm{CO}_{2}$ for all $\mathrm{B} 25$ plumes. 


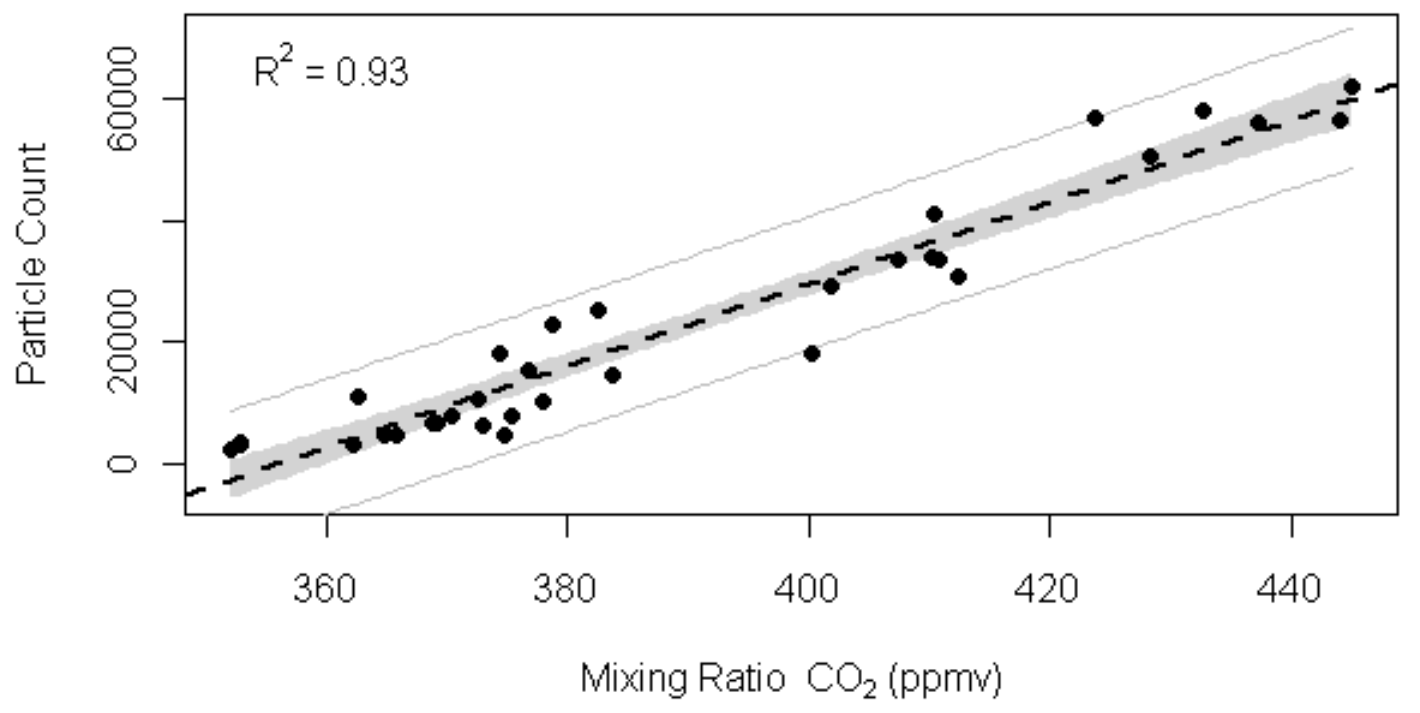

Figure A11: Correlation plot between Particle Count and $\mathrm{CO}_{2}$ for all $\mathrm{B25}$ plumes. 


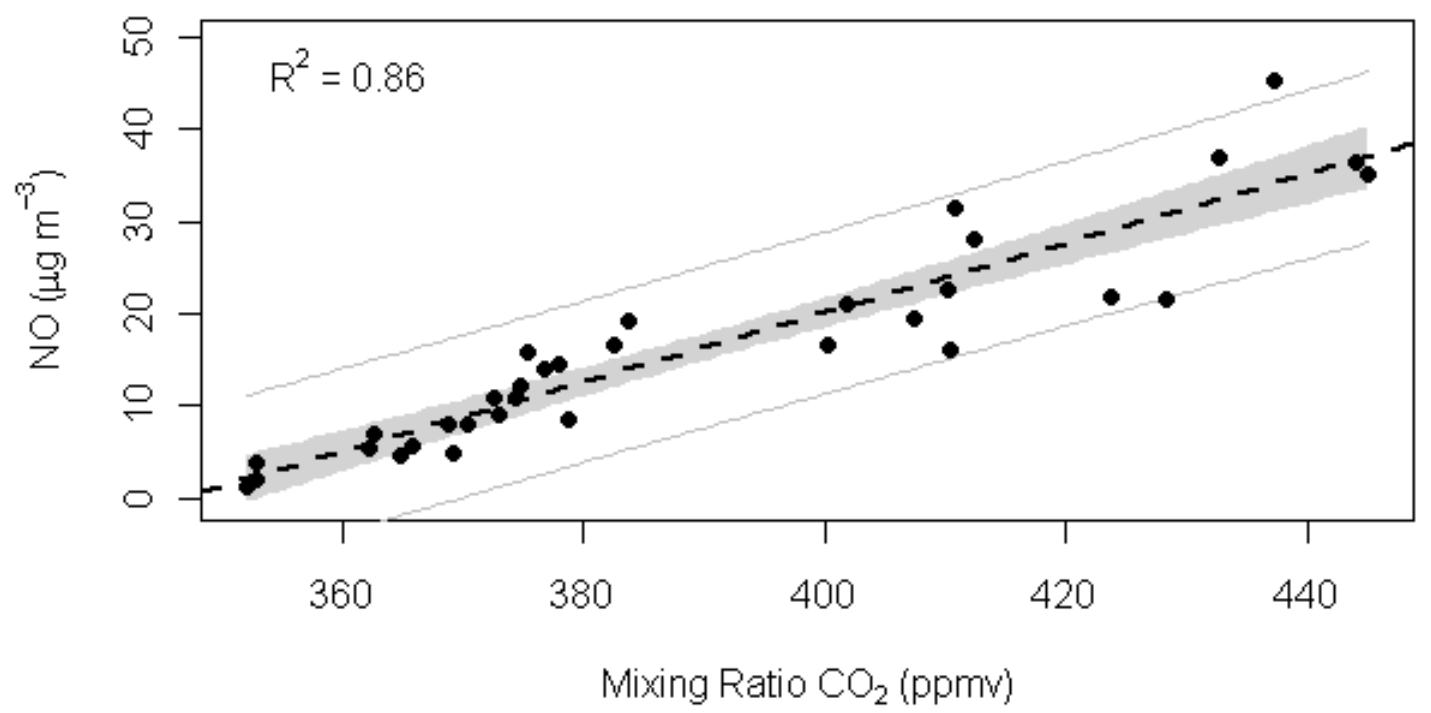

Figure A12: Correlation plot between $\mathrm{NO} \mu \mathrm{gm}^{-3}$ and $\mathrm{CO}_{2}$ for all $\mathrm{B25}$ plumes.

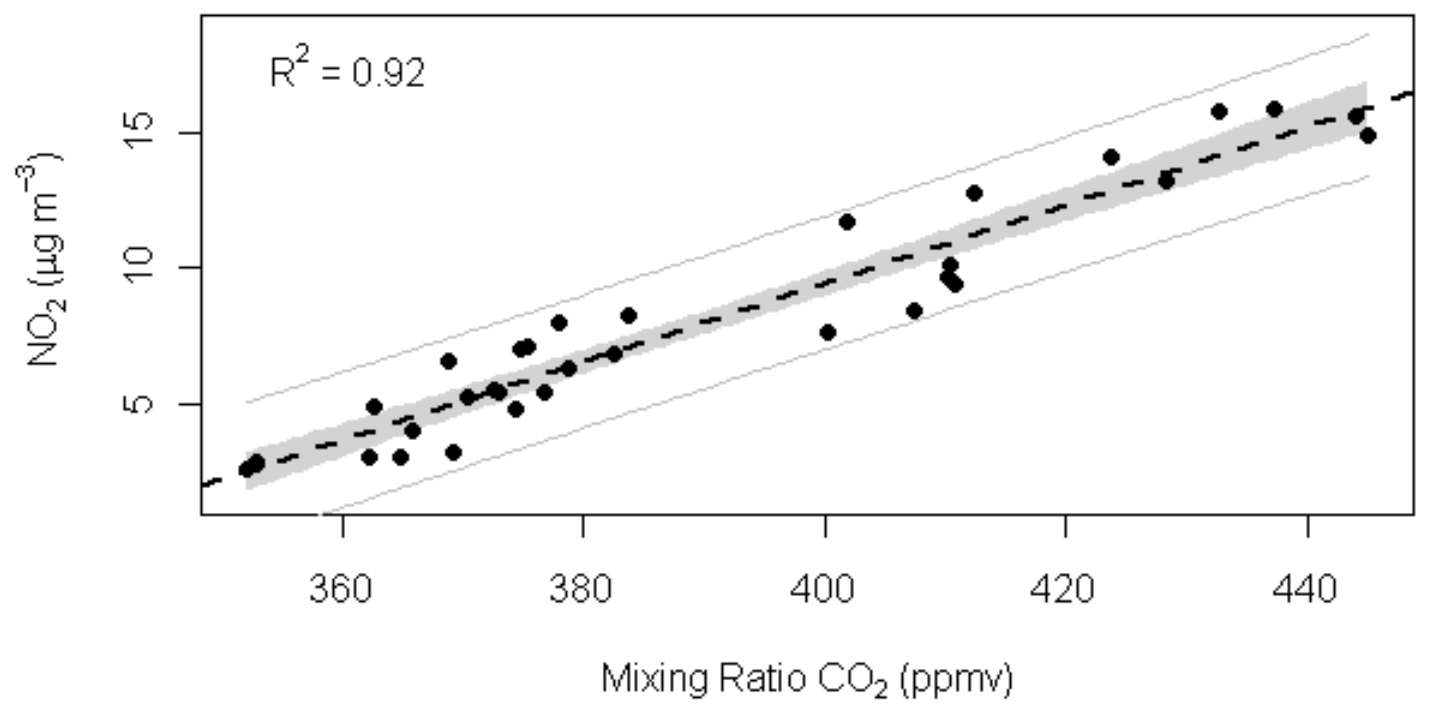

Figure A13: Correlation plot between $\mathrm{NO}_{2} \mu \mathrm{gm}^{-3}$ and $\mathrm{CO}_{2}$ for all $\mathrm{B25}$ plumes 
B50

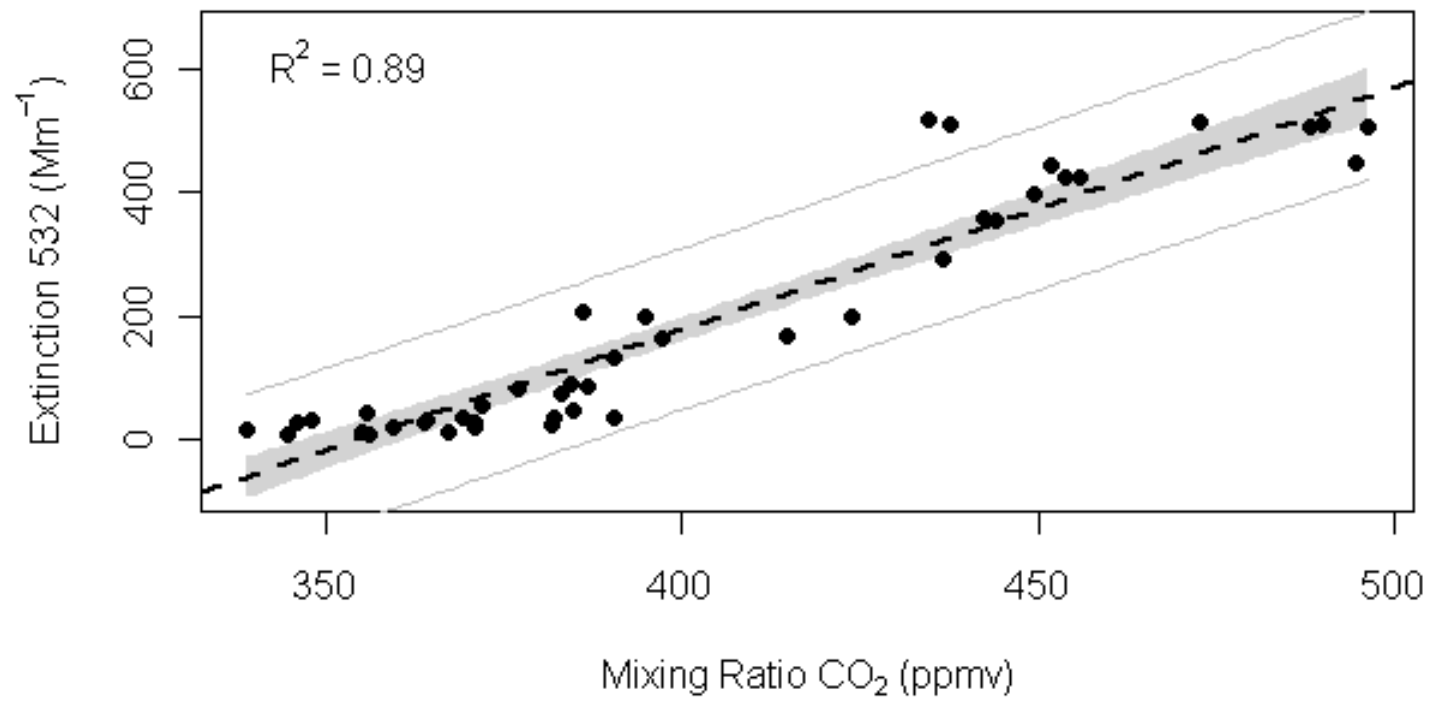

Figure A14: Correlation plot between Extinction $532 \mathrm{~nm}$ and $\mathrm{CO}_{2}$ for all $\mathrm{B50}$ plumes. 


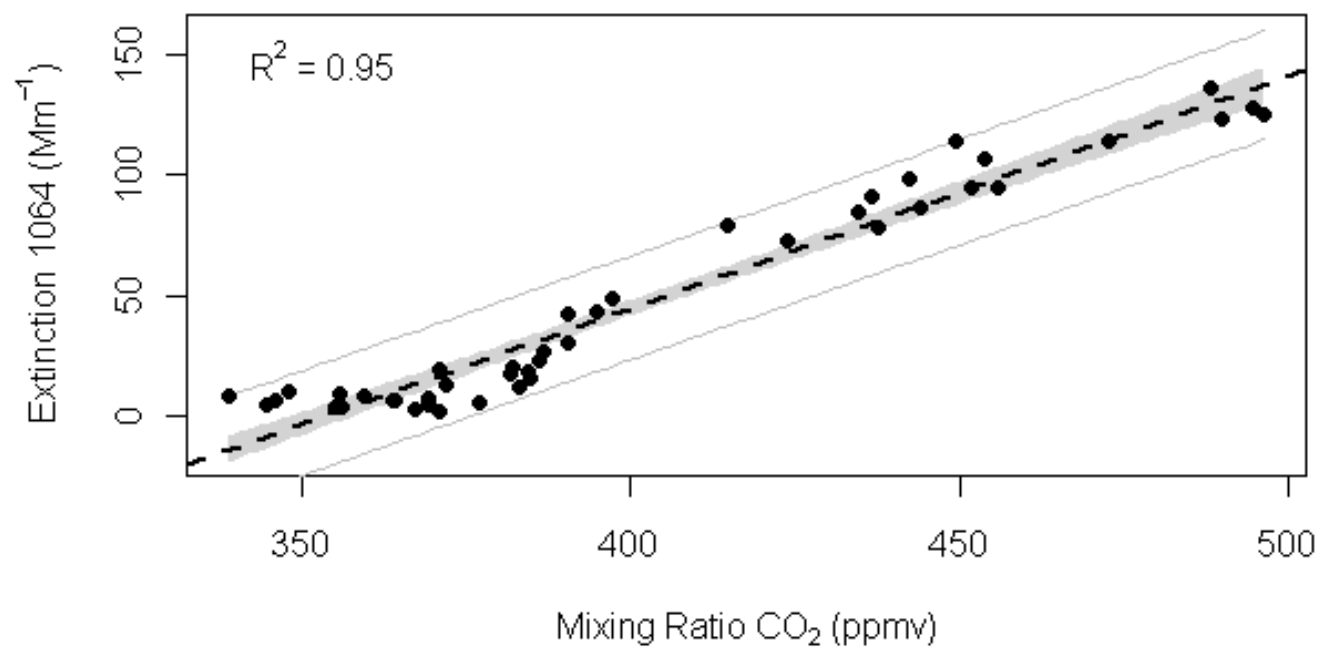

Figure A15: Correlation plot between Extinction $1064 \mathrm{~nm}$ and $\mathrm{CO}_{2}$ for all $\mathrm{B50}$ plumes.

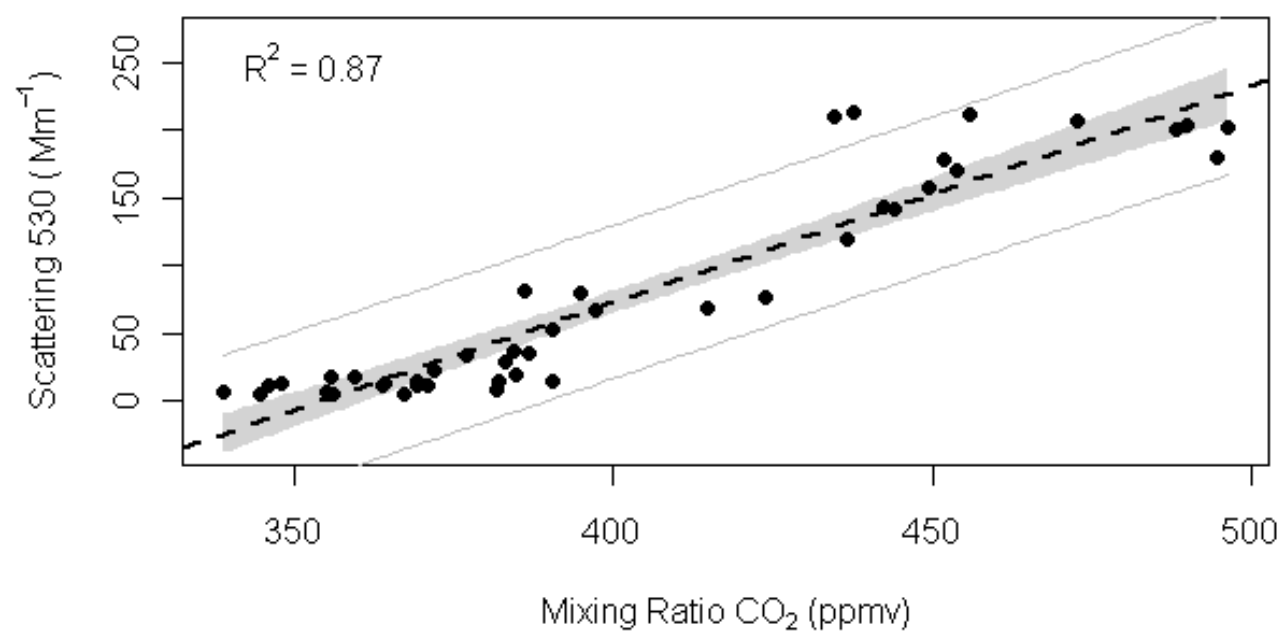

Figure A16: Correlation plot between Scattering $530 \mathrm{~nm}$ and $\mathrm{CO}_{2}$ for all $\mathrm{B50}$ plumes. 


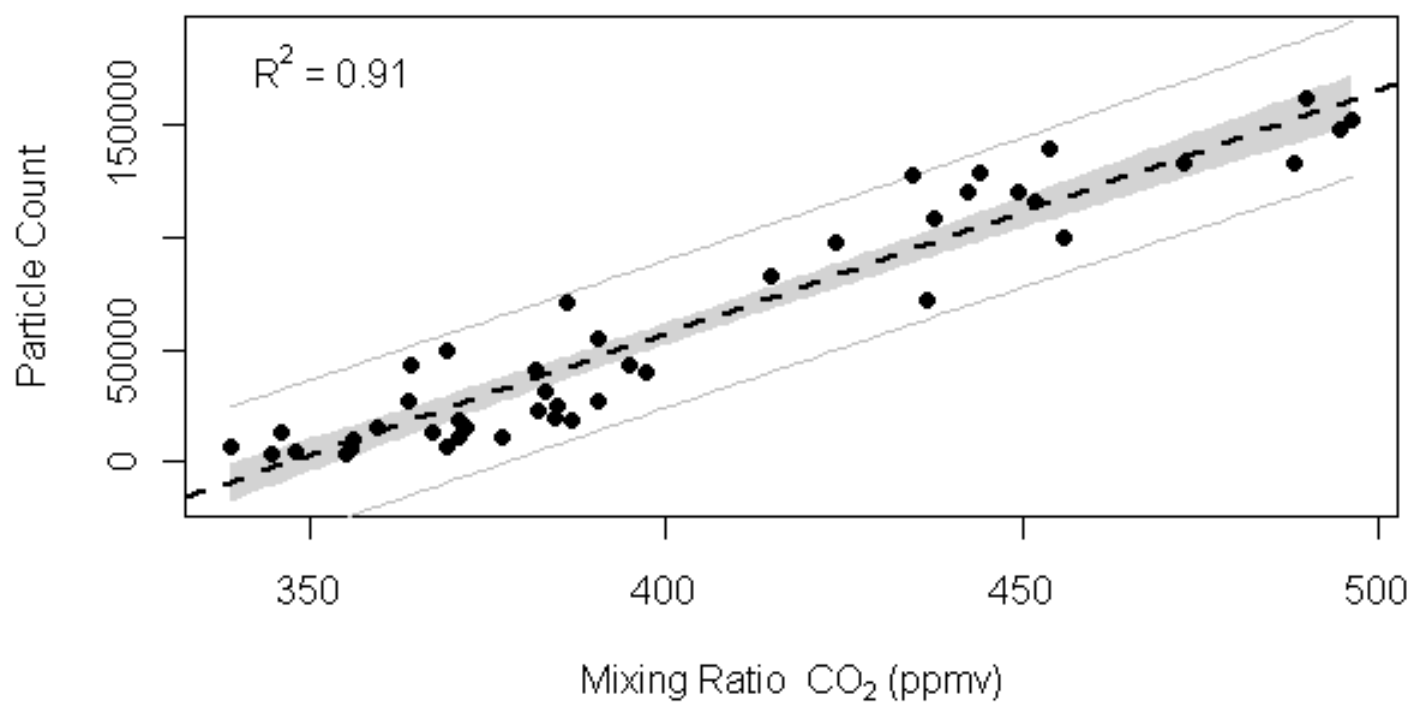

Figure A17: Correlation plot between Particle Count and $\mathrm{CO}_{2}$ for all $\mathrm{B50}$ plumes. 


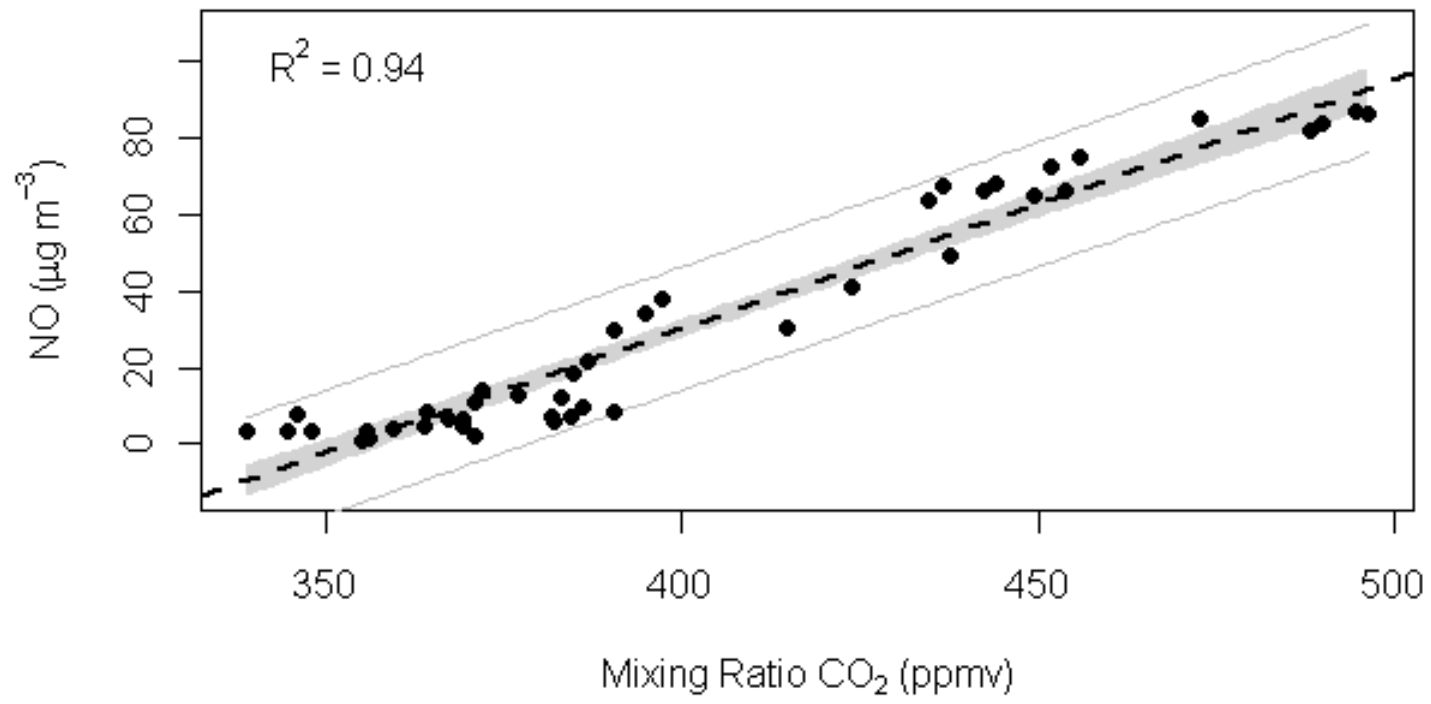

Figure A18: Correlation plot between $\mathrm{NO} \mathrm{\mu gm}^{-3}$ and $\mathrm{CO}_{2}$ for all $\mathrm{B50}$ plumes.

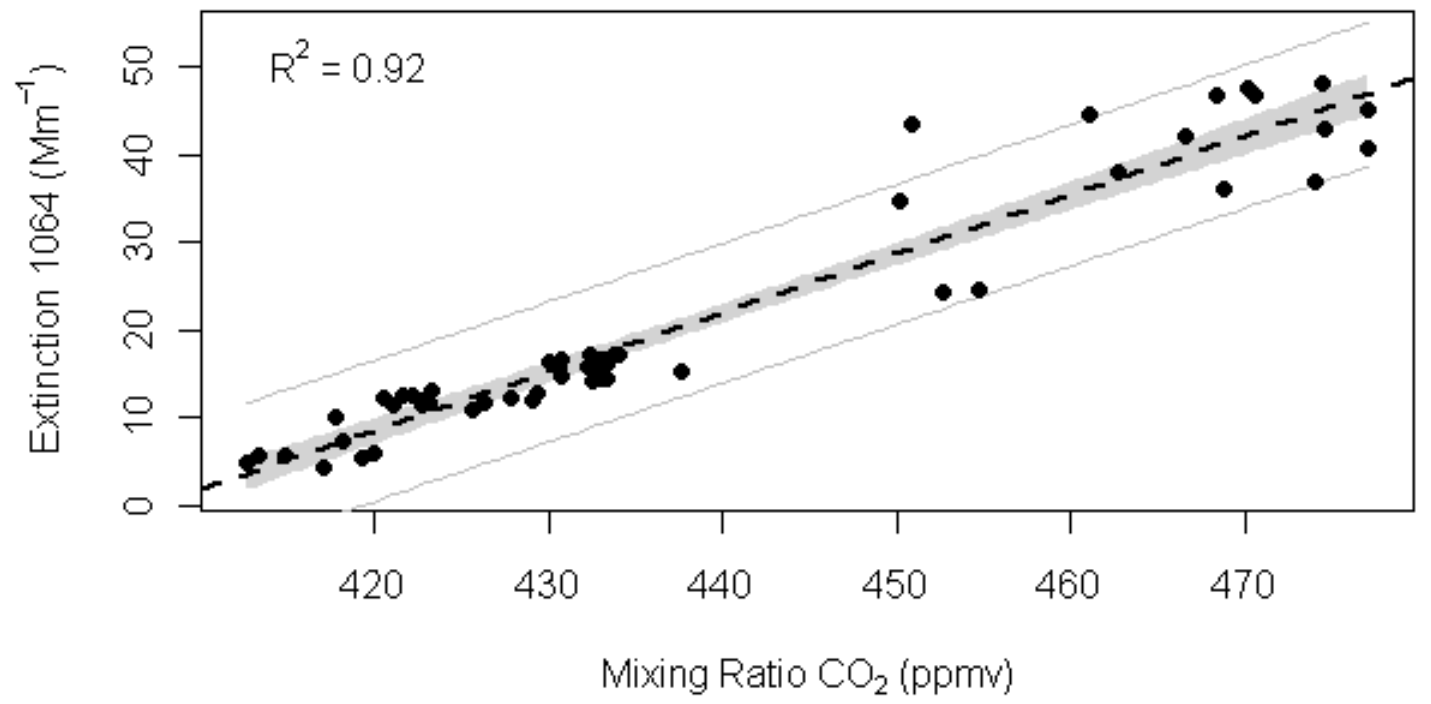

Figure A19: Correlation plot between $\mathrm{NO}_{2} \mu \mathrm{gm}^{-3}$ and $\mathrm{CO}_{2}$ for all $\mathrm{B50}$ plumes. 
B75

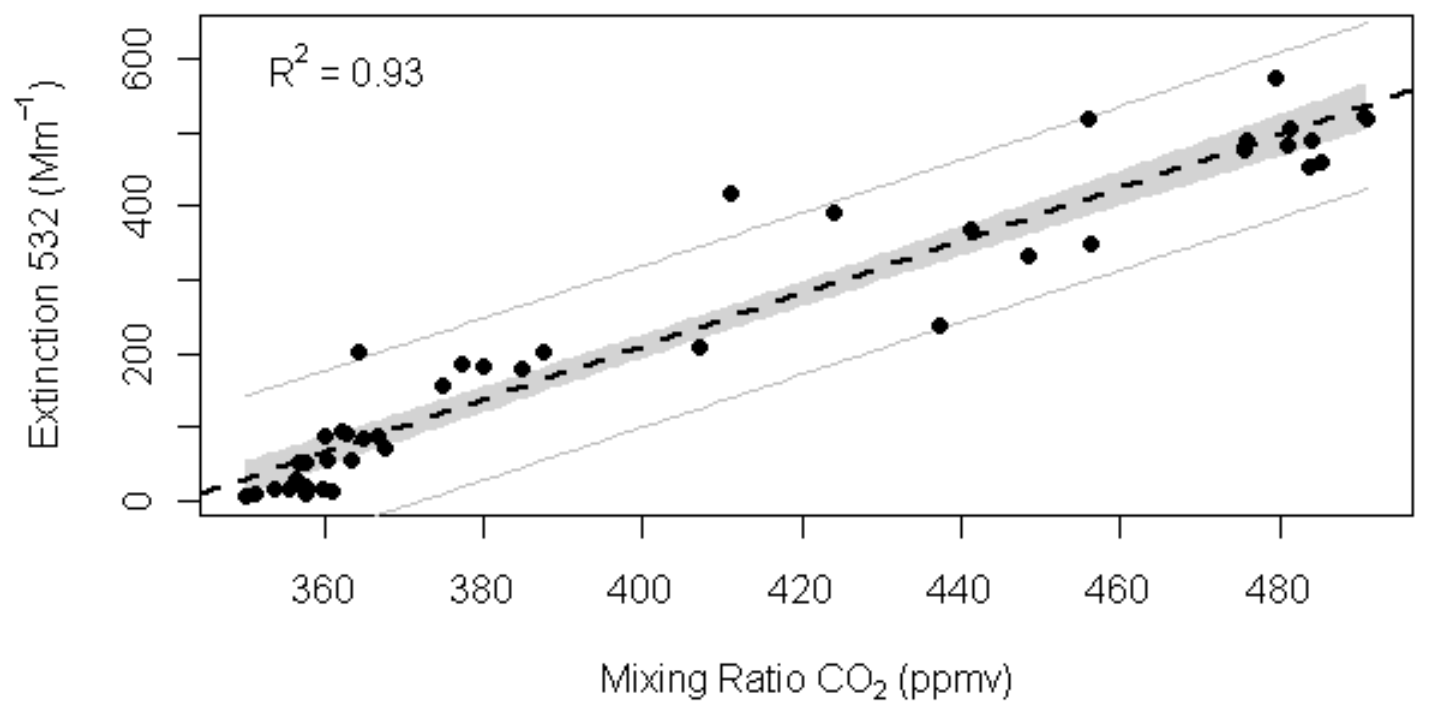

Figure A20: Correlation plot between Extinction $532 \mathrm{~nm}$ and $\mathrm{CO}_{2}$ for all $\mathrm{B} 75$ plumes. 


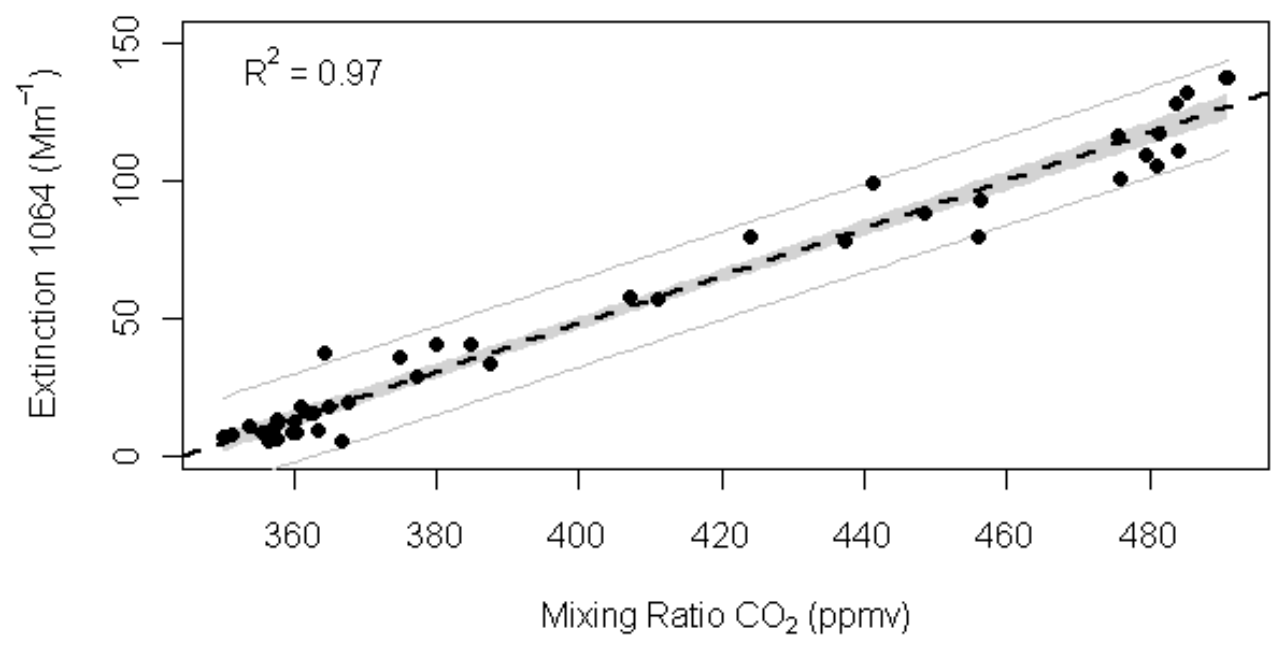

Figure A21: Correlation plot between Extinction $1064 \mathrm{~nm}$ and $\mathrm{CO}_{2}$ for all $\mathrm{B75}$ plumes.

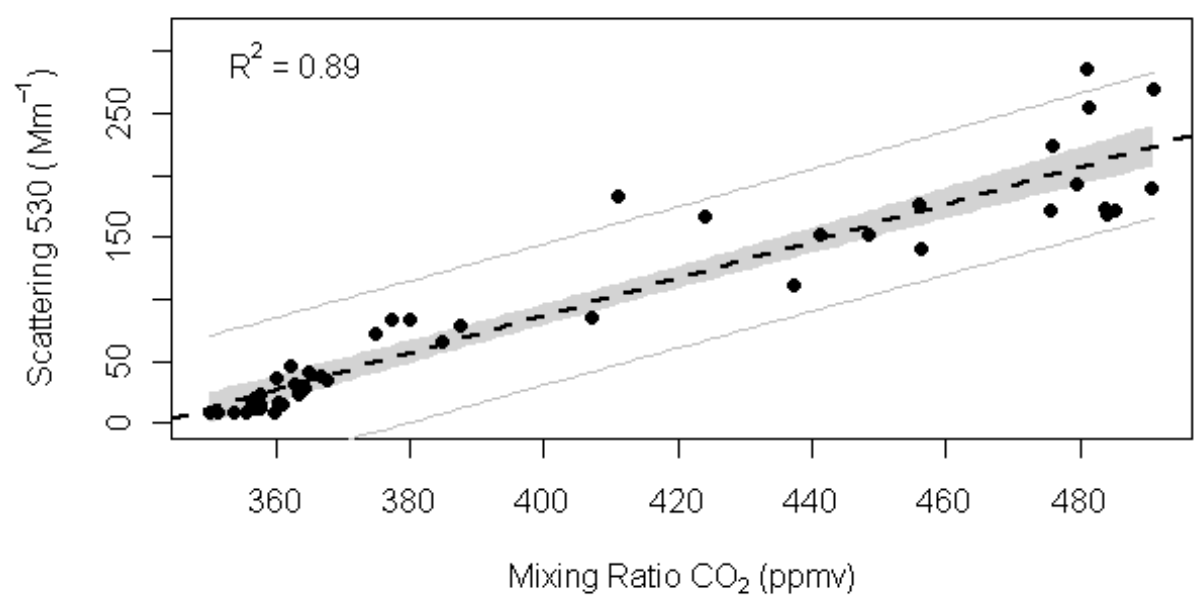

Figure A22: Correlation plot between Scattering $530 \mathrm{~nm}$ and $\mathrm{CO}_{2}$ for all $\mathrm{B} 75$ plumes. 


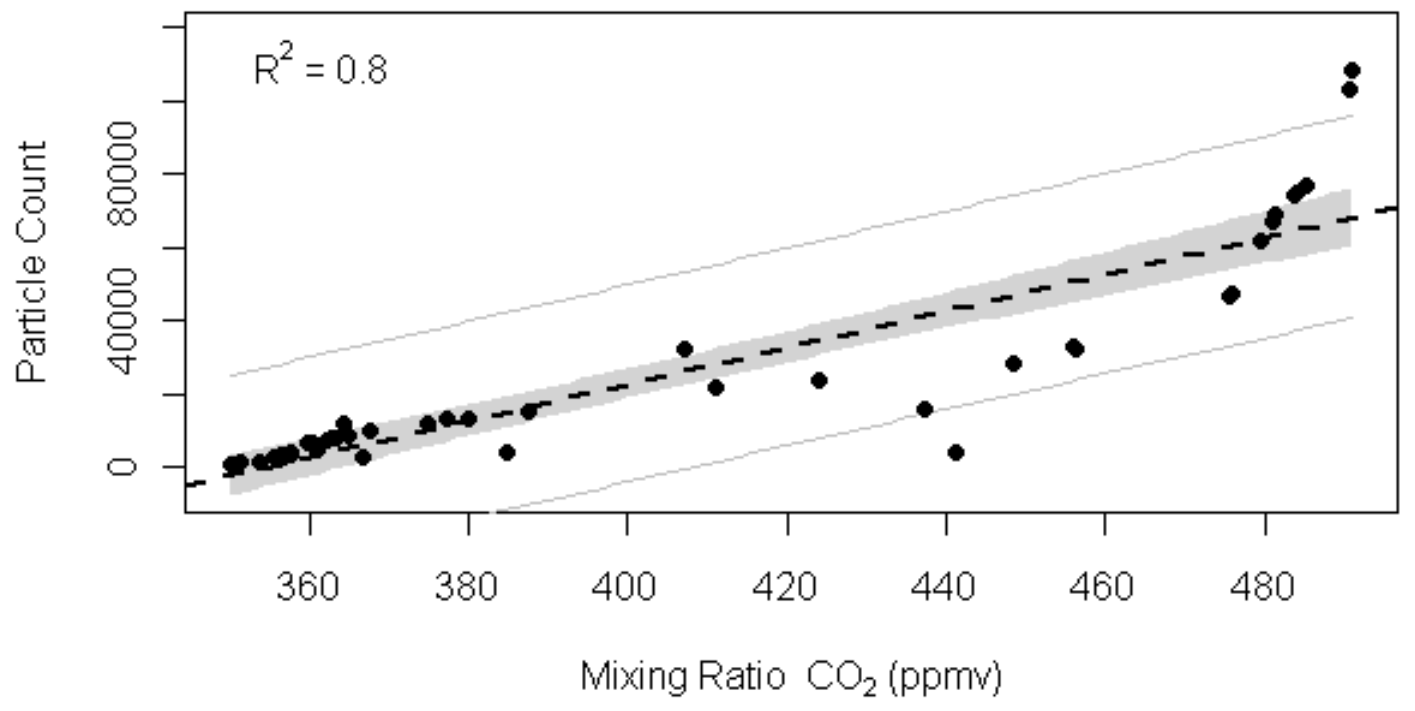

Figure A23: Correlation plot between Particle Count and $\mathrm{CO}_{2}$ for all $\mathrm{B} 75$ plumes.

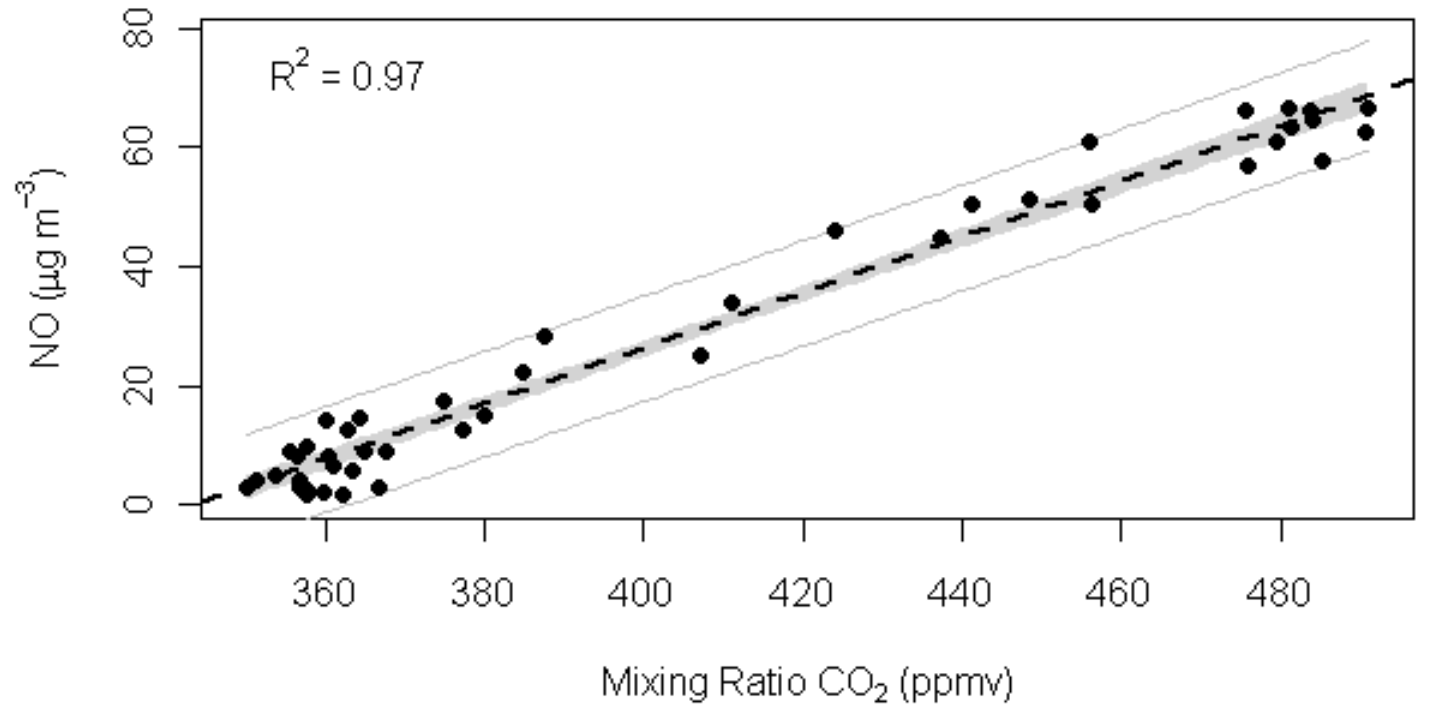

Figure A24: Correlation plot between $\mathrm{NO}^{\mu g^{-3}}$ and $\mathrm{CO}_{2}$ for all $\mathrm{B} 75$ plumes. 132 


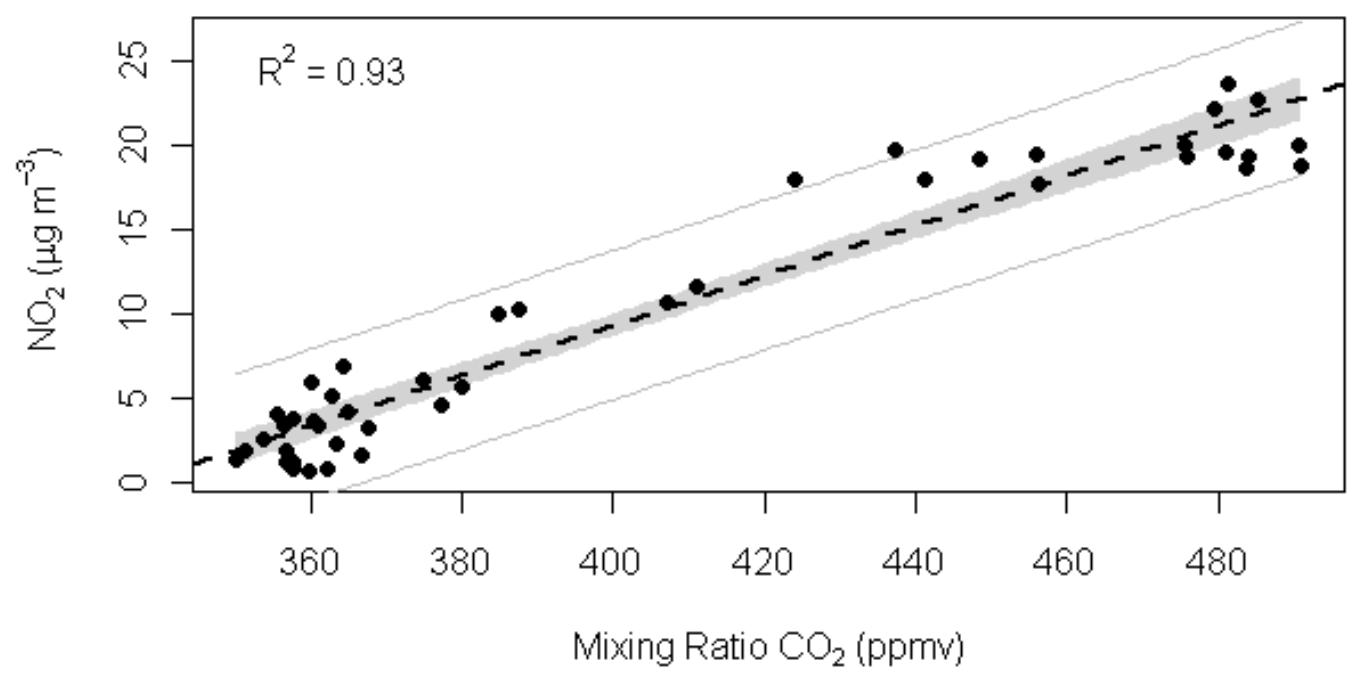

Figure A25: Correlation plot between $\mathrm{NO}_{2} \mu_{\mathrm{gm}}{ }^{-3}$ and $\mathrm{CO}_{2}$ for all $\mathrm{B75}$ plumes B99

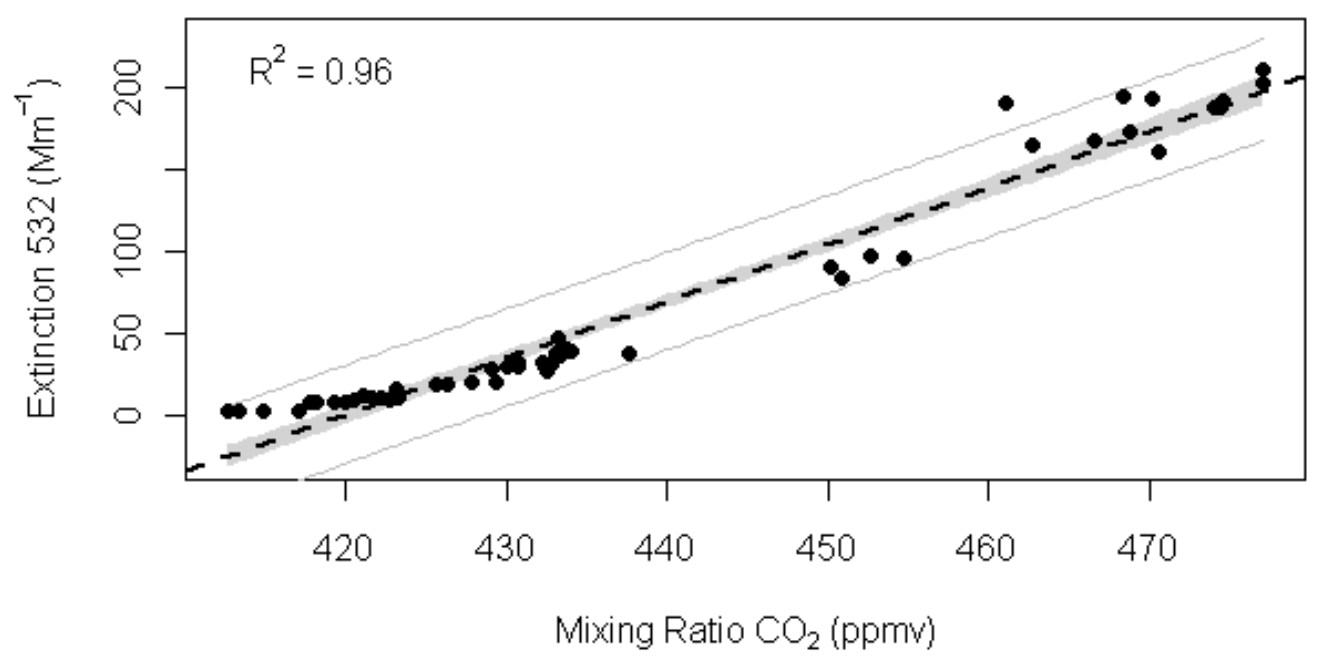

Figure A26: Correlation plot between Extinction $532 \mathrm{~nm}$ and $\mathrm{CO}_{2}$ for all $\mathrm{B} 99$ plumes. 


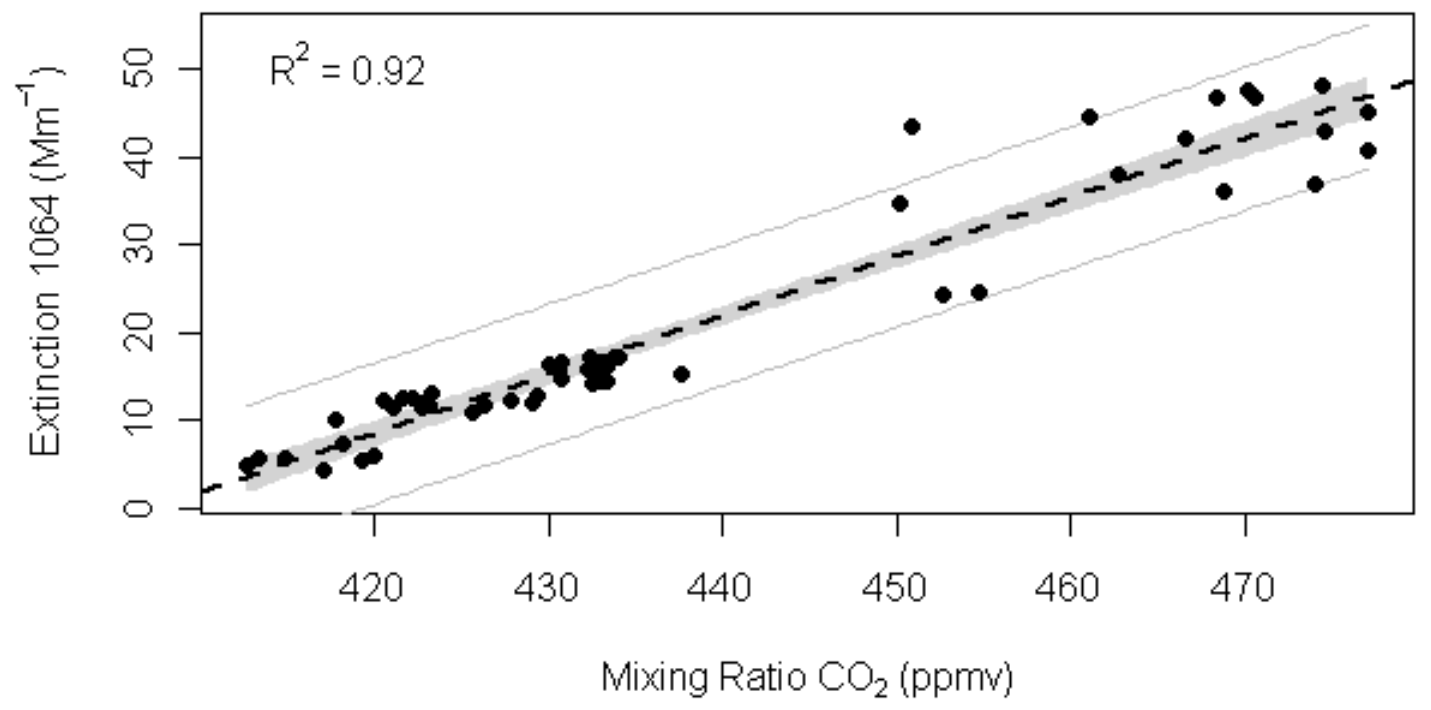

Figure A27: Correlation plot between Extinction $1064 \mathrm{~nm}$ and $\mathrm{CO}_{2}$ for all $\mathrm{B99}$ plumes. 


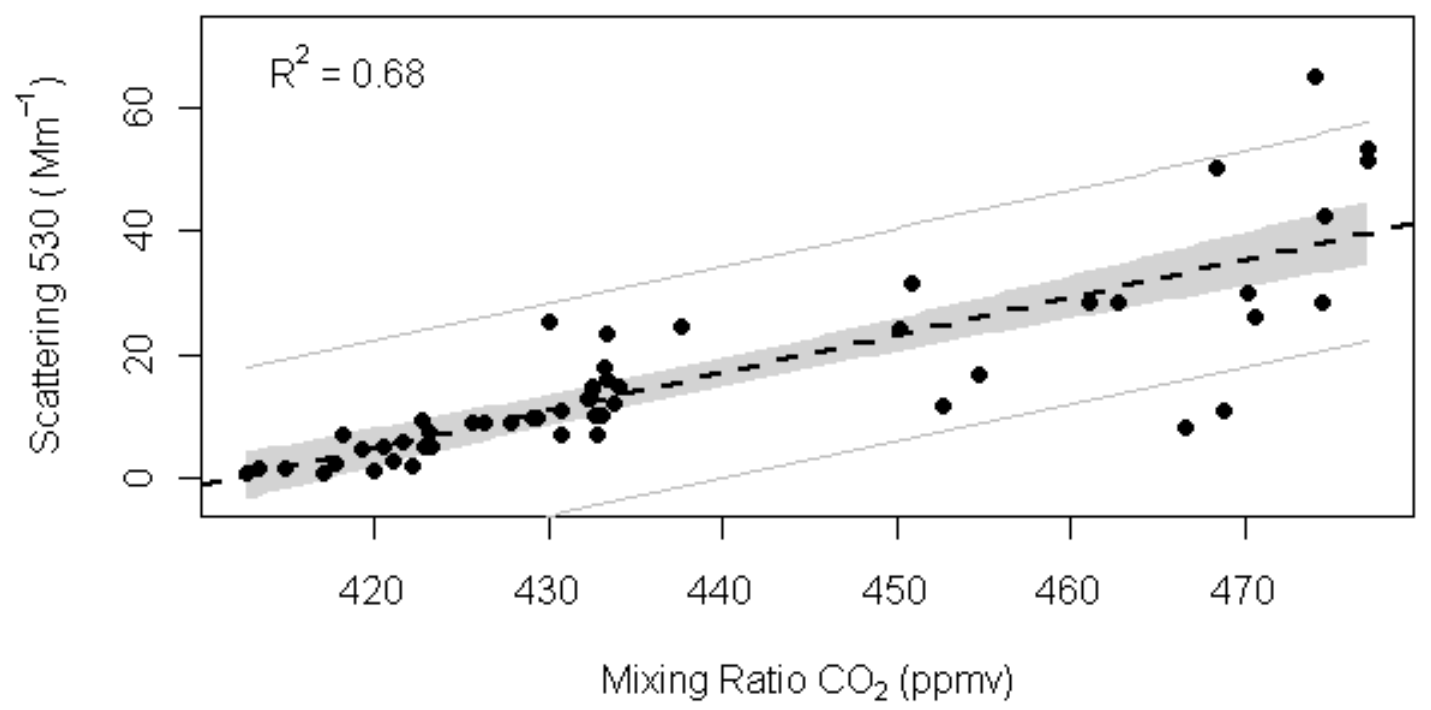

Figure A28: Correlation plot between Scattering $530 \mathrm{~nm}$ and $\mathrm{CO}_{2}$ for all $\mathrm{B} 99$ plumes.

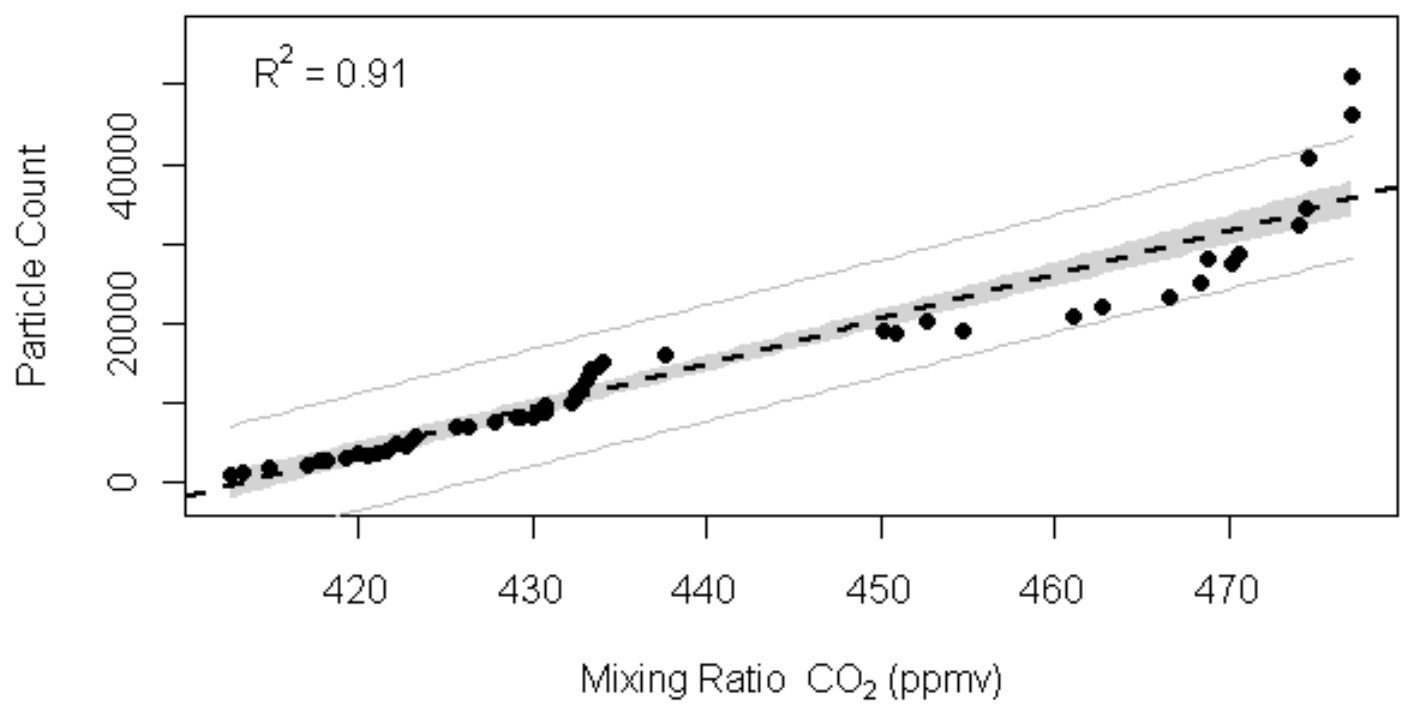

Figure A29: Correlation plot between Particle Count and $\mathrm{CO}_{2}$ for all $\mathrm{B} 99$ plumes. 135 


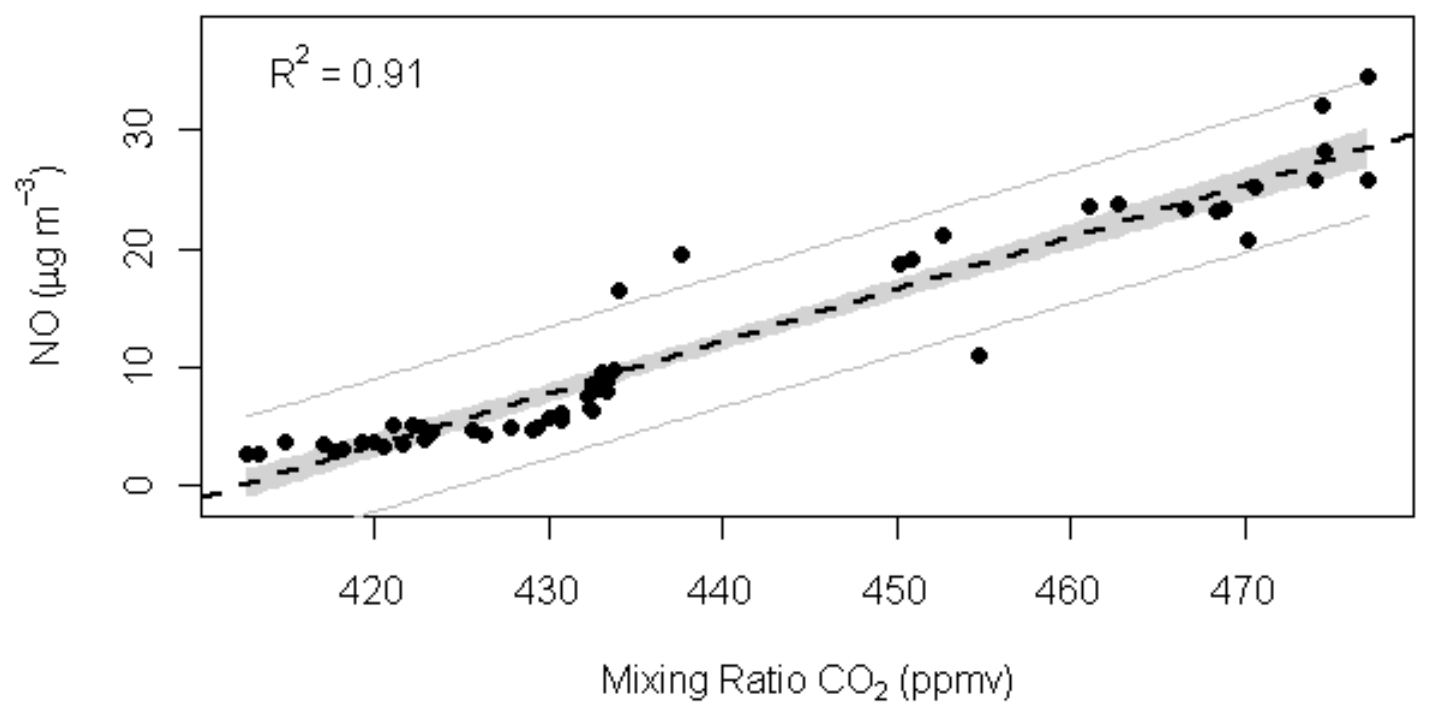

Figure A30: Correlation plot between $\mathrm{NO} \mu \mathrm{gm}^{-3}$ and $\mathrm{CO}_{2}$ for all $\mathrm{B99}$ plumes.

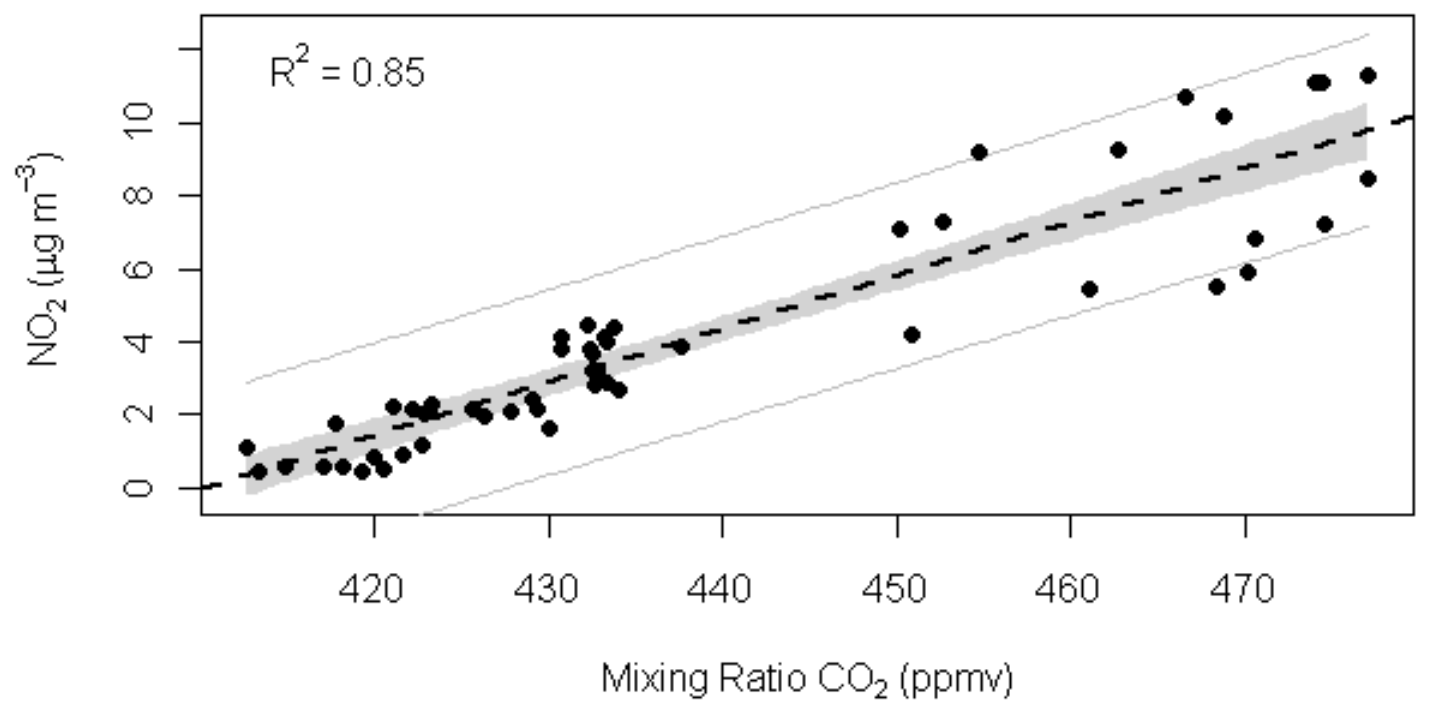

Figure A31: Correlation plot between $\mathrm{NO}_{2} \mu \mathrm{gm}^{-3}$ and $\mathrm{CO}_{2}$ for all $\mathrm{B99}$ plumes. 136 


\section{Appendix B: CRDT/N Validation Studies}

\section{B.1 In-Lab Validation}

The purpose of the in-lab validation was to demonstrate agreement between the CRDT response to well characterized aerosols and Mie theory. The following is a summary of the methods and results of the in-lab validation studies performed with the CRDT. This

work has been previously published. ${ }^{34}$ The in-lab validation demonstrated that the CRDT is capable of sensitive measurements of aerosol extinction coefficients at two wavelengths, simultaneously with scattering coefficients measured using a nephelometer. Agreement between measured extinction and Mie Theory ranged between less than a $1 \%$ deviation to a $12 \%$ deviation depending on the size and composition of the particles measured.

\section{B2.1.1Methods:}

\section{Aerosol generation:}

Polystyrene spheres (Duke Scientific, Inc), $\mathrm{NaCl}$ (reagent grade EM Science), and nigrosin (Aldrich) aerosols were generated by atomization of water solutions of the substances. Deionized water was used to make the solutions and a modified concentrictube nebulizer was used to generate aerosols with clean dry $\mathrm{N}_{2}$ gas (Pacific AirGas, Inc.) Depending on the experiment, aerosol size and concentration were adjusted by either varying the flow through the atomizer or increasing the stock solution concentration. At higher concentrations of stock, a larger number of large particles are present. 
After particles were atomized, they were directed into a $~ 28 \mathrm{~L}$ mixing chamber where the aerosol concentration was diluted with filtered dry air. The aerosol flow was then directed through a 4 micron cyclone inlet followed by a silica gel drier and either into the cavity for polydisperse aerosols measurement or into the DMA for monodisperse aerosols.

\section{Cavity and Flows:}

A pump was used to keep a constant flow of $1.974+/-0.009$ lpm through the cavity. This flow was altered when using the monodisperse polystyrene spheres to accommodate the SMPS DMA sheath flow rate. The cavity is made from copper pipe with an inlet in the center and outlets at either end. There is a bypass for a CPC (TSI 3007) and a relative humidity and temperature sensor (Vaisala Humitter $50 \mathrm{Y}$ )

In order to compare optical measurements with Mie theory, a series of validation experiments were performed with well characterized aerosols. These validations were designed to be similar to the validations performed with other CRD and optical instruments that are typically used to measure ambient aerosol optical properties. ${ }^{117,134,}$

${ }^{144}$ The results demonstrate that the CRDT/N used in this work agrees well with Mie theory in laboratory studies and that the agreement is comparable to other instruments that are used for measuring optical properties.

\section{B2.1.2 Results}

The agreement of the nephelometer's scattering coefficient measurements with the CRDT's extinction coefficient measurements was evaluated using purely scattering aerosols made from ammonium sulfate and sodium chloride. With these aerosols, 
absorption is negligible and single scattering albedo should be one. The results of these measurements show that all of the measured single scattering albedo values are within $3 \%$ of the theoretical value of unity when taken as long time averages of the various properties as seen in Table B.1.

Strongly absorbing pure Nigrosin dye particles were used to show that the single scattering albedo may be precisely determined when it is significantly less than one. The single scattering albedo of Nigrosin aerosols is expected to increase slightly with the liquid stock concentration because higher concentrations cause the particle size distribution to shift towards larger particles. ${ }^{146}$ This trend is evident in Table B.1, but the theoretical single scattering albedo values for Nigrosin could not be calculated because a DMA was not used during these experiments and thus the particle size distribution was not known.

Aerosols produced by atomizing mixtures of ammonium sulfate and Nigrosin were analyzed and their single scattering albedo was calculated based on a simple external mixing rule. For aerosol mixtures, the values for extinction, scattering and absorption are dependent upon how the aerosol is mixed. If the particles are externally mixed - multiple types of single species particles - then the measured values will be the concentration weighted sum of the species individual optical coefficients. If the particles are internally mixed - all chemical components mixed within the particle - then the measured extinction and scattering will appear as a weighted average of the species properties. ${ }^{147}$ The single scattering albedo in our experiment should be a weighted average of the individual components in the solution atomized, assuming equal particle production efficiency for the various concentration combinations. ${ }^{146}$ Table B.1 shows the measured 
and theoretical values for the mixed aerosol solutions. The trend to higher single scattering albedo with higher proportion of ammonium sulfate is evident in the table. All of the measured values are within $3 \sigma$ of their theoretical values of an externally mixed aerosol which implies reasonable agreement between the data and the simple external mixing theory. 
Table B.1: Comparison of Measured and Theoretical Single Scattering Albedo.

\begin{tabular}{lllll}
\hline \hline \multirow{2}{*}{ Solution } & $\begin{array}{l}\text { Relative } \\
\text { Concentration }\end{array}$ & $\begin{array}{l}\text { Measured } \\
\omega_{0}\end{array}$ & $\begin{array}{l}\text { Standard } \\
\text { Deviation }\end{array}$ & $\begin{array}{l}\text { Theoretical } \\
\omega_{0}\end{array}$ \\
\hline \hline \multirow{2}{*}{$\left(\mathrm{NH}_{4}\right)_{2} \mathrm{SO}_{4}$} & Low & 0.99 & 0.01 & 1 \\
& High & 1.01 & 0.007 & 1 \\
\hline \multirow{2}{*}{$\mathrm{NaCl}$} & Low & 0.98 & 0.04 & 1 \\
& High & 0.97 & 0.01 & 1 \\
\hline \multirow{3}{*}{ Nigrosin } & Low & 0.06 & 0.004 & -- \\
& Medium & 0.07 & 0.004 & -- \\
& High & 0.08 & 0.004 & -- \\
\hline \multirow{3}{*}{$\left(\mathrm{NH}_{4}\right)_{2} \mathrm{SO}_{4}:$ Nigrosin } & Low (12.5:1) & 0.90 & 0.01 & 0.92 \\
& Ligh (12.5:1) & 0.90 & 0.06 & 0.92 \\
& High (1:12.5) & 0.14 & 0.01 & 0.11 \\
& 0.10 & 0.006 & 0.11 \\
\hline \hline
\end{tabular}

\section{Concentration Dependence:}

Agreement between Mie theory and the measured $532 \mathrm{~nm}$ extinction of DMA size selected monodisperse scattering and non-scattering polystyrene spheres with $400 \mathrm{~nm}$ and $500 \mathrm{~nm}$ radii at varying measured number concentrations is shown in Figure B.1. Mie calculations were made using MiePlot version 3.5.01 software provided by Philip Laven. ${ }^{148}$ The refractive index $\mathrm{n}=1.5982$ (at $532 \mathrm{~nm}$ ) was used for the polystyrene spheres as suggested by the manufacturer, Duke Scientific, Inc. The recently revised refractive index for Nigrosin $\mathrm{n}(532 \mathrm{~nm})=1.70+0.31$ i based on photoacoustic absorption measurements was used for the black particles. ${ }^{116}$ The correspondence (slope $=1.0254 \pm 0.066, \mathrm{y}$-intercept $=-0.8069 \pm 6.5$, where the stated uncertainties are twice the 
standard errors) between Mie theory and the measured values for both 400 and $500 \mathrm{~nm}$ black and white particles is acceptable.

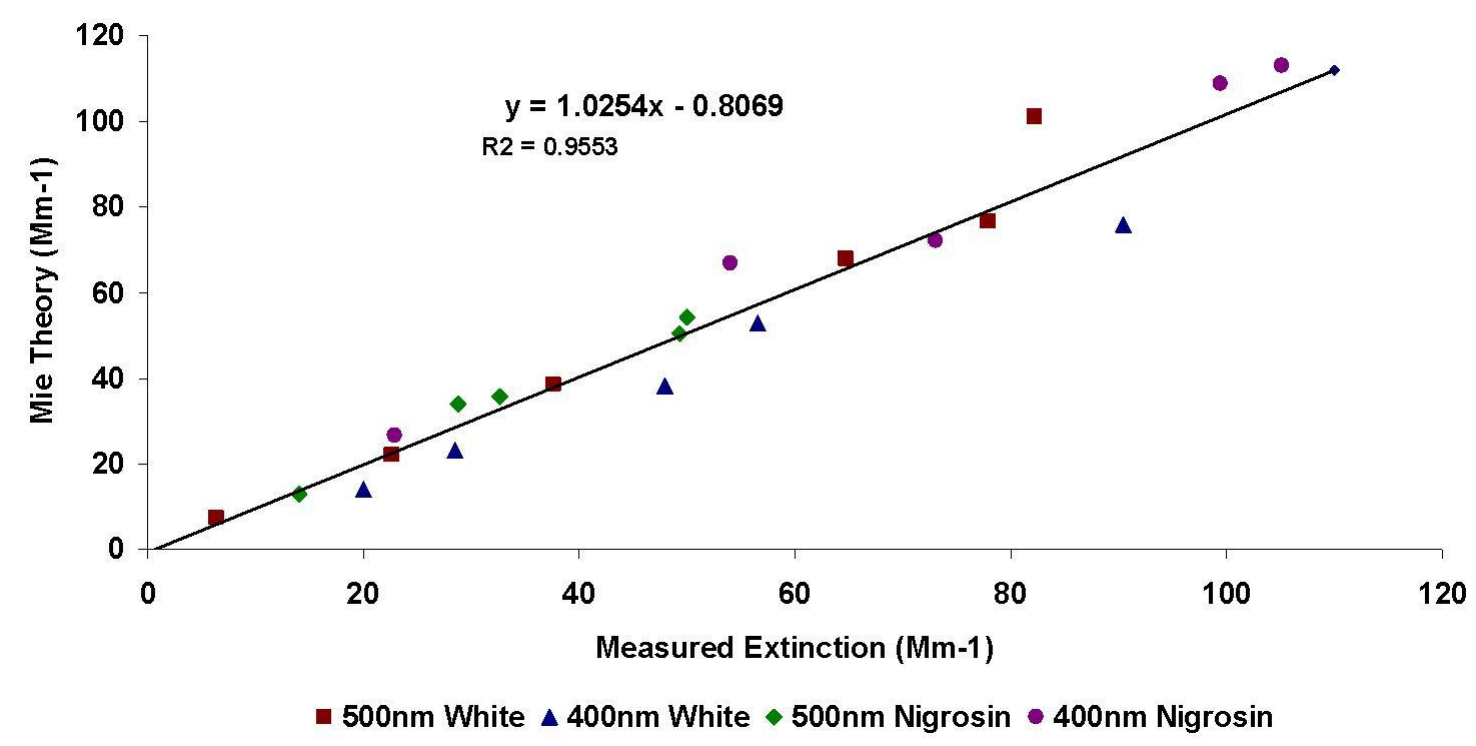

Figure B.1: Plot of the linear model of the measured particles vs. Mie theroy.

The results for both the $400 \mathrm{~nm}$ white and black particles showed less agreement with Mie theory than the $500 \mathrm{~nm}$ particles. It is likely that this is a result of multiple particle modes in the aerosol flow selected by the DMA. When the charge neutralizer on the DMA produces particles with more than unit charge, the electrostatic mobility classification can not distinguish between particles that are multiples of both the nominal size and charge because they have the same ion mobility diameter. When particle modes other than the selected mode are allowed through, the particle size distribution changes and causes strong deviation from theoretical calculations based on the monodisperse assumption. Particles with twice the diameter would have much larger optical effects. This instrumental error has been observed in other aerosol validation studies and attempts 
to resolve the problem with additional DMAs have not been completely successful. ${ }^{149}$ This error may have been avoided for the particles of initial diameter $500 \mathrm{~nm}$ or greater because the SMPS inlet used a $1 \mu \mathrm{m}$ particle impactor, and thus the majority of potentially larger multiply charged particles formed from the $500 \mathrm{~nm}$ spheres are removed before passing into the SMPS.

The agreement between Mie theory and the extinction measurements is compelling and the CRDT/N system appears to be effective for measuring the extinction coefficients of all particle types considered here. Table B.2 summarizes the linear models for each particle type compared with Mie theory. The relative uncertainty of the cavity ring-down (compared with Mie theory) is $6.54 \%$ for all particle types. During all validation experiments a large amount of filtered air data was also collected. This data allows for the estimation of the limit of detection and quantification for extinction measurements calculated using equation $4, \mathrm{LoD}=4.0 \mathrm{Mm}^{-1}$ and $\mathrm{LoQ}=13.4 \mathrm{Mm}^{-1}$. These values are probably an upper bound, being significantly affected by the $400 \mathrm{~nm}$ PSS results, which may be produced by DMA selection problems and not the CRDT/N. 
Table B.2: Measured vs. Modeled Linear Model Statistics.

\begin{tabular}{llllll}
\hline \hline & White PSS & & Nigrosin & & $\begin{array}{l}\text { All } \\
\text { Particles }\end{array}$ \\
\hline \hline Size & $500 \mathrm{~nm}$ & $400 \mathrm{~nm}$ & $500 \mathrm{~nm}$ & $400 \mathrm{~nm}$ & -- \\
Slope & 1.0001 & 0.8813 & 1.0729 & 1.0342 & 1.0254 \\
Intercept & 0.5713 & -2.1048 & -0.0363 & 4.1264 & -0.8069 \\
R2 & 0.9967 & 0.9857 & 0.982 & 0.9786 & 0.9553 \\
SSreg & 3463.714 & 2362.374 & 1049.553 & 4887.259 & 16436.76 \\
RSS & 11.43968 & 34.3365 & 19.21918 & 106.92 & 769.2338 \\
Std. Error & 1.69113 & 2.929868 & 2.531086 & 5.969924 & 6.537218 \\
F-value & 908.34 & 206.39 & 163.84 & 137.13 & 384.6 \\
Pr & $8.02 \mathrm{E}-05$ & 0.000731 & 0.001029 & 0.001338 & $1.35 \mathrm{E}-13$ \\
\hline \hline
\end{tabular}

Over all, the in-lab validation studies demonstrated the ability of the tandem instrument to measure the optical extinction and scattering components due to particles.

\section{B.2 Field Validation}

Once the instrument response to well characterized aerosols was determined, measurements of ambient aerosol were made in conjunction with the Texas Air Quality Study 2006 (TexAQS 2006.) In order to use the ring-down instrument to detect a correlation between observed ring-down extinction coefficients and particle mass concentrations $\left(\mu \mathrm{g} / \mathrm{m}^{3}\right.$ of air) comparisons with standard mass concentration techniques were necessary. Participation in a large collective measurement study of ambient radicals and aerosols allowed for this comparison. Comparisons between the CRDT optical measurements and other aerosol measurement techniques are necessary to understand 
instrument response to various aerosol conditions. Overviews of the field study and data comparisons between instruments are provided here. The majority of the data presented here has been previously published. ${ }^{134}$

\section{B.2.1 Study Overview}

The Second Texas Air Quality Study (Texaqs II), an 18 month-long field campaign in Houston Texas, in 2005 and 2006, was conducted to supply scientific and air quality information to state regulation agencies. As part of the TexAQS II sub-study, TRAMP (TexAQS II Radical and Aerosol Monitoring Project,) the CRDT/N was used to make aerosol optical property measurements on the 200-foot tall Moody Tower at the University of Houston from August 14, 2006 to September 27, 2006. The optical property data from this well mixed site can be compared with other instrumentation to help to characterize the signal of the CRDT.

The CRDT/N was co-located with a suite of aerosol measurement instruments at the TexAQS Radical and Aerosol Monitoring Project (TRAMP) site on the campus of the University of Houston (UH). The location of the instrument allows for a comparison of the CRDT/N real-time response to ambient aerosols with the Aerodyne Quadrupole

Aerosol Mass Spectrometer (Q-AMS) measurements made by Robert Griffin and Luke Ziemba from the University of New Hampshire (now at Rice University).

\section{B.2.2 Texaqs 2 Instrument Comparisons}

Bulk aerosol optical properties were measured for six weeks atop the $70 \mathrm{~m}$ high Southwest Moody Tower on the University of Houston campus during the Texaqs 2 
study. A comprehensive list of the study participants, (including instruments deployed and properties measured) as well as the overall study objectives are summarized in the study overview published elsewhere. ${ }^{150}$

For this analysis, data from the Q-AMS, SMPS and CRDT will be compared. The QAMS measures chemically speciated mass concentrations for the sulfate, organic, nitrate and ammonium components of the sub-micron ambient aerosol. Particle size distributions were measured with a SMPS (GRIMM Technologies Inc.), and optical extinction measurements were obtained with the same CRDT instrument that will be used in the diesel studies. A Teflon coated aluminum cyclone (URG Inc., model URG-2000-30EN) was added to the CRDT/N aerosol inlet. At the CRDT flow rate of $5 \mathrm{lpm}$, this cyclone has a nominal cut-point at an aerodynamic diameter of $4 \mu \mathrm{m}$. Specific operating parameters for the Q-AMS and the SMPS are described in a special issue that summarizes the field experiment and results. ${ }^{150}$ A common unit is necessary to compare across methods. Using the average particle mass concentrations calculated from CRDT, Q-AMS and SMPS measurements also allows for comparison to $\mathrm{PM}_{2.5}$ mass measurements made via a Tapered Element Oscillating Microbalance (TEOM) from the Texas Commission on Environmental Quality (TCEQ) Continuous Air Monitoring Network (CAMS).

The number concentrations and the optical measurements had to be converted to mass for this comparison. The conversions do increase the uncertainty in the measurements, but a general understanding of the instrument agreement is still possible. To convert 532 nm extinction measurements to predicted mass, a correlation between the measured extinction and the average $\mathrm{PM}_{2.5}$ mass made via TEOM from nine of TCEQ CAMS 
stations located in or around Houston was used to determine an appropriate mass extinction coefficient (MEC). A MEC of $6.3 \mathrm{~m}^{2} \mathrm{~g}^{-1}$ was determined to be appropriate as seen in Figure B.2.

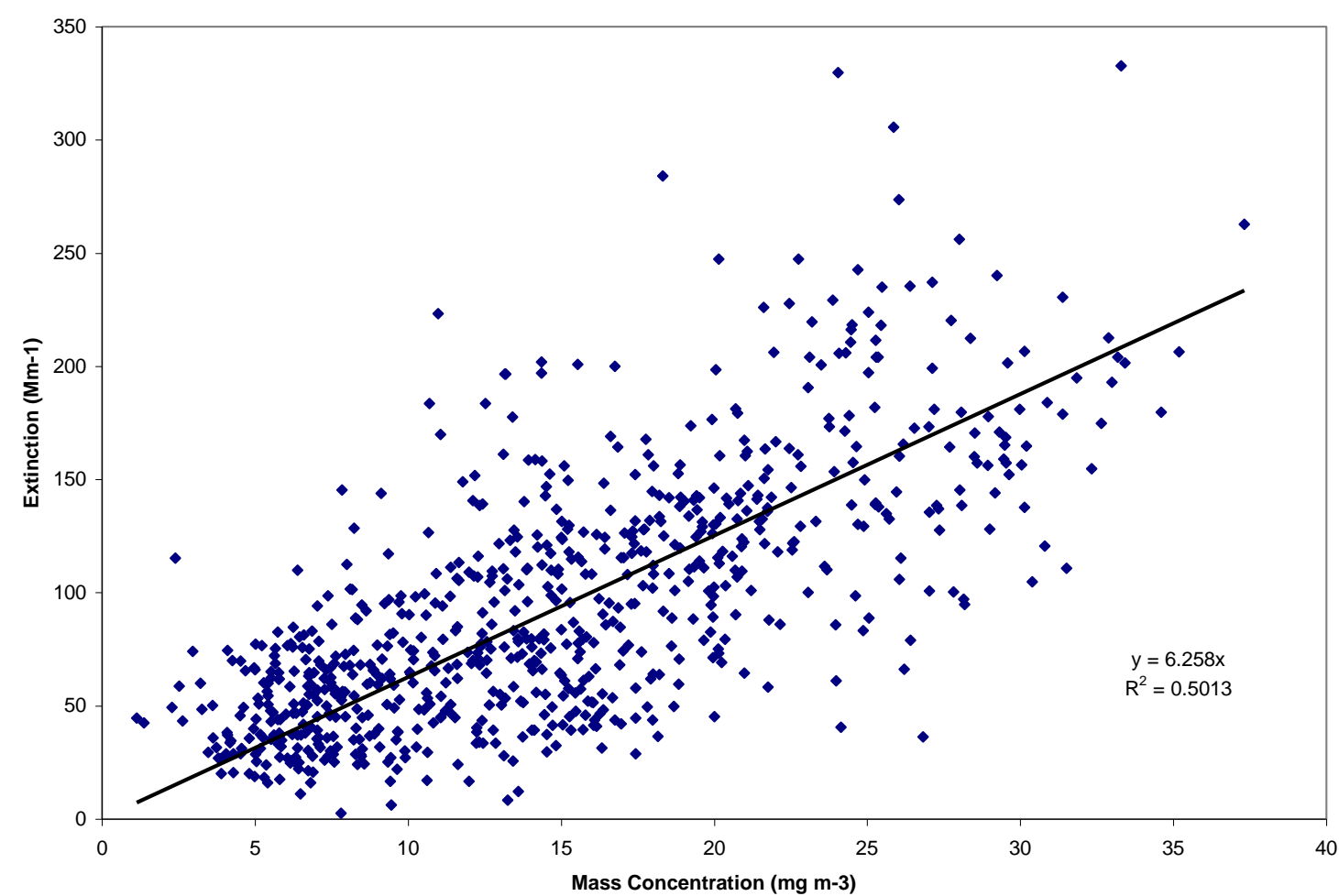

Figure B.2: Determination of the MEC for the Houston Area. $\mathrm{PM}_{2.5}$ measurements

made in nine locations around the city were correlated with $532 \mathrm{~nm}$ extinction measurements to obtain the relationship. A value of $6.3 \mathrm{~m}^{2} \mathrm{~g}^{-1}$ was found.

The correlation of the individual CAMS stations with the average was also verified, results are in Table B.3. The correlation coefficients ranged between 0.82 and 0.95 , which indicates that the average concentration over all of the stations is a good representation of the aerosol in the Houston Area. One station C304, located on Clinton 
Street was omitted from the average because it is located close to local sources and the measurements appear to represent changes in these local sources and not the urban background. The correlation between station C304 and the average of the other nine stations was 0.75 .

Table B.3: Correlation between individual CAMS stations and the average of all of the stations. The correlation coefficients range between 0.82 to 0.95 indicating that the average calculated from all of the stations represents a reliable estimate of the average $\mathrm{PM}_{2.5}$ mass in the Houston Area.

\begin{tabular}{cc}
\hline \hline Station ID & Correlation Coefficient \\
\hline \hline C1 & 0.95 \\
C 8 & 0.82 \\
C15 & 0.95 \\
C35 & 0.94 \\
C45 & 0.89 \\
C78 & 0.89 \\
C235 & 0.94 \\
C309 & 0.89 \\
C416 & 0.89 \\
\hline \hline
\end{tabular}

To convert SMPS measurements to a predicted mass concentration, a volume concentration was determined from the number concentration in each size bin and then this value was multiplied by a composition-weighted density varying from $1.2 \mathrm{~g} \mathrm{~cm}^{-3}$ for pure organics to $1.8 \mathrm{~g} \mathrm{~cm}^{-3}$ for sulfates. The composition of the aerosol was based on the composition data from the Q-AMS. To ensure that the Moody Tower site also qualifies as a background site, the mass measurements from the Q-AMS and converted SMPS measurements and CRDT were compared to the average CAMS data. A time series plot of these data, averaged hourly, is presented in Figure B.4. While there are obvious times 
when the measurements do not agree, there is general agreement between all of the measurements.

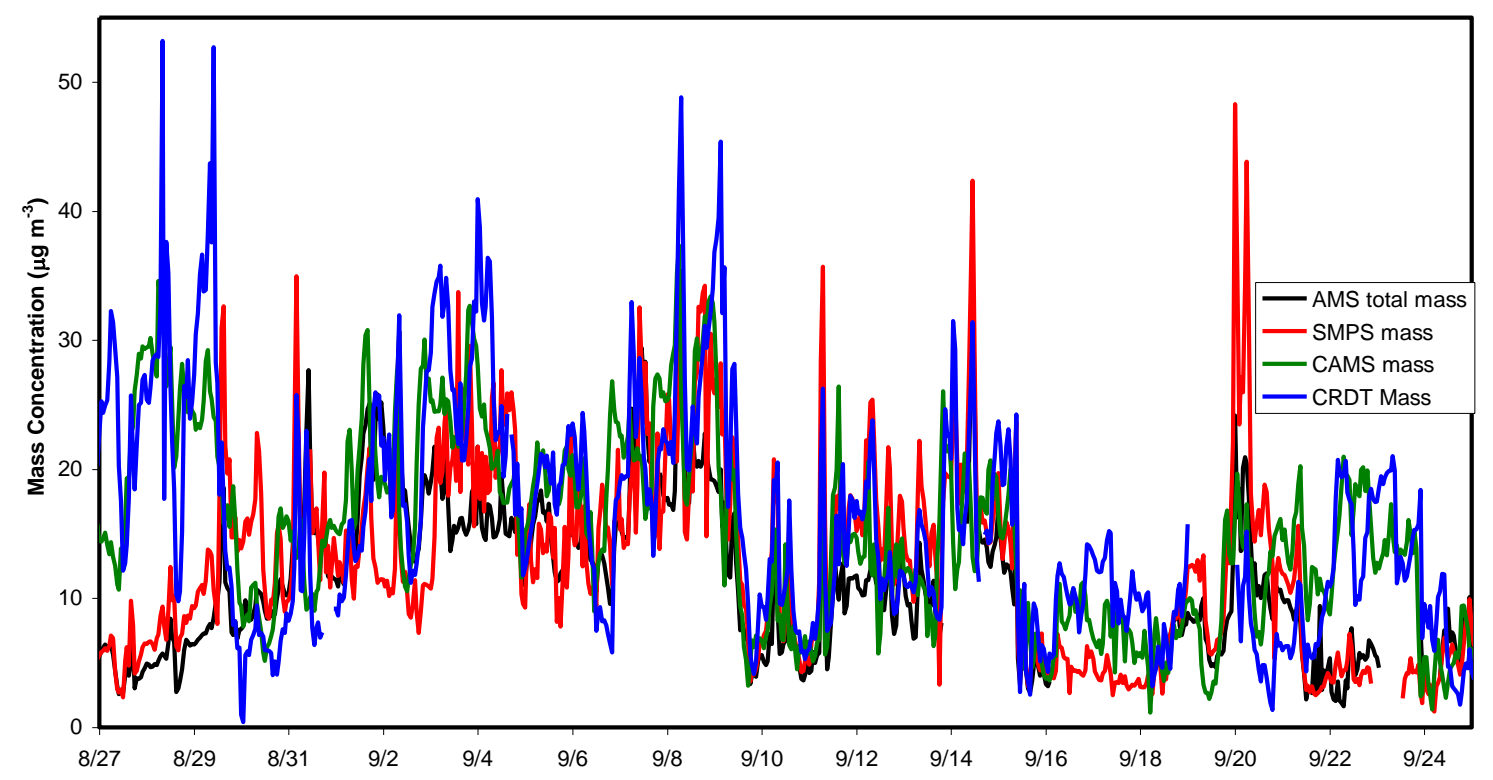

Figure B.4: An overview of aerosol measurements from the Texaqs study. Measurements have been converted to total mass concentration as described in the text.

Several days with well characterized aerosol were chosen for correlation comparison across techniques. By choosing specific days the different instrument responses to varying ambient conditions can be determined. In previous work, the data were analyzed for temporal trends, and synoptic-weather pattern trends. ${ }^{151,152}$ No evidence for a weekly trend or a weekday/weekend signature was found, but longer-term changes in the synoptic weather patterns appeared to be associated with changes in the aerosol background. The specific change point dates were determined with Change Point Analysis (CPA), a method used to identify changes in the long-term trends and to quantify the uncertainty of the assignment of the border between different periods. All changes were supported at $>90 \%$ confidence levels in at least one observable quantity 
other than wind direction. Figure B.5 shows the Cumulative Sum plots for the four aerosol measurements. The change points are marked by a dotted line. The Q-AMS mass concentration and SMPS mass concentration follow the same basic trend for the whole study. While the CRDT and CAMS measurements follow a different trend. The gray shading indicates a period in which measurements differ because of size differences, and the yellow shading indicates a period where all four measures correlate well.

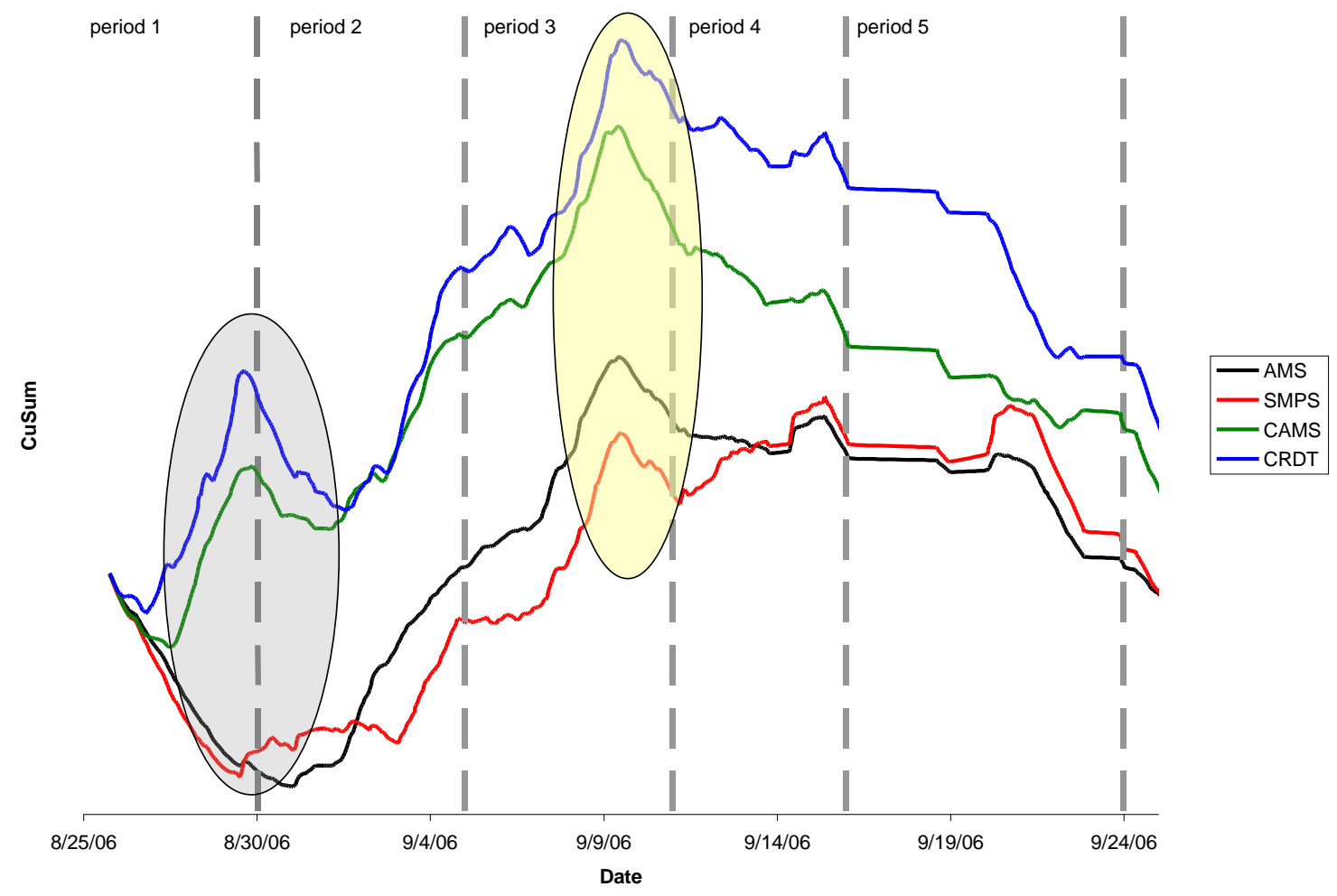

Figure B.5: Cumulative sum plots of the mass concentrations as calculated or measured by four different methods during the TRAMP study period. In addition to the changes in aerosol, changes in gas phase measurements and wind direction were considered when defining the periods indicated here. The area shaded gray is an example of a time span when the measurement techniques did not agree and the yellow shading is an example of a period when the measurements agreed. Over all the AMS and SMPS followed the same basic trend and the CRDT and CAMS data follow the same trend. 
The periods indicated were determined from wind direction and gas phase measurements in addition to the aerosol measurements. A statistical summary of the particle and gas phase measurements separated by the periods can be seen in Tables B.5 and B.6. This summary was used to determine the general aerosol type for the particular period, which is necessary when comparing instruments which are more and less effective under different conditions. For example, the Q-AMS is known to be ineffective in measuring refractory compounds like dust, sea salt and black carbon. During times when these species dominate the aerosol type, the CRDT measurements should give a higher mass than the Q-AMS.

When whole study averages are compared, AMS and optical measurements do not have very good agreement. $\left(\mathrm{R}^{2}<0.3\right)$ A portion of this minimal correlation can be attributed to the instruments differing responses to the aerosol present during period one (the gray shaded span seen in Figure A2.5.) The aerosol measured during this time period was characterized by the influence of long range transport of Saharan dust and sea salt by researchers aboard the $R / V$ Ronald $H$. Brown (RHB) in the Gulf of Mexico; which was part of the Texaqs 2 study. ${ }^{153,154}$ As expected, the covariance between the CRDT and the Q-AMS is quite low $\left(\mathrm{R}^{2}<0.001\right)$ during this time 
Table B.5: Gas phase species statistics for each period, based on one-hour average data.

\begin{tabular}{ccccccc}
\hline Period & $\mathbf{1}$ & $\mathbf{2}$ & $\mathbf{3}$ & $\mathbf{4}$ & $\mathbf{5}$ & Study \\
\hline \hline Average $\mathrm{NO}$ & & & & & & \\
(ppbv) & $\mathbf{1 . 5 1}$ & $\mathbf{2 . 7 5}$ & $\mathbf{2 . 8 3}$ & $\mathbf{1 0 . 1 0}$ & $\mathbf{2 . 9 7}$ & $\mathbf{3 . 7 3}$ \\
Minimum & 0.02 & 0.01 & 0.01 & 0.05 & 0.02 & 0.01 \\
Maximum & 12.10 & 61.24 & 23.89 & 72.03 & 52.43 & 72.03 \\
\hline $\begin{array}{c}\text { Average } \mathrm{NO}_{2} \\
\text { (ppbv) }\end{array}$ & $\mathbf{5 . 3 7}$ & $\mathbf{1 6 . 1 4}$ & $\mathbf{1 4 . 9 3}$ & $\mathbf{2 1 . 7 3}$ & $\mathbf{9 . 8 2}$ & $\mathbf{1 3 . 3 6}$ \\
Minimum & 0.86 & 1.48 & 2.13 & 3.50 & 0.89 & 0.86 \\
Maximum & 14.21 & 72.02 & 47.81 & 53.87 & 56.65 & 72.02 \\
\hline Average NOy & & & & & & \\
(ppbv) & $\mathbf{7 . 8 3}$ & $\mathbf{2 2 . 5 9}$ & $\mathbf{2 1 . 9 8}$ & $\mathbf{3 6 . 7 2}$ & $\mathbf{1 4 . 5 0}$ & $\mathbf{2 0 . 0 4}$ \\
Minimum & 1.84 & 4.76 & 6.20 & 9.13 & 1.48 & 1.48 \\
Maximum & 26.28 & 78.92 & 74.76 & 90.37 & 96.31 & 96.31 \\
\hline Average $\mathrm{CO}$ & & & & & & \\
(ppbv) & $\mathbf{1 4 0 . 1 4}$ & $\mathbf{2 9 4 . 4 6}$ & $\mathbf{2 8 8 . 6 5}$ & $\mathbf{3 5 0 . 1 1}$ & $\mathbf{1 8 3 . 5 8}$ & $\mathbf{2 4 8 . 1 6}$ \\
Minimum & 97.28 & 188.94 & 130.57 & 122.66 & 81.32 & 81.32 \\
Maximum & 294.13 & 626.85 & 904.18 & 991.17 & 682.95 & 991.17 \\
\hline Average $\mathrm{O}_{3}$ & & & & & & \\
(ppbv) & $\mathbf{1 5 . 0 7}$ & $\mathbf{4 5 . 6 2}$ & $\mathbf{4 2 . 2 6}$ & $\mathbf{3 0 . 4 2}$ & $\mathbf{2 1 . 8 1}$ & $\mathbf{3 1 . 5 4}$ \\
Minimum & 2.84 & 4.06 & 1.98 & 2.03 & 2.33 & 1.98 \\
Maximum & 31.87 & 127.53 & 131.93 & 101.20 & 92.58 & 131.93 \\
\hline Average $\mathrm{SO}_{2}$ & & & & & & \\
(ppbv) & $\mathbf{0 . 9 5}$ & $\mathbf{2 . 7 8}$ & $\mathbf{4 . 5 2}$ & $\mathbf{4 . 3 9}$ & $\mathbf{1 . 0 0}$ & $\mathbf{2 . 4 8}$ \\
Minimum & 0.00 & 0.17 & 0.14 & 0.23 & 0.00 & 0.00 \\
Maximum & 12.54 & 35.32 & 77.53 & 68.25 & 8.41 & 77.53 \\
\hline \hline
\end{tabular}


Table B.6: Statistics for ambient aerosol optical properties and particle number concentration for each period.

\begin{tabular}{ccccccc}
\hline \hline Period & $\mathbf{1}$ & $\mathbf{2}$ & $\mathbf{3}$ & $\mathbf{4}$ & $\mathbf{5}$ & Study \\
\hline \hline Mean $\mathrm{b}_{\text {ext, } 532}\left(\mathrm{Mm}^{-1}\right)$ & 129.9 & 109.5 & 124.9 & 95.8 & 65.0 & 100.8 \\
Minimum & 21.3 & 2.6 & 25.8 & 17.2 & 8.4 & 2.6 \\
Maximum & 332.8 & 256.0 & 305.6 & 197.0 & 131.5 & 332.8 \\
\hline Mean $\mathrm{b}_{\text {ext, } 1064}\left(\mathrm{Mm}^{-1}\right)$ & 76.2 & 28.0 & 32.6 & 28.8 & 34.7 & 37.7 \\
Minimum & 9.9 & 1.0 & 7.3 & 7.6 & 0.1 & 0.1 \\
Maximum & 223.6 & 70.5 & 87.5 & 67.1 & 84.9 & 223.6 \\
\hline Mean $\mathrm{b}_{\text {scat, } 530}\left(\mathrm{Mm}^{-1}\right)$ & 48.2 & 80.0 & 79.9 & 55.0 & 28.5 & 57.8 \\
Minimum & 15.6 & 13.7 & 12.8 & 18.8 & 8.5 & 8.5 \\
Maximum & 94.5 & 166.7 & 177.5 & 136.7 & 59.0 & 177.5 \\
\hline Mean PN $\left(\# \mathrm{~cm}^{-3}\right)$ & 12330 & 28267 & 30523 & 32487 & 18176 & 24393 \\
Minimum & 3599 & 6576 & 7132 & 11094 & 1704 & 1704 \\
Maximum & 45152 & 100149 & 142304 & 108244 & 113958 & 142304 \\
\hline Mean Q-AMS & & & & & & \\
mass $\left(\mu \mathrm{g} \mathrm{m}{ }^{-3}\right)$ & 4.87 & 15.12 & 14.84 & 11.39 & 7.46 & 11.22 \\
Minimum & 2.05 & 6.85 & 3.37 & 3.33 & 1.64 & 1.64 \\
Maximum & 9.80 & 30.67 & 35.39 & 34.61 & 24.18 & 35.39 \\
\hline Mean SMPS & & & & & & \\
volume $\left(\mathrm{nm}{ }^{3} \mathrm{~m}^{-3}\right)$ & 4398 & 11499 & 12223 & 12294 & 6071 & 9291 \\
Minimum & 4635 & 5264 & 2585 & 2507 & 1465 & 1465 \\
Maximum & 53183 & 27286 & 23318 & 30433 & 39363 & 39363 \\
\hline \hline
\end{tabular}

The CRDT measured high extinction and moderate scattering values during this time and the CuSum plot indicates an upward trend in the CAMS and CRDT data. These results are consistent with highly absorbing aerosols or large particles. The Q-AMS measured low values for sulfates, nitrates and organics and a downward trend is indicated by the CuSum plot. The Q-AMS was not able to detect the larger absorbing aerosol that dominated this time span. This finding is actually expected when the aerosol size distribution is dominated by large particles or when dust or $\mathrm{BC}$ are principal components of the particles. The Q-AMS has a particle upper size limit of $1 \mu \mathrm{m}$ (the SMPS only 
measures particles less than $800 \mathrm{~nm}$ in diameter) and it is not able to ionize refractory material, while the CRDT measures optical properties from all particles $<4 \mu$ m that enter the cavity.

Comparisons between the CAMS mass concentration and the CRDT show much better correlation $\left(\mathrm{R}^{2}>0.75\right)$ for the same time span. Differences are most likely due to local variation at the CAMS locations and the presence of particles larger than $2.5 \mu \mathrm{m}$. Out of the four techniques, the CRDT is the most approprate choice for measuring aersols that were present at this time. This is because it is capable of measuring all ambient particles including refractory particles and can be used to determine if there are absorbing aerosol present without the need for a filter.

The correlation between all instruments is much higher when the aerosol is dominated by small particles $(<1 \mu \mathrm{m})$. Period 3 featured substantial ozone formation and observation of fine-mode dominated aerosol mass and optical properties by instruments at the TRAMP site (see Tables B.5 and B.6) and on the RHB. ${ }^{150,153,155}$ In this case, it seems highly likely that recirculation of the polluted air mass on a multi-day cycle is responsible for the provision of this fine-mode background PM. ${ }^{152}$ Figure B.6 shows the correlation between the CRDT and the Q-AMS mass concentrations for the period highlighted in yellow from Figure B.3. The ratio of the two measurements is less than 1 indicating that the CRDT mass is greater that the AMS mass. This difference is again due to the CRDT having the larger inlet size and the refractory component. 


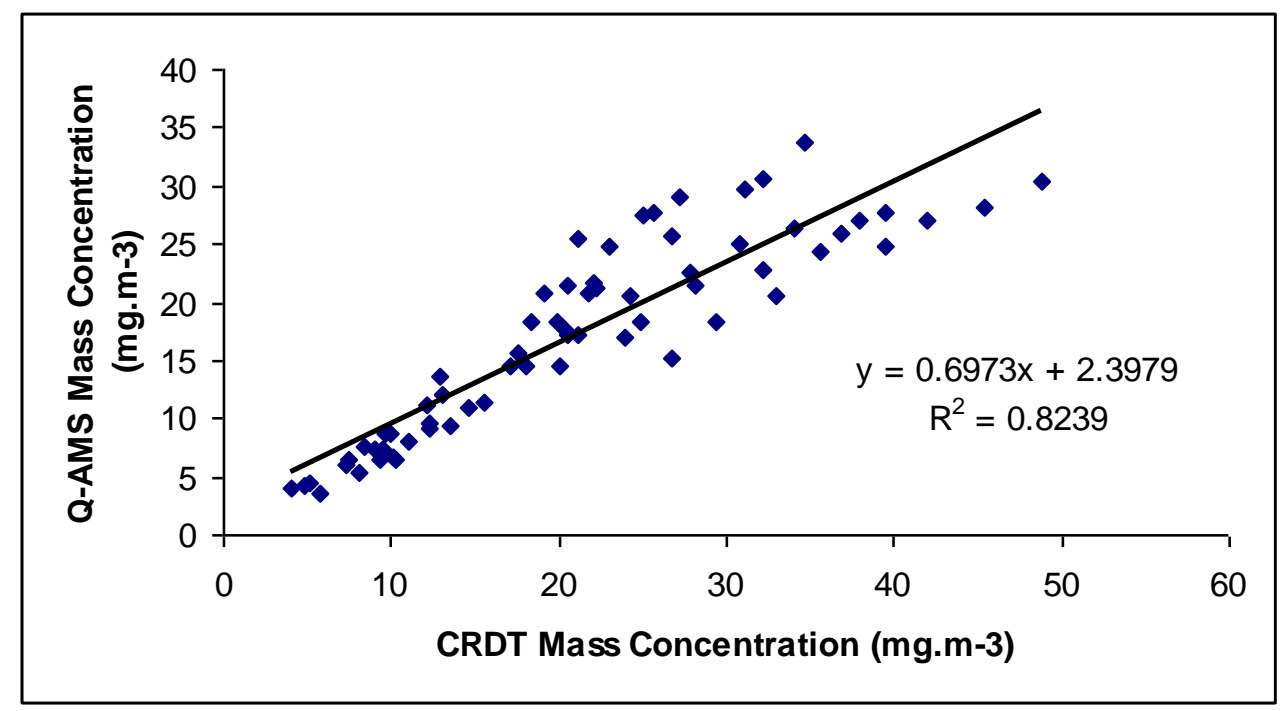

Figure B.6: Correlation between CRDT and Q-AMS mass concentration for a select time period of the TRAMP study. The CRDT appears to be consistently higher than the Q-AMS, most likely because the CRDT measures all aerosol present while the Q-AMS only measures the non-refractory components.

A correlation between the CAMS averaged TEOM data and the CRDT also shows a good agreement during the same period. The $\mathrm{R} 2$ was $>0.83$ and the ratio of the measurement was $\sim 0.88$. This difference can be attributed to either the low bias of the TEOM measurement when there is an abundance of ultrafine or volatile aerosol, or the larger aerosol cut point on the CRDT inlet. Despite this difference, all four instruments have some correlation during this time period. 


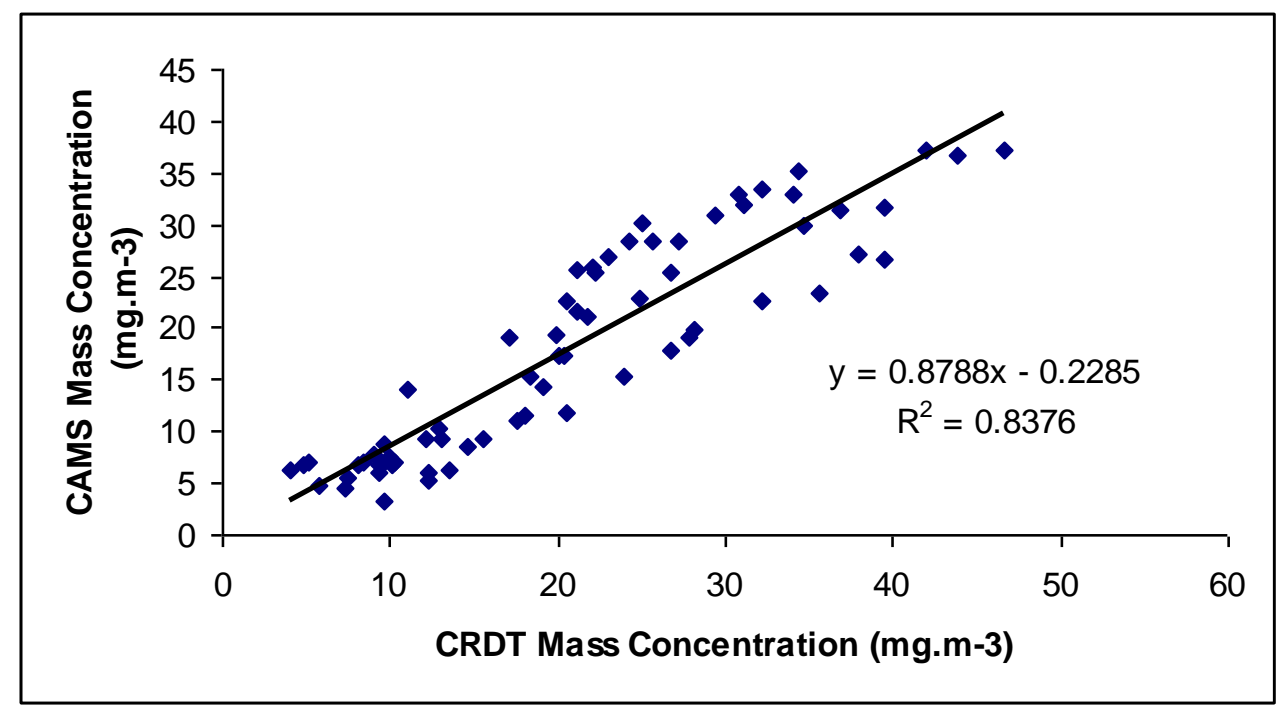

Figure B.7: Correlation between the CRDT and CAMS measurements. The correlation coefficient is 0.84 and the Slope is 0.88 . The CRDT is expected to be slightly higher than the TEOM because the inlet has a larger cut point and the CRDT is more effective measuring ultrafine aerosol.

While PM emissions are regulated only by mass concentration, anthropogenic PM can positively or negatively influence the radiation balance through scattering or absorption of radiation. To determine how the aerosol will impact climate, it is important to know both the scattering component and the absorbing component of the aerosol. During the TRAMP study, the CRDT was able to measure total ambient aerosol as well or better than other measurement techniques that are commercially available. The CRDT technique provides a comparable measurement to the TEOM for the whole study and agrees well with the Q-AMS when the aerosol is dominated by small particles. In addition, only the CRDT has the ability to provide optical data for multiple wavelength visible light extinction and absorption measurements. 